ERNEST $\square R L A N D Q$ LAWRENEE

BERKELEY NATIGNAL LABDRATロRY

\section{Existing Climate Data Sources and Their Use in Heat Island Research}

Brian Pon, Dan M. Stamper-Kurn, Craig K. Smith, and Hashem Akbari Environmental Energy Technologies Division RECEIVED MAR 181999

OSTI

October 1998 


\section{DISCLAIMER}

This document was prepared as an account of work sponsored by the United States Government. While this document is believed to contain correct information, neither the United States Government nor any agency thereof, nor The Regents of the University of California, nor any of their employees, makes any warranty, express or implied, or assumes any legal responsibility for the accuracy, completeness, or usefulness of any information, apparatus, product, or process disclosed, or represents that its use would not infringe privately owned rights. Reference herein to any specific commercial product, process, or service by its trade name, trademark, manufacturer, or otherwise, does not necessarily constitute or imply its endorsement, recommendation, or favoring by the United States Government or any agency thereof, or The Regents of the University of California. The views and opinions of authors expressed herein do not necessarily state or reflect those of the United States Government or any agency thereof, or The Regents of the University of California.

This report has been reproduced directly from the best available copy.

Available to DOE and DOE Contractors

from the Office of Scientific and Technical Information

P.O. Box 62, Oak Ridge, TN 37831

Prices available from (615) 576-8401

Available to the public from the

National Technical Information Service

U.S. Department of Commerce

5285 Port Royal Road, Springfield, VA 22161

Ernest Orlando Lawrence Berkeley National Laboratory

is an equal opportunity employer. 


\section{DISCLAIMER}

Portions of this document may be illegible in electronic image products. Images are produced from the best available original document. 
LBNL-41973

\title{
Existing Climate Data Sources and Their Use in Heat Island Research
}

\author{
Brian Pon, Dan Moses Stamper-Kurn, \\ Craig Kenton Smith, and Hashem Akbari \\ Heat Island Group \\ Environmental Energy Technologies Division \\ Ernest Orlando Lawrence Berkeley National Laboratory \\ University of California \\ Berkeley, Cảlifornia 94720 \\ http://EETD.LBL.gov/HeatIsland
}

October 1998

This work was supported by Office of Energy Efficiency and Renewable Energy of the U.S. Department of Energy under Contract No. DE-AC03-76SF00098. 


\section{Table of Contents}



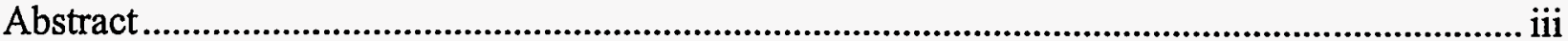

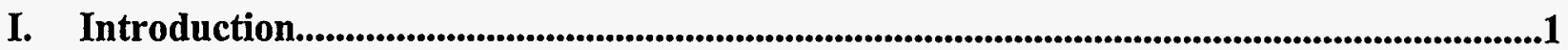





B. Existing Data Sources for Historical Analysis ..................................................................

C. Historical Analysis of the Urban Climate of Los Angeles..................................................

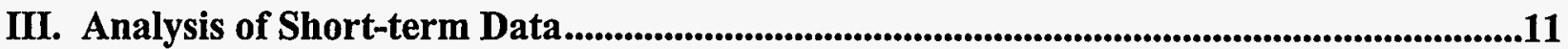

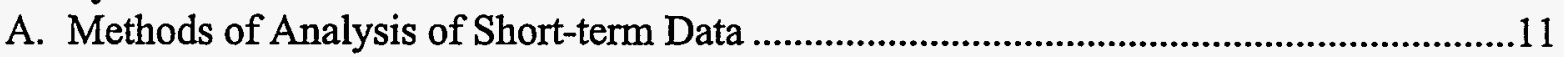

B. Existing Short-term Data Sources of Analysis...........................................................12

C. Analysis of Short-term Data for the Urban Climate of Phoenix .....................................16

IV. Conclusions and Suggested Directions for Future Work ....................................................21

V. Acknowledgements.............................................................................................................................24

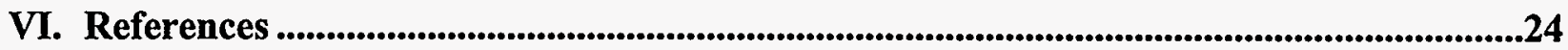

Appendix A. Carbon Dioxide Information Analysis Center (CDIAC).....................................1

Appendix B. National Center for Atmospheric Research (NCAR).............................................1

Appendix C. National Climatic Data Center (NCDC)...................................................................1

Appendix D. Aerometric Information Retrieval System (AIRS) ...............................................D.1

Appendix E. Individual sources of climate data..........................................................................1 


\title{
EXISTING CLIMATE DATA SOURCES
}

\section{AND THEIR USE IN HEAT ISLAND RESEARCH}

\author{
Brian Pon, Dan Moses Stamper-Kurn, Craig Kenton Smith, and Hashem Akbari \\ Heat Island Project \\ Ernest O. Lawrence Berkeley National Laboratory \\ Berkeley, CA 94720
}

\begin{abstract}
Existing climate data sources can be used in two general types of analysis for the detection of urban heat islands. Historical analyses use long-term data records-preferentially from several locations in and around an urban area-to trace the gradual influence of urban development on its climate. Primary sources of such data include the cooperative network, first-order National Weather Service stations, and military weather stations. Analyses of short-term data use information from a dense urban weather station network to discern the location, extent, and magnitude of urban heat islands. Such analyses may use the aforementioned national networks or regional networks such as agricultural, air quality monitoring, or utility networks.

We demonstrate the use of existing data sources with a historical analysis of temperature trends in Los Angeles, California, and an analysis of short-term data of the urban temperature profile for Phoenix, Arizona. The Los Angeles climate was examined with eleven long-term data records from the cooperative network. Statistically significant trends of rising temperature were detected at Los Angeles Civic Center and other stations over some parts of the year, although timing of the increase varied from station to station. Observed increases in temperatures may be due to long-term climate changes, microclimate influences, or local-scale heat islands. The analysis of short-term data was made for Phoenix using the PRISMS station network. Mean diurnal temperature profiles for a month were examined and compared with those for adjacent rural areas. Data from stations in the center of Phoenix showed clear and significant nighttime and daytime temperature differences of $1-2 \mathrm{~K}\left(3-4^{\circ} \mathrm{F}\right)$. These temperature increases may be attributable to a local-scale heat island.
\end{abstract}




\section{Introduction}

Ongoing research by the Heat Island Project at Berkeley Lab has shown that the use of high-albedo building materials and urban vegetation can substantially conserve cooling energy (Taha 1988; Akbari et al. 1993, 1997). These savings result from the direct effects of such actions in reducing the heat flow into conditioned spaces in buildings. Yet large additional savings may indirectly accrue from the reduced air temperatures on the scale of a neighborhood or city (Taha 1988) as both high-albedo surfaces and vegetation reduce the amount of incident solar radiation channeled into sensible heat (Oke 1978). Reduced air temperatures will consequently lower requirements for air-conditioning.

In this paper, we summarize the status of our research on the urban climate data. We describe two different methods for urban climate analysis-historical and short-term-and describe the various bodies of existing data appropriate for each method. These include the national networks of climate data as well as smaller networks particular to specific states or cities. We also present analyses of the urban climates of Los Angeles, California, and Phoenix, Arizona, using these data sources. These analyses reveal some of the advantages and shortcomings of the data sources and point to promising avenues of analysis that should be pursued further.

\section{Historical Analysis}

The influences of cities on local climates can be studied using a historical analysis of climate measurements that are continually recorded in an area in which urban land cover is increasing. Urban effects on climate can then be assessed by comparing present to earlier preurban conditions (Lowry 1977). Statistical tools can be used to determine whether significant differences exist between the two periods.

\section{A. Methods of Historical Analysis}

Statistical comparisons have been made in the past with measurements from weather stations over periods during which significant changes in local land use occurred. For example, Balling et al. (1990) analyzed records of daily maximum, minimum, and mean temperatures collected in July and August from 1948 to 1988 at the National Weather Service Forecast Office 
in the Phoenix Sky Harbor Airport, ${ }^{1}$ located in the center of the city. The 40 -year period of record corresponded to the period during which both the population and urban land cover of the Phoenix metropolitan area tripled. They conclude that average summer temperatures in Phoenix are rising at a rate of $0.072 \mathrm{~K}\left(0.13^{\circ} \mathrm{F}\right)$ per year, with a $0.10 \mathrm{~K}\left(0.18^{\circ} \mathrm{F}\right)$ per year increase in average minimum temperatures and a $0.04 \mathrm{~K}\left(0.07^{\circ} \mathrm{F}\right)$ per year increase in average maximum temperatures. Based on an analysis of the frequency of extreme temperature maxima or minima, the authors caution against predicting extreme temperatures from rises in average temperatures due to the change in the distributions of daily maximum or minimum temperatures over time.

A similar analysis was conducted using temperature and atmospheric moisture records from the National Weather Service site at the Municipal Airport, $12 \mathrm{~km}$ south of the center of Tucson's central business district. During the period of record (1948 - 1985), the population of Tucson increased tenfold. The analysis found no significant trends in the data over the 37-year period of record. Yet over the most recent 18-year period, afternoon temperatures increased significantly by $0.02 \mathrm{~K}\left(0.04^{\circ} \mathrm{F}\right)$ per year. The authors note that because the airport is located some distance from the center of Tucson and because urban land cover is replacing dry desert land, the effects of urban development on the local climate is less than those observed in Phoenix (Balling and Brazel 1987a).

The use of a single urban climate record for heat island analysis, however, may be inadequate. If large differences in climate conditions are detected, it may be improper to attribute them exclusively to urban development since natural oscillations in temperature may bias the climate record. For example, abnormally high summertime temperatures and consecutive drought years characterized California weather during the 1980's. Using a single station, an analysis of urban climate data in California ending in the 1980's may overestimate temperature trends due to urbanization.

This weather bias can be partly removed by considering climate records from at least two locations and observing trends in differences between concurrent measurements. If one climate record is chosen from an urban area and another from a nearby rural location and if the period covered by the record encompasses the entire period of urban growth, the comparison of the two may reveal the entire climate effect of urban development. Karl et al. (1988) used such an

\footnotetext{
${ }^{1}$ The weather station at Phoenix Sky Harbor Airport was in a parking lot (Schaffer 1998) for nearly twenty years beginning in 1971. The location of the weather station itself "was...a heat island" (Ingram 1998) during this time. While the Phoenix Sky Harbor Airport station focused our attention to the Phoenix area, we rely on other weather stations in the state of Arizona for our climate analysis.
} 
approach in an attempt to assess the effect of urbanization in climate records used to detect global warming signals in the United States. Pairs of stations were selected from among the United States Historical Climatological Network $(\mathrm{HCN})$ in which a rural station was located in a community with less than 2000 residents in 1980 and an urban station was located between 30 and $100 \mathrm{~km}$ away in a larger town. They related the rate of change of these differences to a measure of urbanization at the urban station. This method detected clear increases in urban daily minimum temperatures in cities of all sizes but found no tendency toward increasing urban maximum temperatures.

Whether climate data from one or several weather stations are used, historical analysis still requires long-term continuity of meteorological and environmental conditions in the climate measurements. Both discrete changes in the record-due to changes in instrumentation, sensor height, and location - and continuous changes - such as gradual alteration of the microclimate surrounding the sensors-can contribute to any temperature trends found.

\section{B. Existing Data Sources for Historical Analysis}

Historical analysis requires many years-perhaps decades - of continuous data to assess urban temperature trends. Such data is available generally from three sources: the cooperative network, observations at military installations, and first-order National Weather Service (NWS) stations.

\section{The cooperative network}

The cooperative network consists of stations from a variety of sources that voluntarily report their data to the National Climatic Data Center (NCDC) for compilation. Data reported include daily maximum temperature, daily minimum temperature, daily precipitation, and sometimes daily snowfall and daily pan evaporation. The climate record amassed through the cooperative network includes records with coverage ranging from a few years to over a century.

The cooperative network station index is available on-line both through the National Center for Atmospheric Research (NCAR) and through the NCDC. Station records include station names and numbers, latitude, longitude, elevation, and the starting and ending dates of operation. Table 1 illustrates the concentration of weather stations in certain cities in the southwestern U.S. This index can thus be searched to find climate records by location and by coverage period. However, every time a station is moved a new index entry is created. Longer climate records can be created by linking these different records as long as precautions are taken to guarantee historical homogeneity. 


\begin{tabular}{|c|c|c|c|c|c|}
\hline \multirow{5}{*}{$\begin{array}{l}\text { Another larger } \\
\text { collection of cooperative } \\
\text { network data is provided as } \\
\text { the "Summary of Day" data }\end{array}$} & \multirow{2}{*}{ Weather Station } & \multirow{2}{*}{ Latitude } & \multirow{2}{*}{ Longitude } & \multicolumn{2}{|c|}{ \# of Stations } \\
\hline & & & & & \\
\hline & $\begin{array}{l}\text { Atlanta Fulton Co. Stadium, GA } \\
\text { Boston Logan Airport, MA }\end{array}$ & $\begin{array}{l}33^{\circ} 47^{\prime} \\
42^{\circ} 22^{\prime}\end{array}$ & $\begin{array}{l}84^{\circ} 31^{\prime} \\
71^{\circ} 2^{\prime}\end{array}$ & $\begin{array}{c}8 \\
44\end{array}$ & $\begin{array}{c}8 \\
38\end{array}$ \\
\hline & Chicago O'Hare Airport, IL & $41^{\circ} 59^{\prime}$ & $87^{\circ} 54^{\prime}$ & 18 & 16 \\
\hline & Dallas-Ft. Worth, TX & $32^{\circ} 49^{\prime}$ & $97^{\circ} 21^{\prime}$ & 15 & 12 \\
\hline set from NCDC. Each & Denver Int'l Airport, CO & $39^{\circ} 52^{\prime}$ & $104^{\circ} 40^{\prime}$ & 12 & 10 \\
\hline wether station's Summaru & Detroit Metro Airport, MI & $\begin{array}{l}42^{\circ} 14^{\prime} \\
36^{\circ} 10^{\prime}\end{array}$ & $\begin{array}{l}83^{\circ} 20^{\prime} \\
15^{\circ}\end{array}$ & 4 & 19 \\
\hline weather station's Summary & Las Vegas, NV & $36^{\circ} 10^{\prime}$ & $115^{\circ} 8^{\prime}$ & 12 & 7 \\
\hline of the Day data set includes & Los Angeles Int'l Airport, CA & $\begin{array}{l}33^{\circ} 56^{\prime} \\
25^{\circ} 49^{\prime}\end{array}$ & $118^{\circ} 24^{\prime}$ & 57 & 48 \\
\hline & Minneapolis-St. Paul, MN & $\begin{array}{l}23^{\circ} 49^{\prime} \\
44^{\circ} 53^{\prime}\end{array}$ & $93^{\circ} 13^{\prime}$ & 14 & 14 \\
\hline & New York JFK Airport, NY & $40^{\circ} 46^{\prime}$ & $73^{\circ} 47^{\prime}$ & 36 & 29 \\
\hline precipitation, & Omaha Eppley Airfield, NE & $41^{\circ} 18^{\prime}$ & $95^{\circ} 54^{\prime}$ & 13 & 11 \\
\hline direction and speed. This data & Philadelphia Int'l Airport, PA & 39॰53' & $75^{\circ} 15^{\prime}$ & 22 & 7 \\
\hline & $\begin{array}{l}\text { Phoenix, AZ } \\
\text { Richmond, VA }\end{array}$ & $\begin{array}{l}33^{\circ} 27^{\prime} \\
37^{\circ} 42^{\prime}\end{array}$ & $\begin{array}{l}112^{\circ} 4^{\prime} \\
77^{\circ} 26^{\prime}\end{array}$ & $\begin{array}{c}12 \\
8\end{array}$ & $\begin{array}{l}10 \\
8\end{array}$ \\
\hline & Sacramento WSO City, CA & $38^{\circ} 31^{\prime}$ & $121^{\circ} 30^{\prime}$ & 18 & 15 \\
\hline as collected & St. Louis, MO & $38^{\circ} 45^{\prime}$ & $90^{\circ} 22^{\prime}$ & 8 & \\
\hline from EarthInfo, Inc. & $\begin{array}{l}\text { Salt Lake City, UT } \\
\text { Seattle Naval Air Station, WA }\end{array}$ & $\begin{array}{l}40^{\circ} 46^{\prime} \\
47^{\circ} 41^{\prime}\end{array}$ & $\begin{array}{l}111^{\circ} 53^{\prime} \\
122^{\circ} 16^{\prime}\end{array}$ & $\begin{array}{l}10 \\
30\end{array}$ & $\begin{array}{c}9 \\
28\end{array}$ \\
\hline
\end{tabular}

(EarthInfo 1997). The station changes in each record are summarized in station

Table 1: Numbers of stations currently in the Cooperative Stations List in the NCDC inventories for U.S. surface data within $1^{\circ}$ of cities in the United States.

histories, which are available

either in brief encoded format, or as longer descriptions provided by NCDC. Unlike the HCN, the sites included in this resource have not been screened to assure historical homogeneity. Thus, records should be subjected to quality control procedures to adjust for both documented and undocumented discontinuities using several standard techniques (Karl and Williams 1987, Karl et al. 1986).

\section{First Order Stations and military installations}

To fully capture the effect of urban areas on their climate, daily extrema of temperature are insufficient. For example, urban surfaces with high thermal capacities, reduced sky view factors, and diminished convective heat exchange due to reduced winds may cool or heat slower than rural areas. The resulting temperature difference in the late afternoon is especially important for energy use since utility demands peak during that time. However, a comparison of urban and rural temperature extrema will not detect this effect. Higher time-resolution data are available from first-order weather stations operated by the NWS, predominantly at civilian airports. Air temperatures are recorded hourly, as well as other weather conditions such as precipitation, insolation, and wind speed and direction. These stations are useful for obtaining data representative of a larger area due to the flat, uniform surroundings of the sites. However, the number of records is typically limited. Such weather data are available from the NCDC. Daily 
precipitation, snowfall, evaporation, and temperature maxima, minima, and averages from these stations are included in the cooperative network data sets.

Military installations, especially airports, also maintain weather towers and record climate information at hourly intervals. These data can be obtained through the NCDC and are typically quite expensive. However, given the sparse coverage of NWS first-order stations, these data can prove crucial to historical understanding of urban climates in some areas.

An extensive, global inventory of first-order and military stations is available on-line from the NCDC. Data entries include station number, call letter, name, country, latitude, longitude, and elevation. More information about the stations can be gathered by reaching NCDC or often through the journal Local Climatological Data. The number of first-order and military weather stations recording hourly climate data in each state, according to the NCDC's National Weather Service-U.S. Air Force-Navy Station List, is given in Table 2. The number of stations in each state is often roughly proportional to its area.

\section{Other data sources}

Many other collections of data that may be of use in urban heat island research have been compiled. A number of these data sources are accessible through the Carbon Dioxide Information Access Center (CDIAC), NCDC, NCAR, and others (see appendices).

\section{Historical Analysis of the Urban Climate of Los Angeles}

This is an analysis to explore the use of the climate data sources described above in examining the area near Los Angeles, California. This region was selected because previous and ongoing research by our group has focused on the changing urban climate of this area and its

\begin{tabular}{|l|c|l|c|l|l|l|c|}
\hline \multicolumn{1}{|c|}{ State } & $\begin{array}{c}\text { \# of } \\
\text { stations }\end{array}$ & \multicolumn{1}{c|}{ State } & $\begin{array}{c}\text { \# of } \\
\text { stations }\end{array}$ & \multicolumn{1}{c|}{ State } & $\begin{array}{c}\text { \# of } \\
\text { stations }\end{array}$ & \multicolumn{1}{|c|}{ State } & $\begin{array}{c}\text { \# of } \\
\text { stations }\end{array}$ \\
\hline \hline Alabama & 39 & Indiana & 32 & North Carolina & 59 & South Carolina & 28 \\
Alaska & 319 & Iowa & 35 & North Dakota & 29 & South Dakota & 33 \\
Arkansas & 31 & Kansas & 59 & Nebraska & 50 & Tennessee & 30 \\
Arizona & 64 & Kentucky & 25 & New Hampshire & 19 & Texas & 184 \\
California & 317 & Louisiana & 40 & New Jersey & 29 & Utah & 55 \\
Colorado & 81 & Maryland & 28 & New Mexico & 80 & Vermont & 10 \\
Connecticut & 17 & Maine & 39 & New York & 87 & Virginia & 55 \\
Delaware & 6 & Massachusetts & 45 & Nevada & 60 & Washington & 88 \\
Florida & 122 & Michigan & 64 & Ohio & 49 & West Virginia & 19 \\
Georgia & 52 & Minnesota & 46 & Oklahoma & 42 & Wisconsin & 35 \\
Hawaii & 59 & Mississippi & 36 & Oregon & 72 & Wyoming & 47 \\
Idaho & 35 & Missouri & 53 & Pennsylvania & 66 & & \\
Illinois & 53 & Montana & 64 & Rhode Island & 12 & & \\
\hline
\end{tabular}

Table 2: Number of first-order and military weather stations in the United States 
effect on energy use and air quality.

Several studies have established the rising temperature trends in the Los Angeles region. Cayan and Douglas (1984) analyzed records of near-surface temperatures at Los Angeles Civic Center as part of a study of urban influences on temperatures in several southwestern cities. The authors found that annual mean temperatures rose with a linear trend rate of $0.03 \mathrm{~K}\left(0.054^{\circ} \mathrm{F}\right)$ per year $\left(1.4 \mathrm{~K}\right.$ or $2.6^{\circ} \mathrm{F}$ total) between 1932 and 1980 . The temperature rise was more pronounced in summer months, as linear trends for monthly mean temperatures rose over the same period by $0.7 \mathrm{~K}\left(1.2^{\circ} \mathrm{F}\right)$ in January and by $2.3 \mathrm{~K}\left(4.1^{\circ} \mathrm{F}\right)$ in July. They also compared monthly mean maximum and minimum temperatures averaged over the period 1941 - 1970 with those averaged over 1969 - 1980. The increase in mean temperatures in January was largely due to an increase in minimum temperatures, while the increase in July seemed to be caused by rises in both maximum and minimum temperatures.

The same temperature record was examined by Akbari et al. (1990) in a work focusing on energy and air pollution costs of heat islands and the potential for heat island mitigation. Yearly highs between 1880 and 1985 decreased from an average of $38.3^{\circ} \mathrm{C}$ to $37.2^{\circ} \mathrm{C}\left(101^{\circ} \mathrm{F}\right.$ to $99^{\circ} \mathrm{F}$ ) between 1880 and 1930 . Thereafter, yearly highs rose to $41.1 \mathrm{~K}\left(106^{\circ} \mathrm{F}\right)$ by 1985 , an average increase of $0.07 \mathrm{~K}\left(0.13^{\circ} \mathrm{F}\right)$ per year. Temperature increases were also apparent in monthly average temperatures during the summer months, as shown in Table 3.

Both analyses rely solely on the climate record at the Civic Center and thus are susceptible to bias caused by natural temperature trends, changes in documented station location and elevation, and undocumented sources of bias. In fact, the Civic Center station has been located on various rooftops at different heights in the center of downtown Los Angeles, where microclimate conditions have changed dramatically during the period of record as the area became increasingly dense with tall buildings and busy streets. The station maybe thus inappropriate for historical heat island analysis. In order to establish more confidently the presence of increasing temperature trends in the Los Angeles region, we have undertaken a more complete analysis of Summary of Day data.

\section{Station selection}

A commercially available NCDC Summary of Day station inventory was searched for currently operating stations within the Los Angeles area with

\begin{tabular}{|c|c|c|}
\hline & \multicolumn{2}{|c|}{ Rate of Increase } \\
Month & K/year & oF/year \\
\hline \hline June & $0.07 \pm 0.02$ & $0.13 \pm 0.03$ \\
July & $0.06 \pm 0.01$ & $0.11 \pm 0.02$ \\
August & $0.07 \pm 0.01$ & $0.12 \pm 0.02$ \\
September & $0.06 \pm 0.02$ & $0.11 \pm 0.03$ \\
\hline
\end{tabular}

Table 3: Rates of increase in monthly average temperatures for summer months in the L.A. Civic Center climate data record (Akbari et al. 1990). 
data beginning before 1950. Eleven stations were selected, shown on a map in Figure 1 and described in Table 4. The stations at Burbank, Culver City, and the Civic Center are all located in densely built sections of the Los Angeles Basin. The stations in Santa Ana and Tustin/Irvine are located in less dense areas of Orange County. The

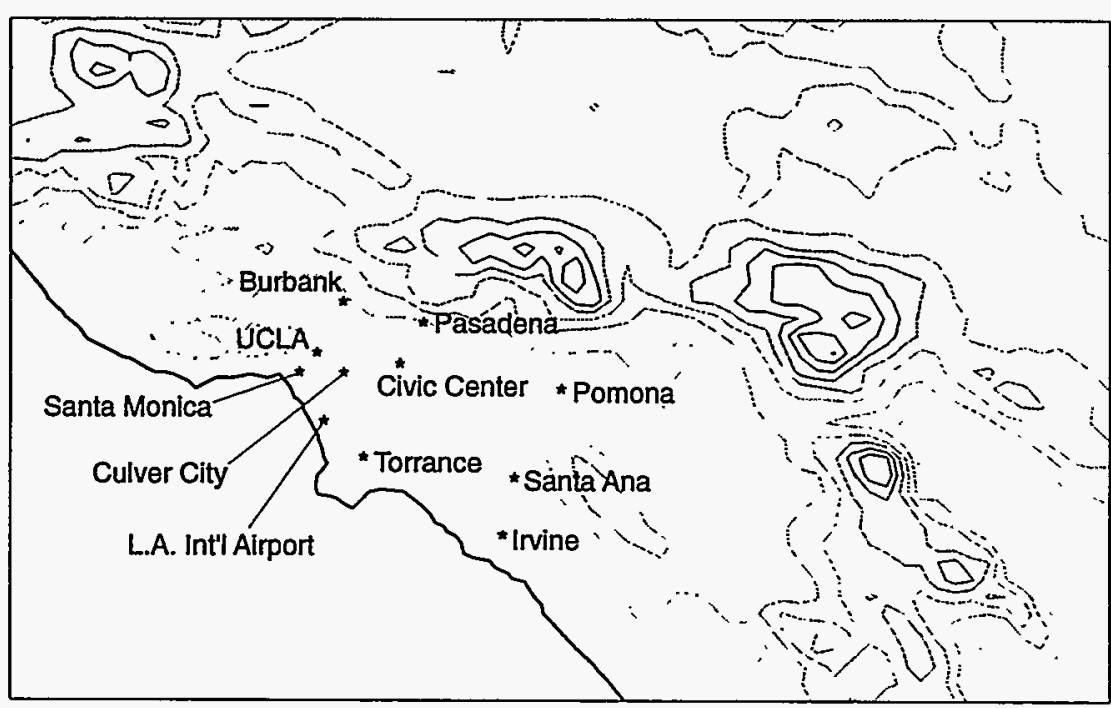

Figure 1: Elevation contour map of Los Angeles area with locations of the cooperative network stations examined. Contours represent changes in elevation of 350 meters. surroundings of Pomona and Pasadena are also less densely built than those areas in the city center. The stations at Santa Monica and Los Angeles International Airport are located in close proximity to the coast and are strongly influenced by coastal breezes and fog. Torrance is located $5 \mathrm{~km}$ from the coast and is also influenced by coastal breezes and fog.

\section{Analysis and results}

We first examined yearly maxima at each of the eleven stations over the period of record

\begin{tabular}{|c|c|c|c|c|c|c|}
\hline \multirow[b]{2}{*}{ Name } & \multicolumn{3}{|c|}{ Current Conditions } & \multirow{2}{*}{$\begin{array}{l}\text { Start of } \\
\text { Record }\end{array}$} & \multirow{2}{*}{$\begin{array}{l}\text { \# of Stn. } \\
\text { Changes }\end{array}$} & \multirow{2}{*}{$\begin{array}{l}\text { Apparent } \\
\text { Quality }\end{array}$} \\
\hline & Lat. & Lon. & Elev. (m) & & & \\
\hline Burbank Valley Pumping Plant & $34^{\circ} 11^{\prime}$ & $118^{\circ} 21^{\prime}$ & 200 & $12 / 1939$ & 2 & good \\
\hline Culver City & $34^{\circ} 1^{\prime}$ & $118^{\circ} 24^{\prime}$ & 20 & $1 / 1935$ & 2 & problems after 1981 \\
\hline L.A. Civic Center & $34^{\circ} 3^{\prime}$ & $118^{\circ} 14^{\prime}$ & 80 & $1 / 1931$ & 2 & $\begin{array}{l}\text { large elevation and } \\
\text { micro-climate changes }\end{array}$ \\
\hline L.A. International Airport & $33^{\circ} 56^{\prime}$ & $118^{\circ} 24^{\prime}$ & 30 & $8 / 1944$ & 2 & good \\
\hline Pasadena & $34^{\circ} 9^{\prime}$ & $118^{\circ} 9^{\prime}$ & 260 & $1 / 1931$ & 2 & good \\
\hline Pomona Cal Poly & $34^{\circ} 4^{\prime}$ & $117^{\circ} 49^{\prime}$ & 230 & $1 / 1931$ & 3 & good \\
\hline Santa Ana Fire Station & $33^{\circ} 45^{\prime}$ & $117^{\circ} 52^{\prime}$ & 40 & $1 / 1931$ & 4 & good \\
\hline Santa Monica Pier & $34^{\circ} 0^{\prime}$ & $118^{\circ} 30^{\prime}$ & 3 & $9 / 1937$ & 3 & apparent discontinuities \\
\hline Torrance & $33^{\circ} 48^{\prime}$ & $118^{\circ} 20^{\prime}$ & 30 & $1 / 1932$ & 4 & good \\
\hline Tustin Irvine Ranch & $33^{\circ} 44^{\prime}$ & $117^{\circ} 47^{\prime}$ & 40 & $1 / 1931$ & 1 & good \\
\hline UCLA & $23^{\circ} 4^{\prime}$ & $118^{\circ} 27^{\prime}$ & 130 & $1 / 1933$ & 2 & good \\
\hline
\end{tabular}

Table 4: Information on selected cooperative network stations in the Los Angeles region. 
available. Linear regressions were performed to discern overall trends in the data. The statistical significance of these trends were assessed using a t-statistic to determine the probability $p$ that these trends could be obtained from a population satisfying the one-sided null hypothesis (in this case, slope $=0$ or of the opposite sign). Table 5 summarizes characteristics of the data and the regression analysis. Significant trends, using a $95 \%$ confidence level $(\mathrm{p}<5 \%)$, are observed at Burbank, Culver City, and the Civic Center weather stations. The rate of increase in yearly maximum temperatures at the Civic Center, discussed in Akbari et al. (1990), is the largest observed of all stations. The warming effect experienced by the Civic Center area may be compounded by increasing microclimate influences. The Civic Center data record is not representative of the entire Los Angeles region; at most stations, a more modest rate of change is found or the trends are not statistically significant. In similar fashion, we examined monthly averages of daily maximum and minimum temperatures for linear trends at the eleven stations selected. Again, a t-statistic is used to assess the significance of the trends. We present the regression results for the months of March, June, September, and December in Table 6.

The three stations at which large, statistically significant trends were found in yearly temperature maxima-Burbank, Culver City, and the Civic Center-and UCLA show June rates between 0.05 and $0.09 \mathrm{~K}\left(0.09\right.$ and $\left.0.16^{\circ} \mathrm{F}\right)$ per year. Milder increases are observed in March and September averages. These increases suggest that the daytime warming is becoming more important over time at these stations during the summer months. However, whether this rise in daily maxima is caused by local-scale heat island effects or simply by changes in microclimate below canopy height is uncertain. Other significant increases in daily maximum temperatures are

\begin{tabular}{|c|c|c|c|c|c|c|c|}
\hline \multirow[b]{2}{*}{ Station } & \multirow{2}{*}{$\begin{array}{l}\text { First } \\
\text { Year of } \\
\text { Record }\end{array}$} & \multicolumn{3}{|c|}{ Yearly Maximum } & \multicolumn{3}{|c|}{ Regression vs. Year } \\
\hline & & $\begin{array}{c}\mathrm{M} \\
\left({ }^{\circ} \mathrm{C}\right)\end{array}$ & ( $\left.{ }^{\circ} \mathrm{F}\right)$ & $\begin{array}{l}\text { Std Dev } \\
\text { (Kelvin) }\end{array}$ & (K/year) $^{\mathrm{Slc}}$ & ( ${ }^{\circ} \mathrm{Fe} /$ year $)$ & $p($ Slope $=0)$ \\
\hline Burbank Valley Pumping & 1940 & 41.2 & 106.1 & $\overline{2.1}$ & $0.04 \pm 0.02$ & $008 \pm 0,03$ & 0.02 \\
\hline Culver City & 1935 & 37.7 & 99.9 & 2.9 & $006 \pm 0.03$ & $0.14 \pm 0.05$ & 0.01 \\
\hline L.A. Civic Center & 1948 & 39.2 & 102.6 & 2.3 & $0,07+0,03$ & $0.14 \geq 0.05$ & 0.005 \\
\hline L.A. Int'l Airport & 1944 & 36.9 & 98.4 & 3.0 & $0.02 \pm 0.04$ & $0.04 \pm 0.07$ & 0.52 \\
\hline Pasadena & 1927 & 40.0 & 104.0 & 1.8 & $0.02 \pm 0.01$ & $0.03 \pm 0.02$ & 0.17 \\
\hline Pomona Cal Poly & 1927 & 40.9 & 105.7 & 1.5 & $-0.01 \pm 0.01$ & $-0.02 \pm 0.02$ & 0.29 \\
\hline Santa Ana Fire Station & 1948 & 39.3 & 102.8 & 2.0 & $0.02 \pm 0.02$ & $0.03 \pm 0.04$ & 0.46 \\
\hline Santa Monica Pier & 1948 & 32.4 & 90.4 & 3.1 & $0.02 \pm 0.04$ & $0.04 \pm 0.07$ & 0.58 \\
\hline Torrance & 1949 & 37.3 & 99.1 & 1.0 & $0.03 \pm 0.03$ & $0.05 \pm 0.06$ & 0.42 \\
\hline Tustin Irvine Ranch & 1927 & 39.6 & 103.2 & 1.9 & $0.01 \pm 0.01$ & $0.02 \pm 0.02$ & 0.42 \\
\hline UCLA & 1948 & 36.9 & 98.4 & 2.7 & $0.04 \pm 0.03$ & $0.08 \pm 0.06$ & 0.2 \\
\hline
\end{tabular}

Table 5: Yearly maximum mean, standard deviation, regression results, and their significance at eleven cooperative network stations in the Los Angeles Area. Significant regression results, for which $\mathrm{p}($ Slope $=0) \leq 0.05$, are in gray. 
detected at Pasadena (June, $0.04 \pm 0.01 \mathrm{~K}$ per year), Pomona (December, $0.01 \pm 0.01 \mathrm{~K}$ per year), and Torrance (June, $0.05 \pm 0.02^{\circ} \mathrm{F}$ per year).

\begin{tabular}{|c|c|c|c|c|c|c|c|c|c|c|}
\hline \multirow[b]{2}{*}{ Month } & \multicolumn{5}{|c|}{ Monthly Average of Daily Maxima } & \multicolumn{5}{|c|}{ Monthly Average of Daily Minima } \\
\hline & \multicolumn{2}{|c|}{ Mean } & $\begin{array}{r}\text { Std. Dev. } \\
\text { (Kelvin) }\end{array}$ & $\begin{array}{l}\text { Slope } \\
(\mathrm{K} / \mathrm{yr})\end{array}$ & $\mathrm{p}($ Slope $=0)$ & \multicolumn{2}{|c|}{ Mean } & $\begin{array}{c}\text { Std. Dev. } \\
\text { (Kelvin) }\end{array}$ & $\begin{array}{l}\text { Slope } \\
(\mathrm{K} / \mathrm{yr})\end{array}$ & $\mathrm{p}($ Slope $=0)$ \\
\hline \multicolumn{11}{|c|}{ Burbank Valley Pumping Plant, 1940-1991 } \\
\hline March & 21.3 & 70.3 & 1.9 & $0.04 \pm 0.02$ & 0,03 & 7.4 & 45.4 & 1.6 & $0.01 \pm 0.02$ & 0.84 \\
\hline June & 27.7 & 81.9 & 2.6 & $0.09 \pm 0.02$ & 0,00 & 13.8 & 56.8 & 1.2 & $0.04 \pm 0.01$ & 0,00 \\
\hline September & 30.7 & 87.3 & 2.2 & $0.02 \pm 0.02$ & 0.28 & 14.9 & 58.8 & 1.7 & $0.03 \pm 0.01$ & 0.03 \\
\hline December & 19.8 & 67.7 & 2.1 & $0.00 \pm 0.02$ & 0.93 & 5.4 & 41.7 & 1.4 & $0.03 \pm 0.01$ & 0.03 \\
\hline \multicolumn{11}{|c|}{ Culver City, 1935-1991 } \\
\hline March & 19.9 & 67.9 & 1.4 & $0.04 \pm 0.01$ & 0,00 & 8.9 & 48.0 & 1.6 & $0.06 \pm 0.01$ & 0.00 \\
\hline June & 23.4 & 74.1 & 1.8 & $0.07 \pm 0.01$ & 0,00 & 14.2 & 57.6 & 1.3 & $0.04 \pm 0.01$ & $0: 00$ \\
\hline September & 26.1 & 78.9 & 1.8 & $0.06 \pm 0.01$ & 0.00 & 15.8 & 60.4 & 1.6 & $0.05 \pm 0.01$ & 0.00 \\
\hline December & 20.1 & 68.1 & 1.8 & $-0.03 \pm 0.02$ & 0.07 & 7.8 & 46.0 & 1.3 & $0.03 \pm 0.01$ & 0.02 \\
\hline \multicolumn{11}{|c|}{ L.A. Civic Center, 1948-1991 } \\
\hline March & 20.6 & 69.1 & 1.8 & $0.04 \pm 0.02 \mid$ & 0.06 & 10.7 & 51.3 & 1.5 & $0,06 \pm 0.02$ & 0.00 \\
\hline June & 25.6 & 78.1 & 2.1 & $0.05 \pm 0.02$ & 0,05 & 15.9 & 60.6 & 1.4 & $0.07+0.02$ & 0.00 \\
\hline September & 28.3 & 82.9 & 1.8 & $0.01 \pm 0.02$ & 0.78 & 17.8 & 64.0 & 1.6 & $0.06 \pm 0.02$ & 0.00 \\
\hline December & 19.9 & 67.8 & 2.0 & $0.03 \pm 0.02$ & 0.19 & 9.4 & 48.9 & 1.5 & $0.02 \pm 0.02$ & 0.32 \\
\hline \multicolumn{11}{|c|}{ L.A. International Airport, 1944-1991 } \\
\hline March & 18.4 & 65.2 & 1.6 & $0.01 \pm 0.02$ & 0.50 & 10.1 & 50.1 & 1.4 & $0.06 \pm 0.01$ & 0.00 \\
\hline June & 22.2 & 72.0 & 1.6 & $0.02 \pm 0.02$ & 0.41 & 15.3 & 59.5 & 1.0 & $0.03 \pm 0.01$ & 0.02 \\
\hline September & 24.6 & 76.3 & 1.6 & $0.01 \pm 0.02$ & 0.50 & 16.9 & 62.5 & 1.4 & $0.06 \pm 0.02$ & 0.00 \\
\hline December & 18.9 & 66.1 & 1.8 & $0.01 \pm 0.02$ & 0.58 & 8.7 & 47.7 & 1.3 & $0.04 \pm 0.01$ & 0,01 \\
\hline \multicolumn{11}{|c|}{ Pasadena, 1927-1991 } \\
\hline March & 21.1 & 70.0 & 2.1 & $0.02 \pm 0.01$ & 0.20 & 7.7 & 45.8 & 1.3 & $0.03 \pm 0.01$ & 0.00 \\
\hline June & 27.3 & 81.1 & 2.1 & $0.04 \pm 0.01$ & $0.0 \%$ & 13.3 & 55.9 & 1.2 & $0.04 \pm 0.0 \pm$ & 0,00 \\
\hline September & 30.6 & 87.0 & 1.9 & $0.02 \pm 0.01$ & 0.07 & 14.9 & 58.9 & 1.6 & $0.04 \pm 0.01$ & 0.00 \\
\hline December & 19.9 & 67.9 & 2.0 & $0.01 \pm 0.01$ & 0.62 & 6.3 & 43.3 & 1.3 & $0.02 \pm 0.01$ & 0.06 \\
\hline \multicolumn{11}{|c|}{ Pomona Cal Poly, 1927-1991 } \\
\hline March & 21.0 & 69.8 & 2.0 & $-0.01 \pm 0.01$ & 0.77 & 5.6 & 42.1 & 1.8 & $0.06 \pm 0.01$ & 0,00 \\
\hline June & 28.5 & 83.3 & 1.8 & $0.00 \pm 0.01$ & 0.98 & 11.7 & 53.1 & 1.3 & $0.04 \pm 0.0 \mathrm{I}$ & 0.00 \\
\hline September & 31.2 & 88.2 & 2.0 & $-0.01 \pm 0.01$ & 0.62 & 13.1 & 55.6 & 1.9 & $0.07 \pm 0.01$ & 0.00 \\
\hline December & 19.3 & 66.8 & 2.4 & $0.04 \pm 0.02$ & 0.00 & 3.5 & 38.3 & 1.8 & $0.06 \pm 0.01$ & 0.00 \\
\hline
\end{tabular}

Table 6a: Mean, standard deviation, and regression results against year for monthly averages of daily temperature maxima and minima at various cities over time. Statistically significant slopes at $95 \%$ confidence level, for which $\mathrm{p}(\mathrm{Slope}=0) \leq 0.05$, are in gray. 


\begin{tabular}{|c|c|c|c|c|c|c|c|c|c|c|}
\hline \multirow[b]{2}{*}{ Month } & \multicolumn{5}{|c|}{ Monthly Average of Daily Maxima } & \multicolumn{5}{|c|}{ Monthly Average of Daily Minima } \\
\hline & \multicolumn{2}{|c|}{  } & $\begin{array}{r}\text { Std. Dev. } \\
\text { (Kelvin) } \\
\end{array}$ & $\begin{array}{l}\text { Slope } \\
\text { (K/yr) }\end{array}$ & $\mathrm{p}($ Slope $=0)$ & \multicolumn{2}{|c|}{\begin{tabular}{c|c}
\multicolumn{2}{c}{ Mean } \\
$\left({ }^{\circ} \mathrm{C}\right)$ & $\left({ }^{\circ} \mathrm{F}\right)$ \\
\end{tabular}} & \multirow[t]{2}{*}{$\begin{array}{r}\text { Std. Dev. } \\
\text { (Kelvin) }\end{array}$} & $\begin{array}{l}\text { Slope } \\
(\mathrm{K} / \mathrm{yr}) \\
\end{array}$ & $\mathrm{p}($ Slope $=0)$ \\
\hline \multicolumn{10}{|c|}{ Santa Ana Fire Station, 1948-1991 } & \\
\hline March & 21.1 & 70.0 & 1.5 & $0.02 \pm 0.02$ & 0.22 & 8.5 & 47.3 & 2.0 & $0.12 \pm 0.02$ & 0.00 \\
\hline June & 25.6 & 78.0 & 1.7 & $0.01 \pm 0.02$ & 0.80 & 14.5 & 58.1 & 1.6 & $009 \pm 0.02$ & 0,00 \\
\hline September & 28.8 & 83.8 & 1.7 & $-0.02 \pm 0.02$ & 0.24 & 15.9 & 60.7 & 1.8 & $0.11 \pm 0.02$ & 0.00 \\
\hline December & 20.3 & 68.6 & 1.8 & $0.01 \pm 0.02$ & 0.67 & 6.8 & 44.3 & 1.8 & $008 \pm 0.02$ & 0.00 \\
\hline \multicolumn{11}{|c|}{ Santa Monica Pier, 1948-1991 } \\
\hline March & 17.4 & 63.3 & 1.4 & $-0.01 \pm 0.02 \mid$ & 0.56 & 10.3 & 50.6 & 1.3 & 00640,02 & 0.00 \\
\hline June & 19.9 & 67.8 & 2.1 & $-0.05 \pm 0.03$ & 0.07 & 14.6 & 58.3 & 0.9 & $0.03 \pm 0.01$ & 0.01 \\
\hline September & 22.3 & 72.2 & 1.7 & $-0.02 \pm 0.02$ & 0.42 & 16.3 & 61.4 & 1.4 & $0.06 \pm 0.01$ & 0.00 \\
\hline December & 18.4 & 65.1 & 1.7 & $0.01 \pm 0.02$ & 0.53 & 9.8 & 49.6 & 1.4 & $0.04+0.02$ & 0.04 \\
\hline \multicolumn{11}{|c|}{ Torrance, 1949-1991 } \\
\hline March & 19.8 & 67.6 & 1.4 & $0.03 \pm 0.02 \mid$ & 0.09 & 8.3 & 47.0 & 1.4 & $0.08 \pm 0.01$ & 0.00 \\
\hline June & 23.6 & 74.5 & 1.6 & $0.05 \times 0.02$ & 0,02 & 13.8 & 56.9 & 1.1 & $005 \pm 0.01$ & 0,00 \\
\hline September & 26.1 & 79.0 & 1.7 & $0.04 \pm 0.02$ & 0.08 & 15.5 & 59.9 & 1.4 & $0.06 \pm 0.02$ & 0.00 \\
\hline December & 19.8 & 67.6 & 1.9 & $-0.01 \pm 0.02$ & 0.80 & 7.3 & 45.1 & 1.4 & $0.04 \pm 0.02$ & 0.02 \\
\hline \multicolumn{11}{|c|}{ Tustin Irvine Ranch, 1927-1991 } \\
\hline March & 20.8 & 69.4 & 1.9 & $-0.02 \pm 0.01 \mid$ & 0.27 & 6.6 & 43.9 & 1.6 & $0.01 \pm 0.01$ & 0.40 \\
\hline June & 26.1 & 79.0 & 1.8 & $-0.02 \pm 0.01$ & 0.19 & 13.1 & 55.5 & 1.3 & $0.02+0.01$ & 0.04 \\
\hline September & 29.1 & 84.3 & 1.8 & $-0.02 \pm 0.01$ & 0.12 & 13.6 & 56.5 & 1.7 & $0004 \pm 0,01$ & 0.00 \\
\hline December & 20.0 & 68.0 & 2.0 & $-0.01 \pm 0.01$ & 0.52 & 4.7 & 40.4 & 1.4 & $-0.01 \pm 0.01$ & 0.34 \\
\hline \multicolumn{11}{|c|}{$U C L A, 1948-1991$} \\
\hline March & 18.9 & 66.1 & 1.7 & $0.02 \pm 0.02$ & 0.26 & 10.0 & 50.0 & 1.2 & $0.03 \pm 0.02$ & 0.06 \\
\hline June & 22.2 & 72.0 & 1.7 & $005 \pm 002$ & 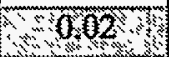 & 14.3 & 57.7 & 1.0 & $0.03 \pm 0.01$ & 0.04 \\
\hline September & 25.3 & 77.5 & 1.9 & $0.01 \pm 0.02$ & 0.57 & 16.3 & 61.3 & 1.6 & $0.03 \pm 0.02$ & 0.18 \\
\hline December & 19.2 & 66.6 & 1.9 & $0.00 \pm 0.02$ & 0.99 & 10.4 & 50.7 & 1.4 & $0.00 \pm 0.02$ & 0.90 \\
\hline
\end{tabular}

Table 6b: Mean, standard deviation, and regression results against year for monthly averages of daily temperature maxima and minima at various cities over time. Statistically significant slopes at $95 \%$ confidence level, for which $\mathrm{p}(\mathrm{Slope}=0) \leq 0.05$, are in gray.

On the other hand, significant increases in monthly averages of daily minimum temperatures are present for most months at all stations. The timing of the warming trends is different also; in many cases, the March and September trends are comparable in size to those for June. Stations which showed no tendency for daytime warming trends-L.A. International Airport, Pomona, Santa Ana, and Santa Monica-show large trends in their monthly mean minima. The largest increase is seen for Santa Ana. The increase in the number and size of the trends over those for daytime indicates the general tendency for urban warming to be most prevalent at night. 
The analysis confirms the presence of historical increases in daytime and nighttime temperatures at Burbank, Culver City, the Civic Center, and UCLA. These four stations are all located within areas of dense urban development, and the findings are consistent with the presence of strong heat.island effects. However, this level of analysis is inadequate to discern among the various causes for these temperature increases, such as heat island effects, microclimate changes, and long-term synoptic climate variations.

Climate records from other cooperative network stations show milder increases in yearly and daily maximum temperatures. These differences must be kept in mind when estimating, for example, the energy and air pollution costs of heat island effects in the Los Angeles area. If one assumes that the microclimate changes at the less densely developed urban areas outside of the city center are relatively small, then findings from Pasadena, Pomona, or Santa Ana should be more representative of local-scale effects. Synoptic climate variations may be assessed by expanding the analysis to include more historical climate records from non-urban areas, although this task is complicated by the expansive scale of urban development in the Los Angeles region.

\section{Analysis of Short-term Data}

Another method of studying the urban climate involves analysis of high spatial-resolution climate data. Data recorded at a large number of locations throughout a city can be analyzed simultaneously using the following approach.

\section{A. Methods of Analysis of Short-term Data}

Consider a collection of simultaneous temperature measurements at several locations as a vector, $\mathbf{T}(t)$. The temperature readings are thought to consist of a synoptic pre-urban signal $\mathbf{T}_{\mathbf{S}}(t)$, a local-scale urban signal $T_{\mathbf{u}}(\mathrm{t})$, and a systematic micro-scale signal $\varepsilon_{\mathbf{m}}(\mathrm{t})$ at each data point. These contributions are considered additive (albeit not totally independent) quantities:

$$
T(t)=T_{\mathbf{s}}(t)+T_{\mathbf{u}}(t)+\varepsilon_{\mathbf{m}}(t) .
$$

In order to isolate the urban contribution to the measurements, both the synoptic weather and the microclimate signals must be known.

The synoptic conditions can be approximated through climate measurements in locations free of the influence of urban land-use. Thus, stations in rural surroundings close enough to the city must be located such that rural climate readings may characterize the urban area, and yet 
these stations must be distant enough from the city to be free of urban influences extending downwind (Lowry 1977, Changnon et al. 1977). However, in some cases, strong local-scale climate influences can cause large variations in the background weather pattern, making an estimation of the synoptic weather signal difficult. For example, in the Los Angeles Basin, proximity to the Pacific Ocean and numerous mountain ranges makes the background climate of the urban areas highly variable, requiring a spatial resolution beyond that available in existing data (Kurn et al. 1994). In other cases, the terrain surrounding the city is sufficiently uniform to allow an easy estimation of the synoptic signal.

It is important to obtain a spatially resolved urban signal so that it can be correlated with variations in surface characteristics determined from land-use maps or remote sensing. Particular attention must be paid to the microclimate signal incorporated in the data. Measurements made in the canopy layer can be strongly influenced by factors such as reduced sky factors, solar heating of nearby objects, shading, and advection of heat. Under extreme conditions, these microclimate influences can change temperature variations by as much as 2 or $3 \mathrm{~K}\left(5\right.$ or $\left.6^{\circ} \mathrm{F}\right)$ (Smith et al. 1996). To overcome this difficulty and extract the urban signal from climate measurements, stations must either be located in controlled areas ${ }^{2}$ or in the absence of significant microclimate effects (either above the canopy height or in open areas, such as airports).

\section{B. Existing Short-term Data Sources for Analysis}

Unfortunately, high-resolution data collection efforts in urban areas are not centrally documented in the national or regional climate centers. Thus far, we have found several potentially useful sources of data.

\section{Cooperative network stations}

The cooperative network consists of a large number of stations, as discussed previously. As shown in Table 1, large urban areas contain many of such stations. While these stations usually do not offer the spatial resolution required for correlation with urban surface characteristics, they may be adequate for analysis that is more modest. Unfortunately, many of the characteristics of the heat island signal may be lost due to the low time resolution of the cooperative network temperature data, which includes only local daily extrema.

\footnotetext{
2The PRISMS network stations in Phoenix are all located in utility substation yards distant from the fence or wall surrounding the substation compound. Thus, this network attempts to approximate identical microclimates at all its stations, and measurements at different stations are compared in an attempt to discern variations in the heat island signal.
} 


\section{First-order stations and military installations}

Higher time resolution is offered by first-order stations and military weather stations, which record data hourly. In addition, since these stations are typically located at airports (i.e. in areas without dense canopies) microclimate effects are very weak, and those that do exist are similar at all stations. Thus, data at different stations can be directly compared and temperatures are representative of large areas. However, the spatial density of such stations is very limited.

\section{Agricultural Networks}

To obtain higher spatial densities of weather stations, one must turn to regional or cityscale weather networks operated by various agencies. Due to the need for accurate local climate data for farming, agricultural weather networks have been assembled in a number of states to provide on-line access to hourly weather data.

One such network is the Oklahoma Mesonet, a network of 156 automated observation stations that are operated and maintained by Oklahoma State University (OSU) and Oklahoma University (OU). The stations are located in fenced 10-meter square compounds and are separated by an average spacing of $30 \mathrm{~km}$. This provides a partly uniform microclimate for comparison between stations. Yet, again, the spatial resolution provided by the data is low (Crawford 1993). Each records rainfall, barometric station pressure, solar radiation, air temperature and relative humidity at 1.5 meters, wind speed and direction at 10 meters, and soil temperature under both bare soil and a natural grass cover at $10 \mathrm{~cm}$ depth. At approximately half of these stations, several supplemental parameters are also recorded, including air temperature at 9 meters, wind speed at 2 meters, leaf wetness, and soil temperatures at additional depths. Measurements are made every five minutes, and fifteen-minute averages are sent to OU and OSU where they are checked and archived.

A similar network is operated by the High Plains Climate Center. The station density is much lower, as over one hundred automated weather stations cover four states (Kansas, Nebraska, North Dakota, and South Dakota) and parts of five others (Colorado, Iowa, Minnesota, Missouri, and Wyoming). Urban centers, naturally, receive denser coverage than rural areas.

\section{Utility operated networks}

Utility forecasting and demand management rely heavily on accurate weather information. Given the heterogeneity of urban climates, some utilities have established urban weather station networks to improve their characterization of weather conditions. These can add significantly to the station density in urban climate research. 
One such network is operated by the Southern California Edison Company (SCE) serving the Los Angeles area, excluding the city of Los Angeles itself and a few neighboring cities. The stations record drybulb and wetbulb air temperature, insolation, wind speed and direction, and atmospheric pressure at hourly intervals. The stations also provide averages and extrema of several recorded parameters at daily intervals. Data have been recorded continually since May 1987 and can be obtained through SCE. Once again, as discussed in Kurn et al. (1994), these stations by themselves cannot provide adequate coverage for interpolation between stations. Adequate coverage may be obtained by supplementing the measurements with other data sources. Unfortunately, the SCE stations are not examined and calibrated on a regular basis. Rather, inspections and adjustments are performed when SCE is notified of probable errors by researchers using the data. Thus, previously recorded data from these stations should probably not be used in urban climate studies, where the resolution of temperature data need to be on the order of $0.5 \mathrm{~K}$. However, if a period of data collection is accompanied with regular calibrations, the network can be used fruitfully.

The densest existing station network we have encountered is the Phoenix Real-time Instrumentation for Surface Meteorological Studies (PRISMS) network in Phoenix, Arizona. The station network is co-operated by the Salt River Project (utility serving the greater Phoenix area), the National Severe Storms Laboratory, and Arizona State University (ASU). The network consists of 16 stations located in open areas within utility substation compounds, at least 10 feet away from the border of the compound marked by a fence or wall (see Table 7). Weather parameters, recorded every five minutes at each of the sites, include air temperature, humidity,

\begin{tabular}{|c|l|c|c|c|c|l|}
\hline ID\# & Name & Latitude & Longitude & Elev. $(\mathrm{m})$ & Compound & \multicolumn{1}{|c|}{ Notes } \\
\hline \hline 1 & Alameda & $33^{\circ} 26^{\prime} 47^{\prime \prime}$ & $111^{\circ} 55^{\prime} 9^{\prime \prime}$ & 360 & 2 -m wall & urban, tree canopy close \\
2 & Arcadia & $33^{\circ} 30^{\prime} 36^{\prime \prime}$ & $112^{\circ} 0^{\prime} 10^{\prime \prime}$ & 380 & 3 -m wall & urban, south of canal \\
3 & Collier & $33^{\circ} 27^{\prime} 46^{\prime \prime}$ & $112^{\circ} 17^{\prime} 22^{\prime \prime}$ & 325 & fence & rural \\
4 & Corbell & $33^{\circ} 21^{\prime} 25^{\prime \prime}$ & $111^{\circ} 49^{\prime} 41^{\prime \prime}$ & 370 & fence & rural, open \\
5 & Falcon & $33^{\circ} 28^{\prime} 9^{\prime \prime}$ & $111^{\circ} 43^{\prime} 56^{\prime \prime}$ & 415 & fence & asphalt, airport \\
7 & Fountain & $33^{\circ} 36^{\prime}$ & $11^{\circ} 42^{\prime} 33^{\prime \prime}$ & 495 & fence & rural, desert \\
9 & Kay & $33^{\circ} 24^{\prime} 47^{\prime \prime}$ & $11^{\circ} 9^{\prime} 9^{\prime \prime}$ & 315 & unfenced & agricultural, commercial \\
& & & & & & \\
11 & Pera & $33^{\circ} 27^{\prime} 51^{\prime \prime}$ & $111^{\circ} 56^{\prime} 19^{\prime \prime}$ & 385 & fence & desert to west, resid. to east \\
12 & Pringle & $33^{\circ} 34^{\prime} 14^{\prime \prime}$ & $112^{\circ} 6^{\prime} 27^{\prime \prime}$ & 375 & fence & urban, open \\
13 & Rittenhouse & $33^{\circ} 15^{\prime} 38^{\prime \prime}$ & $111^{\circ} 38^{\prime} 14^{\prime \prime}$ & 430 & fence & agricultural, houses nearby \\
14 & Sheely & $33^{\circ} 29^{\prime} 10^{\prime \prime}$ & $112^{\circ} 12^{\prime} 59^{\prime \prime}$ & 325 & fence & residential \\
15 & Stapley & $33^{\circ} 26^{\prime}$ & $111^{\circ} 48^{\prime} 15^{\prime \prime}$ & 365 & 2-m wall & urban, tree canopy \\
16 & Stewart Mt. & $33^{\circ} 33^{\prime} 30^{\prime \prime}$ & $11^{\circ} 32^{\prime} 12^{\prime \prime}$ & 440 & fence & canyon, near dam \\
17 & Sun Lakes & $33^{\circ} 13^{\prime} 28^{\prime \prime}$ & $111^{\circ} 52^{\prime} 27^{\prime \prime}$ & 365 & 3-m wall & residential to south, open \\
& & & & & & east and west \\
18 & Superstition & $33^{\circ} 25^{\prime} 7^{\prime \prime}$ & $11^{\circ} 32^{\prime} 12^{\prime \prime}$ & 535 & 3.5-m wall & desert, residential \\
19 & Spurlock & $33^{\circ} 21^{\prime} 30^{\prime \prime}$ & $11^{\circ} 27^{\prime} 19^{\prime \prime}$ & 550 & 4-m wall & desert \\
\hline
\end{tabular}

Table 7: PRISMS network sites (from Blumberg and Brazel 1992). 
air pressure, wind speed and direction, and rainfall. Placement of sensors conforms to NWS standards, except that wind is monitored at 6.1 meters from the surface and precipitation is recorded at the surface. Data are collected at ASU's Office of Climatology on a real-time basis for archiving, and quality control programs are applied to the data. Data errors, which result mostly from communication errors, are flagged in the archives. Calibration errors are assumed negligible because SRP personnel inspect the sensors constantly. The spacing between stations within the dense central urban area (within a triangle with vertices at Arcadia, Falcon, and Corbell stations) is about $8 \mathrm{~km}$.

\section{Air quality monitoring stations}

Finally, a large amount of data may be obtained from air quality monitoring stations that are abundant in large urban areas with air pollution problems. While these stations primarily monitor the levels of several types of air constituents, many stations also record weather conditions and insolation levels. For example, in the Los Angeles area, air temperature, humidity, wind speed and direction, and insolation are monitored hourly at more than thirty locations, providing the most complete picture of the Los Angeles urban climate.

Air quality monitoring stations are operated in the United States by local, state, and federal organizations. Fortunately, the large body of data collected at these stations is centrally compiled and made available to the public through the Aerometric Information Retrieval Service (AIRS) operated by the U.S. Environmental Protection Agency. Through this service, one may perform searches through station inventories; obtain detailed station descriptions that include a description of sensors, their placement, and a history of changes at the station; and obtain archived climate data. AIRS can be accessed either by requesting queries and sets of data or by obtaining remote computer access through the National Computing Center (see appendices).

\section{Obtaining maximal data coverage of specific urban regions}

Even when no single station provides sufficient coverage for an analysis, the various sources of climate data in combination may suffice. For example, in the Los Angeles region (as far east as Palm Springs), SCE, SCAQMD, first-order NWS, and military weather stations combine to over ninety stations recording hourly weather conditions. This would enable a detailed study of climate variations in different parts of the city and thus the potential for studying the effects of various surface conditions on the scale of a city neighborhood. However, since the climate variation between nearby neighborhoods is slight (perhaps $0.5-1 \mathrm{~K}$ in air temperature, $0.5 \mathrm{~g} / \mathrm{kg}$ in absolute humidity), the records must be very accurate. Thus, it is doubtful whether the data previously recorded by different weather networks could be directly combined into a single analysis. For example, systematic absolute humidity differences of as 
much as $6 \mathrm{~g} / \mathrm{kg}$ were observed between several pairs of SCAQMD and SCE stations, each separated by no more than $24 \mathrm{~km}$. Data from the various stations should, thus, probably be combined only if their collection is accompanied by a rigorous ongoing calibration effort.

\section{Analysis of Short-term Data of the Urban Climate of Phoenix}

The heat island over Phoenix, Arizona, has been the focus of intense research, both because the location of the city and the characteristics of its environs are ideal for heat island analysis and because the city has experienced tremendous growth in recent years. ${ }^{3}$

Balling and Brazel (1987b) analyzed longterm temperature records from the cooperative network in Phoenix. Twelve stations were selected, all of which experienced location changes of less than a kilometer and elevation changes of less than $30 \mathrm{~m}$ over their period of operation. The locations of these stations in the Phoenix area are shown in Figure 2. Averages of daily temperature maxima and minima for the summer months of June, July, and August were examined for trends over the period 1949-1985. The significance of observed trends was tested using the Mann-Kendall Rank Statistic (Mann 1945, Mitchell et al. 1966). The findings of Balling and Brazel are presented in Table 8. Significant increases in summer averages of daily maximum and minimum temperatures are

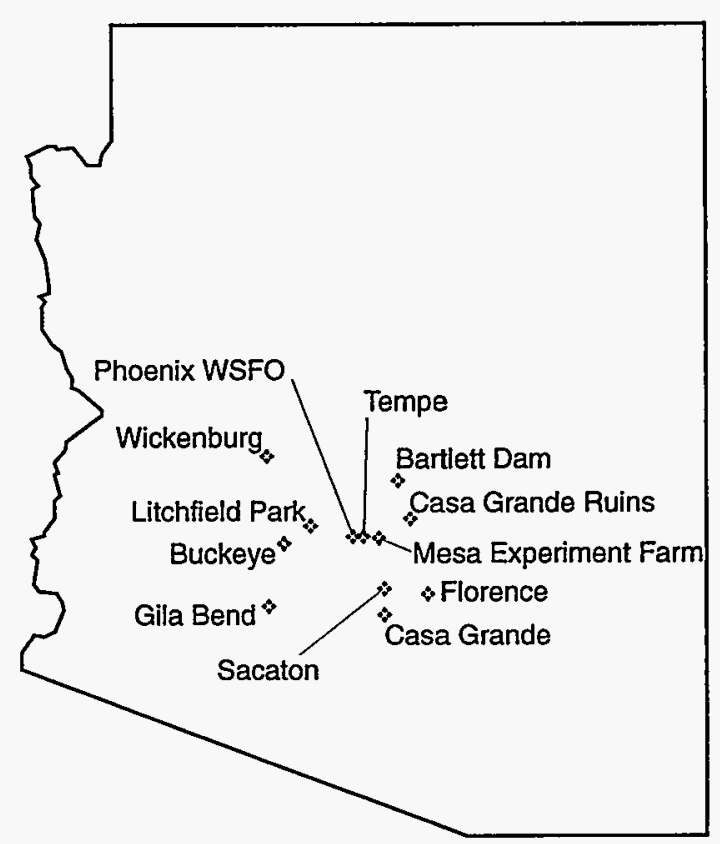

Figure 2: Locations of National Weather Service and amateur-operated weather stations near Phoenix used for heat island analysis in Balling and Brazel (1987b). observed at eight and six of the twelve stations, respectively. Climate records at the three stations located in the center of greater Phoenix (Mesa Experiment Farm, Phoenix WSFO, and Tempe) all showed significant increases in both maximum and minimum temperatures, indicative of heat island effects. However, significant increases were also observed at Buckeye, Casa Grande Ruins, Florence, Gila Bend, and Sacaton, which are all distant from the urbanized areas of Phoenix.

\footnotetext{
${ }^{3}$ The population of Phoenix has risen from 150,000 in 1945 to 1.8 million in 1984 (Balling and Brazel 1986).
} 


\begin{tabular}{|c|c|c|c|c|c|c|c|c|}
\hline \multirow[b]{2}{*}{ Station } & \multicolumn{4}{|c|}{ Summertime Avg. of Daily Maxima } & \multicolumn{4}{|c|}{ Summertime Avg. of Daily Minima } \\
\hline & $\begin{array}{c}\text { Significance } \\
\text { (Yes/No) }\end{array}$ & R-Squared & $\begin{array}{r}\mathrm{Sl} \\
(\mathrm{K} / \text { year })\end{array}$ & $\begin{array}{l}\text { ope } \\
\mid\left({ }^{\circ} \mathrm{F} / \text { year }\right)\end{array}$ & $\begin{array}{c}\text { Significance } \\
\text { (Yes/No) }\end{array}$ & R-Squared & $\begin{array}{r}\mathrm{Sl} \\
\text { (K/year) }\end{array}$ & $\begin{array}{l}\text { ope } \\
\mid\left({ }^{\circ} \mathrm{F} / \text { year }\right)\end{array}$ \\
\hline Bartlett Dam & 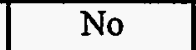 & 02 & 0.012 & 0.021 & restes & 0 & 00036 & -0.064 \\
\hline Buckeye & Yes & 0,52 & 0,073 & 01132 & & No, $\sigma_{2}$ & 10053 & 0.095 \\
\hline Casa Grande & No & 0.05 & 0.022 & 0.040 & No & 0.10 & -0.036 & -0.064 \\
\hline Casa Grande Ruins & Yes. & $0.17: 2$ & 0.038 & 0,068 & No & 0.01 & 0.006 & 0.011 \\
\hline Florence & Yès & 0.16 & 0,031 & 0.055 & No & 0.06 & 0.028 & 0.050 \\
\hline Gila Bend & No & 0.10 & 0.029 & 0.053 & Yes & $\therefore 0.18^{\circ}$ & 0.046 & 0.082 \\
\hline Litchfield Park & Yes & 031 & $0.051+$ & 0.091 & No & 0.08 & 0.027 & 0.049 \\
\hline Mesa Experiment & Yes & 0.16 & 0,029 & 0,053 & Yes & 0064 & 0.088 & 0.159 \\
\hline Phoenix WSFO & Yes & 029 & 0.054 & 0.097 & Yes & 0.50 & 0.114 & 0.205 \\
\hline Sacaton & Yés & 040 & 0,063 & 0.133 & No & 0.00 & 0.004 & 0.008 \\
\hline Tempe & Yes & 0,30 & 10054 & 0.097 & Yes & 0.00 & 0.046 & 0.083 \\
\hline Wickenburg & No & 0.02 & 0.018 & 0.032 & No & 0.04 & 0.023 & 0.041 \\
\hline
\end{tabular}

Table 8: Significance of trend, linear regression r-square statistic and rate of change for summertime averages (June - August) of daily temperature maxima and minima at twelve cooperative network stations in the Phoenix area. Significance tested with Mann-Kendall Rank Statistic. Significant items are shaded gray (from Balling and Brazel 1987b).

In the same work, the authors examine daily maximum and minimum temperatures recorded between 1980 and 1985 at 35 sites. Amateur weather observers supervised by ASU performed measurements at 29 of these sites. These sites are predominantly located in residential areas and supplement data from the other six sites, all operated by the National Weather Service. Contour maps using this data reveal average heat island profiles over the Phoenix areas with high values $1-2 \mathrm{~K}\left(2-4^{\circ} \mathrm{F}\right)$ for daily maxima and $3-4.5 \mathrm{~K}\left(6-8^{\circ} \mathrm{F}\right)$ for minima. ${ }^{4}$ Distances as large as $3 \mathrm{~km}$ in the urban area and $15-30 \mathrm{~km}$ in the surrounding areas separate the measurement locations. This makes an interpretation of the linear contour maps presented by the authors problematic since the city environs, which are used to characterize synoptic weather characteristics and thus define the magnitude of the heat island, are insufficiently characterized.

The creation of the PRISMS network made possible a much more sensitive temporal and spatial characterization of the heat island of Phoenix. This network has been used for a small number of research works. Blumberg and Brazel (1992) demonstrated some potential uses of the network with two case studies. In one, they studied the synoptic weather patterns over the

4PRISM data neither indicate nor quantify the impact of the microclimate on the recorded local air temperatures. The microclimate can have an impact of as much as 2 or $3 \mathrm{~K}\left(5\right.$ or $\left.6^{\circ} \mathrm{F}\right)$ on local air temperatures (Smith et al. 1996). 
Phoenix areas during October 27 - 29, 1991, which helped interpret data from an AVHRR satellite overpass on October 28.5 Another work (Verville et al. 1992) compared temperature measurements made at 6 and 20 feet at both the Alameda PRISMS site and a residential site one mile away. They concluded that PRISMS site temperature measurements made at 6 feet above ground are approximately equal to temperature measurements made 6 feet above canopy height. In other words, the PRISMS measurements are relatively free of microclimate effects.

We performed an exploratory analysis of PRISMS data to study the heat island of Phoenix. Our analysis initially focused on a sample of data for the months of May and June in the years 1992 and 1993. We relied on the data quality control techniques used by researchers at ASU. All data that were flagged as questionable were removed from the data set and replaced with interpolated values between valid data before and after the questionable ones. We supplemented this data with insolation, wind speed and direction, and air temperature and humidity measurements at the General Motors Testing Ground north of Phoenix and with wind speed and direction, air temperature and humidity, and sky cover measured at Phoenix Sky Harbor Airport.

\section{Analysis and Results}

Synoptic weather conditions were characterized by averaging data collected at Corbell, Falcon, and Kay, three rural stations. Temperature data were averaged over the 31 days of May 1992 to create average diurnal temperature profiles both for each individual station and for the rural stations above. In the comparison of some urban and rural average diurnal temperature profiles, clear heat island signals were discerned. For example, night-time site temperatures were $1-1.5 \mathrm{~K}\left(2-2.5^{\circ} \mathrm{F}\right)$ higher at Alameda, Arcadia, Pera, Falcon, Pringle, and Stapley, all located near the urban center of Phoenix, than at the three rural stations. The predominance of high average temperatures at stations near the city center and low average temperatures at rural stations agrees with expected heat island effects. This comparison is presented in Figure 3.

While the average diumal profiles discussed above exhibit clear heat island signals, the urban-rural temperature difference was found to vary from day to day. We began our analysis with Arcadia station, which is located within the Phoenix city center and exhibited clear signs of heat island effects. In Figure 4, the solid line is the mean urban-rural temperature difference at Arcadia for May 1992, averaged by hour. The variation in the urban-rural temperature

\footnotetext{
5 In another study, they examined the night-time heat island of Phoenix using contour maps made from interpolation of temperatures from all 16 sites.
} 


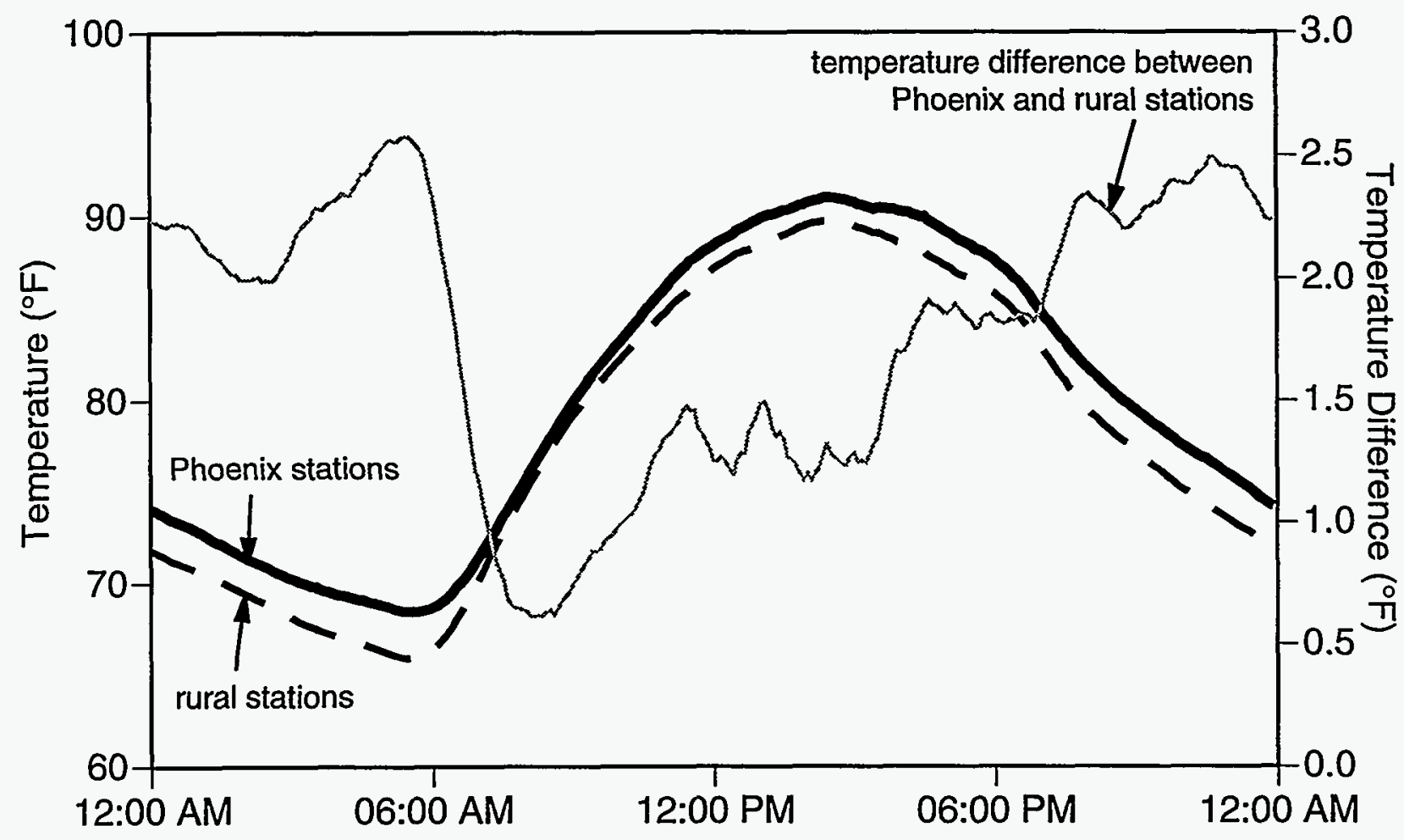

Figure 3: Urban versus rural temperatures at PRISMS sites. The thick solid line is the hourly running average temperature of six weather stations located near the urban center of Phoenix, Arizona. The dashed line is the hourly running average of three rural weather stations. The light solid line represents the difference in temperatures between the two averages.

difference, as measured by the standard deviation of the 372 measurements that are averaged in each hour (twelve readings per hour for 31 days), is $0.5-1 \mathrm{~K}\left(0.9-2^{\circ} \mathrm{F}\right)$. The dashed lines in Figure 4 are one standard deviation from the mean. However, given the large number of measurements, the estimated standard deviation error in the mean hourly difference is only approximately $0.5 \mathrm{~K}\left(0.9^{\circ} \mathrm{F}\right)$, shown by the dotted lines.

One does not expect these deviations from the mean urban-rural temperature difference to be random. Rather, climate conditions, such as wind, precipitation, humidity, and insolation, can determine whether a strong heat island develops within a city. Strong winds dissipate the influence of surface characteristics on local-scale air temperatures, and high humidity or rain mitigates the difference in water availability between urban and rural surfaces. Conversely, strong urban heat islands can develop under calm and dry conditions. We explored the PRISMS data for correlations between the urban-rural temperature difference and other climate measurements that would reveal these causal relations. 


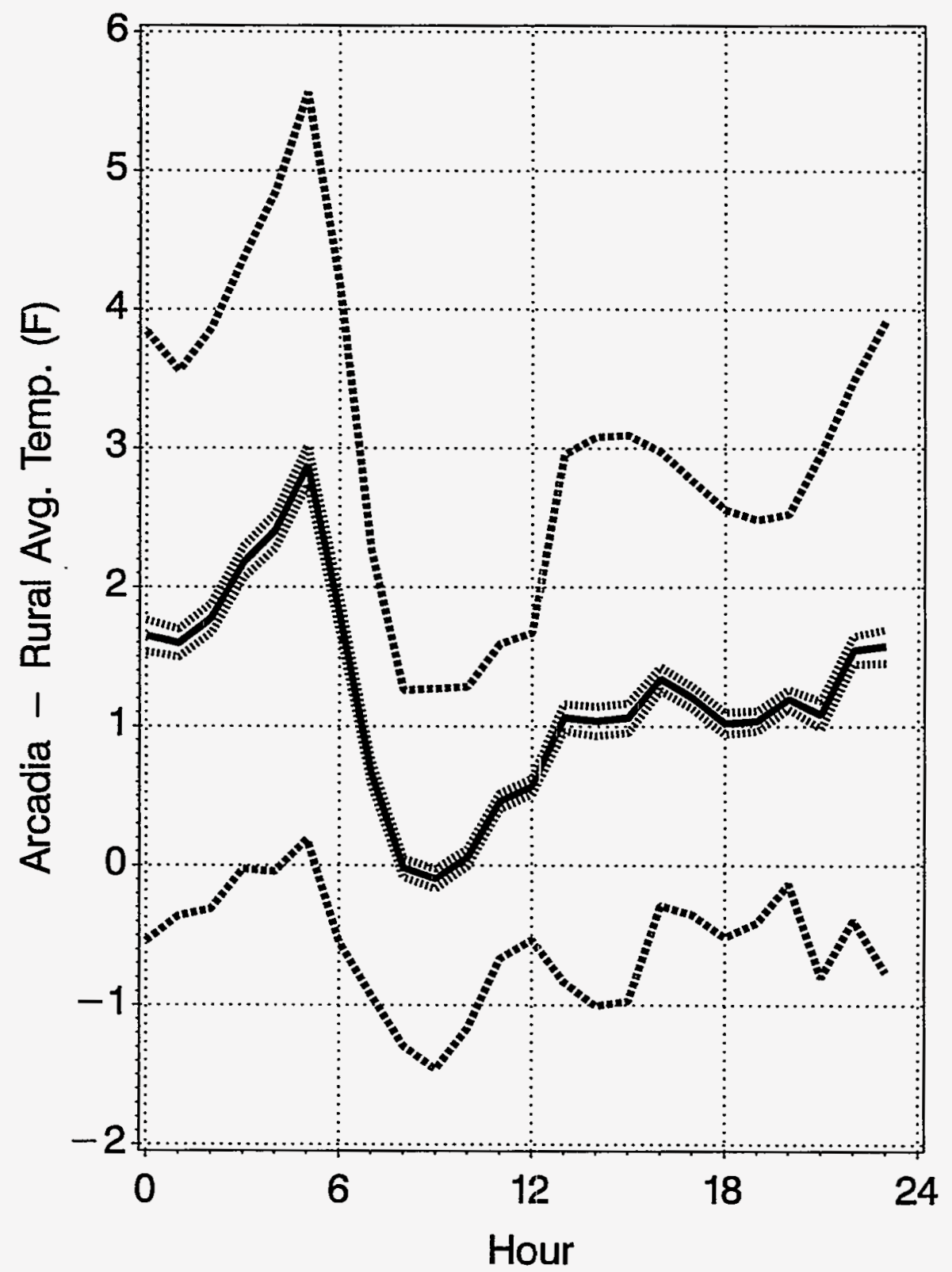

Figure 4: Characteristics of population of differences between Arcadia and rural average temperatures for May 1992, separated by hour. The solid line is the population means. Dashed lines are one standard-deviation from mean. The dotted lines are the estimated errors of mean.

A clear and significant positive correlation was found between rural temperatures, which were assumed to be influenced by synoptic conditions, and the magnitude of afternoon urbanrural temperature differences. However, no correlations were found between urban-rural temperature differences and various measurements of wind speed, precipitation, or insolation. 


\section{Conclusions and Suggested Directions for Future Work}

This review paper may be considered a progress report on some aspects of our ongoing research on characterizing the urban heat island effect. The objectives of this research are to understand the spatial variation of urban heat islands within cities and their severity under different climate and land-use conditions across the nation. This understanding will help guide efforts to cool cities intentionally in order to increase human comfort, conserve energy and resources, and reduce air pollution.

Heat island analysis methodologies may analyze historical or short-term data. Historical analysis uses long-term climate records to detect significant changes in climate conditions within cities as they develop and to isolate the contribution of urban development within these trends. Such an analysis strongly benefits from the presence of climate records from several locations within the city and in non-urban areas in close proximity, since a comparison of climate data from different stations allows one to eliminate the bias of long-term synoptic climate changes. Yet, any historical analysis is sensitive to changes in instrumentation, data recording methods, sampling, and station microclimate. Significant efforts must be performed to ensure historical homogeneity in selected climate records.

Existing long-term climate data records include records from the cooperative network, first-order National Weather Service stations, and military installations. The cooperative network consists of stations from a variety of sources that voluntarily report their data to the National Weather Service for compilation. Data from this network include daily maximum and minimum temperature and daily total precipitation, evaporation, and snowfall. Inventories of records from the cooperative network are available through the NCDC. Several subsets of cooperative network data have been amassed wherein consequent records from nearby stations (resulting from station moves) have been combined and tests for historical homogeneity have been performed. Most notable among these collections are the U.S. Historical Climatology Network data set and the NCDC Summary of Day data set.

First-order National Weather Service stations and military installations also provide longterm climate data records. While fewer in number, these stations record climate conditions at hourly intervals and are less influenced by microclimate effects. Finer heat-island analysis is thus possible, and climate measurements can be considered more representative of local-scale conditions and less biased by microclimate changes. Station inventories of this body of data are available through NCDC. 
Another methodology for heat island analysis uses short-term data from a dense network of urban stations to detect neighborhood scale variations in the heat island. To isolate the heat island signal in these climate data, it is necessary to characterize synoptic weather conditions using non-urban stations-a task complicated by strong local-scale climate influences, such as bodies of water and mountains, or by the lack of representative non-urban stations in cities of extreme size-and to assess or eliminate microclimate effects. Further, spatial interpolations should only be performed when the spacing between stations is commensurate with the "neighborhood" size that the data represent.

Data sources for such analysis include sources with national or global coverage, such as the cooperative network, first-order National Weather Stations, and military stations, and smaller scale station networks. Some such networks are established where accurate real-time climate information is needed for agricultural purposes, such as the Oklahoma Mesonet, with 156 automated stations in Oklahoma, and the network operated by the High Plains Climate Center covering all or parts of nine states. Other dense urban weather station networks are established for the purpose of monitoring and studying air pollution. A compilation of data from and descriptions of all air quality monitoring stations in the United States is available through the Aerometric Information Retrieval Service (AIRS) of the U.S. Environmental Protection Agency. Finally, in several cities dense weather station networks have been established by utilities for demand forecasting. Examples include the SCE weather station network in Southern California and the PRISMS network in Phoenix, Arizona. In combination, these various sources may provide adequate data coverage for heat island analysis of short-term data, but problems may arise in inter-calibration of these data sources.

To test methodologies of heat island characterization with existing data sources, we have performed some analysis of heat island effects in Los Angeles, California, and Phoenix, Arizona. In the analysis of Los Angeles, eleven stations were chosen from the cooperative network with data coverage from at least 1950 to the 1990's. Yearly maximum temperatures were analyzed and found to be rising significantly in Burbank, Culver City, and the L.A. Civic Center weather stations, in agreement with other analyses. However, as data at the other stations demonstrated, the large increases observed at these three stations are not characteristic of the entire Los Angeles urban region. At the other eight stations, regression results, which failed to pass a $95 \%$ significance level, showed yearly maximum temperatures to increase at a much lower rate. We also analyzed monthly averages of daily temperature maxima and minima for the months of March, June, September, and December. We found that within a $95 \%$ confidence, June monthly averages of daily temperature maxima are rising at Burbank, Culver City, the L.A. Civic Center, 
and UCLA, by $0.05-0.09 \mathrm{~K}\left(0.09\right.$ to $\left.0.16^{\circ} \mathrm{F}\right)$ per year. Milder, significant increases were also seen in March and September. The fact that the largest increases occur in June suggests that these temperature elevations are responses to solar radiation and may be due to micro- or localscale climate responses to changing surface conditions. A few other stations showed significant rises in daily maximum temperatures. On the other hand, significant increases in monthly averages of daily minimum temperatures were prevalent, in agreement with widespread findings that night-time heat island effects are usually larger than daytime ones.

For the Phoenix area, we examined data gathered at the sixteen PRISMS network stations during May 1992, using a spatial analysis of historical data. Synoptic weather conditions were characterized by averaging data gathered at three rural stations. Then, monthly averages of diurnal temperature profiles were taken at each of the sixteen stations and compared with the rural average. Daytime heat islands of $1-2 \mathrm{~K}\left(2-4^{\circ} \mathrm{F}\right)$ were detected at several stations including those in the central Phoenix area. Large night-time temperature differences were also observed at a variety of stations. These heat island data may include the impact of the local microclimate. These phenomena clearly point to a significant local-scale heat island over the urbanized areas of Phoenix. Some effort was also spent to understand the day-to-day variations in the heat island pattern, although little progress has been made.

These analyses with existing data clearly lay the groundwork for more extensive heat island analyses to be performed in the future. First, the extensive coverage of existing data sources allows for many more limited analyses of heat islands in cities across the United States. Such analyses should be performed on a city-by-city basis so that significant and unique characteristics of each city can be taken into account (unlike the approach of Karl et al. 1988). Next, these analyses can be significantly expanded by the combination of several existing weather station networks, as illustrated by the example of Los Angeles, where hourly climate data is available from over ninety locations. However, detailed analysis with existing weather networks would require a great effort in calibrating the various stations and, more difficult, in accounting for microclimate influences at each of the stations.

Because of microclimate differences, it may be advisable to use only those existing stations where microclimate effects can be assumed to be negligible. For this reason, the PRISMS network may prove especially useful in a detailed spatial heat island analysis since these stations have comparable microclimate influences. The Phoenix area is further suited to heat island analysis due to the absence of complicating local-scale influences such as large bodies of water or large elevation changes within city. In addition, the development of Phoenix is historically recent and a fairly well-documented in the climate record. However, to provide 
spatial coverage to the degree where small variations in the heat island signal may be properly linked to surface characteristics, additional weather stations will be necessary. These should also be located in locations free of microclimate complications, such as open fields.

\section{Acknowledgements}

This work was sponsored by the U.S. Department of Energy under Contract No. DEAC03-76SF00098.

\section{References}

Akbari, H., D. Kurn, H. Taha, S. Bretz, and J. Hanford, 1997, "Peak Power and Cooling Energy Savings of Shade Trees," Energy and Buildings - Special Issue on Urban Heat Islands and Cool Communities, 25(2), pp. 139-148. Excerpts from Lawrence Berkeley National Laboratory Report LBL-34411, Berkeley, CA.

Akbari, H., S. Bretz, J. Hanford, D. Kurn, B. Fishman, and H. Taha. 1993. "Monitoring Peak Power and Cooling Energy Savings of Shade Trees and White Surfaces in the Sacramento Municipal Utility District (SMUD) Service Area: Data Analysis, Simulations, and Results," Lawrence Berkeley National Laboratory Report LBL-34411, Berkeley, CA.

Akbari, H., A. Rosenfeld, and H. Taha. 1990. "Summer Heat Islands, Urban Trees, and White Surfaces," Proceedings of American Society of Heating, Refrigerating and Air-Conditioning Engineers, Atlanta, GA, (February). Also Lawrence Berkeley National Laboratory Report LBL28308, Berkeley, CA.

Balling, R. C., J. A. Skindlov, and D. H. Phillips. 1990. "The impact of increasing summer mean temperatures on extreme maximum and minimum temperatures in Phoenix, Arizona," Journal of Climate, 3, pp. 1491-1494.

Balling, R. C., and S. W. Brazel. 1987a. "Temporal variations in Tucson, Arizona summertime atmospheric moisture, temperature and water stress levels," Journal of Climate and Applied Meteorology, 26, pp. 995-999. 
Balling, R. C. and S. W. Brazel. 1987b. "Time and space characteristics of the Phoenix urban heat island," Journal of the Arizona-Nevada Academy of Science, 21, pp. 75-81.

Balling, R. C. and S. W. Brazel. 1986. "New' weather in Phoenix? Myths and realities," Weatherwise, 39(2), pp. 86-90.

Blumberg, D. G. and A. J. Brazel. 1992. "Climate uses of the PRISMS network in Phoenix, Arizona," Proceedings of the 4th Arizona Weather Symposium, Scottsdale, Arizona.

Cayan, D. R. and A. V. Douglas. 1984. "Urban influences on surface temperatures in the southwestern United States during recent decades," Journal of Climate and Applied Meteorology, 23(11), pp. 1520-1530.

Changnon, S. A., F. A. Huff, P. T. Schickendanz, and J. L. Vogel. 1977. Summary of METROMEX, Volume 1: Weather Anomalies and Impacts. Illinois State Water Survey, Urbana, Bulletin 62.

Crawford, K., ed. 1993. The Oklahoma Mesonet. Oklahoma Climatological Survey, Norman, OK.

EarthInfo, Inc. 1997. "NCDC Summary of the Day," published on 4 CD-ROMs.

Ingram, B. Meteorologist-in-Charge, Office of Climatology, Arizona State University. 1998. Personal communication.

Karl, T. R., H. F. Diaz, and G. Kukla. 1988. "Urbanization: its detection and effect in the United States climate record," Journal of Climate, 1, pp. 1099-1123.

Karl, T. R., and C. N. Williams Jr. 1987. "An approach to adjusting climatological time series for discontinuous inhomogeneities," Journal of Climate and Applied Meteorology, 26, pp. 17441763.

Karl, T. R., C. N. Williams Jr., P. J. Young, and W. M. Wendland. 1986. “A model to estimate the time of observation bias associated with monthly mean maximum, minimum, and mean temperatures for the United States," Journal of Climate and Applied Meteorology, 25, pp. 145160.

Kurn, D., S. Bretz, B. Huang, and H. Akbari. 1994. "The Potential for Reducing Urban Air Temperatures and Energy Consumption Through Vegetative Cooling," Proceedings of the 
ACEEE 1994 Summer Study on Energy Efficiency in Buildings, August 1994, Pacific Grove, CA, 9, p. 155. Also Lawrence Berkeley National Laboratory Report LBL-35320, Berkeley, CA.

Lowry, W. P. 1977. "Empirical estimation of urban effects on climate: a problem analysis," Journal of Applied Meteorology, 16, p. 129.

Mann, H. B. 1945. "Non-parametric test against trend," Econometrika, 13, pp. 245-259.

Mitchell, J. M. Jr., B. Dzerdzeevskii, H. Flohn, W. L. Hofmeyr, H. H. Lamb, K. N. Rao, and C. C. Wallen. 1966. Climatic Change. WMO Technical Note No. 79, Geneva, Switzerland.

Oke, T. R. 1978. Boundary Layer Climates, Methuen and Co. London.

Schaffer, P. Office of Climatology, Arizona State University. 1998. Personal communication.

Smith, C., H. Akbari, and S. Bretz. 1996. "Microclimate Effects Near the Ground in the Suburban Environment," Lawrence Berkeley National Laboratory Report LBL-37876, Berkeley, CA.

Taha, H., H. Akbari, A. Rosenfeld, and J. Huang, 1988. "Residential Cooling Loads and the Urban Heat Island: The Effects of Albedo," Energy and Environment, 23(4), pp. 271-283. Also Lawrence Berkeley National Laboratory Report LBL-24008, Berkeley, CA.

Verville, H. J., S. W. Brazel, and A. J. Brazel. 1992. "PRISMS Alameda station temperature observations," Proceedings of the 4th Arizona Weather Symposium, Scottsdale, Arizona, pp. 94100. 


\section{Appendix A}

Information from the Carbon Dioxide Information Analysis Center (CDIAC)

A.2 - A.3 Information about CDIAC from the CDIAC web page

(source: http://cdiac.esd.oml.gov/cdiac/about/intro.html)

A.4 - A.16 Information about data sources from CDIAC that may be useful to heat island research

(source: ftp://cdiac.esd.ornl.gov/pub/README) 

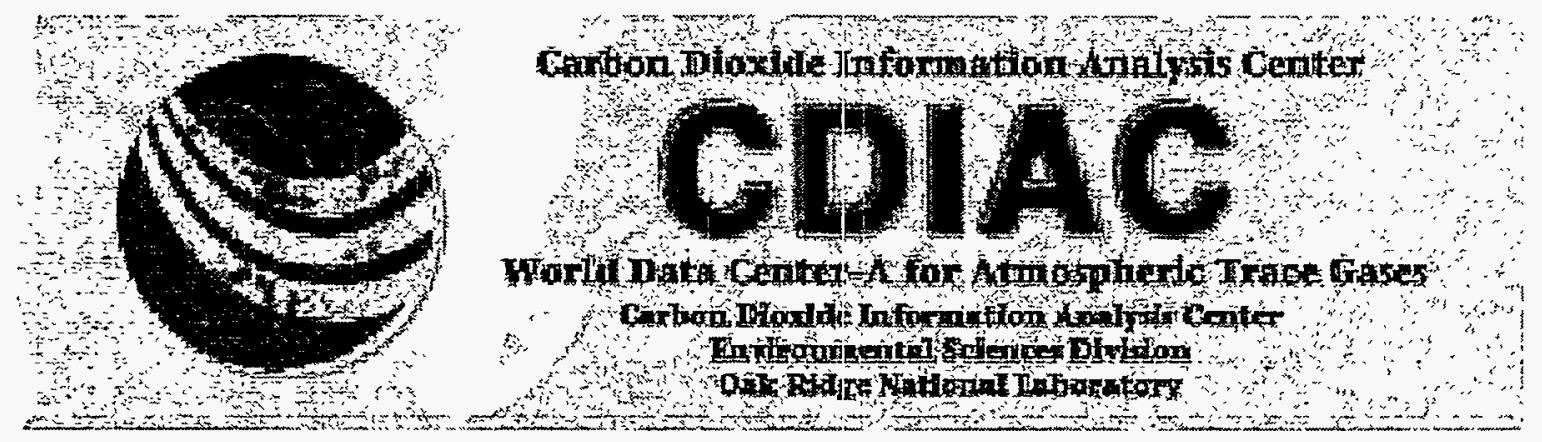

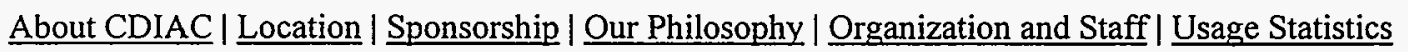

Sarch Use Harvest to search CDIAC's data holdings and web area.

About CDIAC

C.

The Carbon Dioxide Information Analysis Center (Robert M. Cushman, Director), which includes the World Data Center-A for Atmospheric Trace Gases, is the primary global-change data and information analysis center of the U.S. Department of Energy (DOE). More than just an archive of data sets and publications, CDIAC has - since its inception in 1982 - enhanced the value of its holdings through intensive quality assurance, documentation, and integration. As opposed to many traditional data centers that are discipline-based (for example, meteorology or oceanography), CDIAC's scope includes potentially anything and everything that would be of value to users concerned with the greenhouse effect and global climate change, including concentrations of carbon dioxide and other radiatively active gases in the atmosphere; the role of the terrestrial biosphere and the oceans in the biogeochemical cycles of greenhouse gases; emissions of carbon dioxide to the atmosphere; long-term climate trends; the effects of elevated carbon dioxide on vegetation; and the vulnerability of coastal areas to rising sea level.

Location

CDIAC is located within the Environmental Sciences Division (Stephen G. Hildebrand, Director) at Oak Ridge National Laboratory in Oak Ridge, Tennessee. CDIAC is co-located with Environmental Sciences Division researchers investigating global-change topics such as the global carbon cycle and the effects of carbon dioxide on vegetation. And CDIAC staff are connected with current Oak Ridge National Laboratory research on related topics such as renewable energy and supercomputing technologies. CDIAC and its World Data Center are part of the Environmental Sciences Division's Environmental Information Analysis Program, managed by Paul Kanciruk. CDIAC is also a part of Oak Ridge National Laboratory's Center for Global Environmental Studies, headed by Michael P. Farrell.

Sponsorship

CDIAC is supported by the Environmental Sciences Division (Michelle Broido, Director) of the Office of Biological and Environmental Research. CDIAC represents the USDOE in the multi-agency Global Change Data and Information System. Bobbi Parra is DOE's Program Manager with responsibility for CDIAC.

Our Philosophy

Focus on the data and information products that are most in demand by our diverse user community of 
researchers, educators, students, policy makers, corporate officials, and the interested lay public, such as the landmark record of rising atmospheric $\mathrm{CO}_{2}$ at Mauna Loa, Hawaii, high-quality and long-term U.S. climate data and global climate data, and global and national $\mathrm{CO}_{2}$ emissions from fossil-fuel combustion.

Emphasize data quality, so that our understanding of global climate change is based on the best possible information.

Thoroughly document important data bases, so that 20 years from now users - especially those who are not experts in the particular disciplinary area - will be able to understand how a data base was produced and what the data mean.

Provide proper credit to data contributors, so that our users will understand that the data they receive from us originated not with CDIAC but, rather, with the investigators who so generously chose to share their data with CDIAC.

Offer data and information to all users without restriction or charge, so that society receives the greatest possible benefit from the originating research programs.

Take advantage of current developments in computing technologies for data archival and distribution, so that we provide a secure home for important data and provide the information to our users in the format most appropriate for them. At the same time, CDIAC appreciates that many users still prefer to receive information in more traditional formats, and we do our best to accommodate the diversity in the needs of our user community.

See also: CDIAC's General Guidance on Data Usage and Management

Organization and Staff

CDIAC is divided into three functional groups - Global Change Data, Computing Systems, and User Services (click here to see CDIAC's organization). CDIAC's staff includes environmental scientists, computer scientists, and information scientists (click here for staff listing).

\section{How to Order $\mid$ Comments and Suggestions | Usage Statistics | Reference Tools | Annual Reports}

CDIAC

Oak Ridge National Laboratory

P. O. B0x 2008

Oak Ridge, TN 37831-6335 USA

(423) 574-0390 or (423) 574-3645

(423) 574-2232(FAX)

INTERNET: cdiac@ornl.gov

trn 
The following text is excerpted from the README file that can be obtained by anonymous ftp at cdiac.esd.ornl.gov/pub:

\author{
CARBON DIOXIDE INFORMATION ANALYSIS CENTER - CDIAC
}

The Carbon Dioxide Information Analysis Center (CDIAC), located within the Environmental Sciences Division of Oak Ridge National Laboratory in Oak Ridge, Tennessee, provides information to help international researchers, policymakers, and educators evaluate complex environmental issues associated with elevated levels of atmospheric carbon dioxide ( $\mathrm{CO} 2)$ and other radiatively active trace gases, including potential climate change. CDIAC is sponsored by the U.S. Department of Energy's (DOE) Global Change Research Program (GCRP). Michelle Broido is the Director of DOE's Environmental Sciences Division and Program Manager of GCRP. Bobbi Parra is the GCRP program manager with responsibility for CDIAC. Robert M. Cushman is Director of CDIAC. In operation since 1982, CDIAC

(1) obtains, evaluates, and archives data,

(2) compiles and distributes digital numeric data packages and computer model packages,

(3) distributes related reports,

(4) produces the newsletter, CDIAC Communications, and

(5) in general acts as the information focus for the U.S. DOE research programs

Since its inception, CDIAC has responded to thousands of requests for information, and since 1985 has distributed more than 95,000 reports and numeric data packages to over 110 countries worldwide. The center's staff members explore both general and technical aspects of issues related to carbon dioxide, methane, and other trace gas emissions; the carbon cycle; and other climate-change topics. The center's eclectic data holdings are related to the issues of concern rather than the specific scientific disciplines.

NUMERIC DATA PACKAGES (NDP)

CDIAC's principal products are its quality-assured, fully documented Numeric Data Packages (NDPS). These information products provide comprehensive documentation of benchmark data sets provided by investigators from around the world. NDPs consist of written documentation and transfer media containing machine-readable text, retrieval codes, and data files. In addition to being available through this anonymous FTP area, available transfer media include CD-ROM; 2.3 and 5 GB Exabyte tapes; 150 MB QIC tape cartridges; 9-track magnetic tapes; and IBM-formatted, floppy diskettes.

The most critical components of the NDP process are quality assurance, documentation of the data, and review before distribution. CDIAC puts the data through a rigorous and extensive quality- assurance review. After the data are checked, they are documented with text, data listings, 
illustrations, and computer codes. Unabridged reprints of pertinent literature are included as part of the documentation. Individuals contributing data are actively involved in the documentation process, and no NDP is distributed without written permission from the person or agency that contributed the data.

An NDP contains sections containing the following information:

\section{Contributors}

Background information

Applications of the data

References

Summary of data checks

Transfer media descriptions

Verification of data transport

\section{Keywords}

Source and scope of data

Data limitations and restrictions

Copyright-cleared reprints

ordering information

Listing of data retrieval programs

Tabular listings and graphic output

CDIAC has produced more than 55 of these specialized NDPs, and since 1985 CDIAC has supplied more than 7,000 NDPs to researchers, policymakers, and educators in 62 countries.

\section{ANONYMOUS FTP AREA CONTENTS}

This CDIAC anonymous FTP area provides all the data files, retrieval codes, and descriptive files for CDIAC's NDPs that are presently available. A full listing of the NDPs and a brief description of their contents are provided below. The data bases are arranged as subdirectories, each subdirectory corresponding to an NDP number (e.g., NDP001). Within each subdirectory, you will find a descriptive file (*.DES) that outlines the basic contents and formats of the other files in the subdirectory. All files are compressed (UNIX) ASCII text files. All the data bases provided in this area are fully documented and are also available on 9-track magnetic tape; CD-ROM; 2.3 or 5 GB $8 \mathrm{~mm}$ tapes; $150 \mathrm{MB}$ QIC tape cartridges; or IBM-formatted, high or lowdensity floppy diskettes. To receive the complete documentation for an NDP, please contact CDIAC by calling or writing to the following:

CDIAC

Oak Ridge National Laboratory

P. O. Box 2008

Oak Ridge, TN 37831-6335 USA

(423) 574-0390

(423) 574-2232 (FAX)

INTERNET: cdiaclornl.gov

Even if you do not want the documentation we would appreciate receiving your complete mailing address (postal) so that we may notify you of updates and revisions to the datasets that you access. If you wish we can also add you to our World Directory of $\mathrm{CO} 2$ Researchers and Policymakers. Inclusion ensures that you will routinely receive our newsletter, "CDIAC Communications", and other announcements about CDIAC data products and services. 
We hope you enjoy and benefit from using CDIAC's anonymous FTP area. Since this area will be updated periodically, we welcome your comments and suggestions for improving future holdings.

\section{A LIST of NDPs THAT MAY BE USEFUL TO HEAT ISLAND RESEARCH}

The following is a list of the NDPs presently available from CDIAC including the NDP number, publication date, title, author/contributor and affiliation, and a brief description of the data base.

NDP-001/R7 (Rev. August 1997)

ANNUAI AND SEASONAL GLOBAL TEMPERATURE ANOMALIES IN THE TROPOSPHERE AND LOW STRATOSPHERE, 1958-1996

$\mathrm{J}$. K. Angell

Air Resources Laboratory

National Oceanic and Atmospheric Administration

Surface temperatures and thickness-derived temperatures from a global network of 63 radiosonde stations have been used to estimate annual and seasonal temperature anomalies over the globe and several zonal regions from 1958 through 1996. These estimates are calculated relative to a 1958-1977 reference period mean, and pertain to the surface and the following atmospheric layers: troposphere $(850-300 \mathrm{mb})$, tropopause $(300-100 \mathrm{mb})$, $10 \mathrm{w}$ stratosphere (100-50 and 100-30 mb), and from the surface up to $100 \mathrm{mb}$. Individual data sets containing the above measurements are provided for the globe, the Northern and Southern Hemispheres, and the following latitudinal zones: North $(60-90 \mathrm{~N})$ and South $(60-90 \mathrm{~S})$ Polar; North $(30-60 \mathrm{~N})$ and South (30-60 S) Temperate; North $(10-30 \mathrm{~N})$ and South $(10-30$ S) Subtropical; Tropical $(30 \mathrm{~N}-30 \mathrm{~S})$; and Equatorial $(10 \mathrm{~N}-10 \mathrm{~S})$.

Most of the values are column-mean temperatures obtained from the differences in height between constant-pressure surfaces at individual radiosonde stations. The pressure-height data before 1980 were obtained from published values in Monthly Climatic Data for the Norld. These temperature anomalies may be used to analyze long-term temperature trends for a layer of the atmosphere (i.e., surface, troposphere, tropopause, and low stratosphere), a region (i.e., polar, temperate, subtropical, and equatorial), a hemisphere, or the globe. The data are in 11 files totaling $98 \mathrm{kB}$.

NDP-019/R3 (Rev. 1995)

UNITED STATES HISTORICAL CLIMATOLOGY NETWORK (U.S.HCN) SERIAL TEMPERATURE AND PRECIPITATION DATA

David R. Easterling, Thomas R. Karl, Elaine H. Mason, Pamela Y. Hughes, National Oceanic and Atmospheric Administration, National Climatic Data Center

Asheville, North Carolina 28801, U.S.A.

David P. Bowman

Dyntel Central Zone Program, National Climatic Data Center

Asheville, North Carolina 28801, U.S.A. 
One of the objectives in establishing the U.S. HCN was to detect temporal changes in regional rather than local climate. Therefore, only stations not influenced to any substantial degree by artificial changes in their local environments were included in the network. Some of the stations in the U.S. HCN are first-order weather stations, but the majority were selected from the $\sim 5,000$ stations in the U.S. cooperative weather station network. To be included in the U.S. HCN a station had to be currently active (in 1987), have at least 80 years of mean monthly temperature and total monthly precipitation data, and have experienced relatively few station moves and equipment changes (see Appendix A for a complete listing of the stations in the U.S. HCN). An additional criterion used in selecting the 1221 U.S. HCN stations that sometimes compromised the preceding requirement, was the desire to have a uniform distribution of stations across the continental United States.

The U.S. HCN database contains station histories, monthly temperature data (mean, mean minimum, average [i.e., (monthly minimum + monthly maximum) / 2], and mean maximum), and total monthly precipitation data that were compiled from digital and non-digital data sets archived at the National Climatic Data Center (NCDC). These data sets originated from a variety of sources, including climatological publications, universities, federal agencies, individuals, and data archives. All stations were quality controlled by NCDC through the use of outlier and areal edits. Each station record was then corrected for time-of-observation (TOB) differences, instrument changes, instrument moves, and station moves (Karl and Williams 1987). The effects of urbanization were then removed and four urban temperature files produced (Karl et al. 1988).

A unique feature of these data are that within most temperature and precipitation data files, both original (or estimated) and adjusted data are given along with confidence factors for each adjusted data value. Another unique feature of the database is that in comparison with the long periods of record, only a small portion of the data are represented as missing. In order to make the U.S. HCN record as serially complete as possible, values for stations missing data have been estimated using data from neighboring stations. Since 1900, over 50\% of the 1221 stations have data records that are serially complete (i.e., have original, or estimated, and adjusted data).

This NDP provides 27 files: 6 FORTRAN input/output routines; 6 SAS input/output routines; 1 station inventory file; 1 station history file; 4 U.S. HCN files containing monthly mean, mean minimum, average (i.e., [ monthly minimum + monthly maximum] / 2), and mean maximum temperatures; 1 file containing total monthly precipitation data; 3 quality assessment files for the U.S. HCN temperature and precipitation data files; 4 temperature files (mean, mean minimum, average, and mean maximum) that have been adjusted for urban heat island effects; and this documentation file.

NDP-020/R1 (Rev. 1990)

AN URDATED GLOBAL GRID POINT SURFACE AIR TEMPERATURE ANOMALY DATA SET: 18511988

P. D. Jones, S. C. B. Raper, B. S. G. Cherry, C. M. Goodess, T. M. L. Wigley, B. Santer, and P. M. Kelly

University of East Anglia

R. S. Bradley

University of Massachusetts

H. F. Diaz

National Oceanic and Atmospheric Administration 
This document presents monthly surface air temperature anomalies (departures from a 1951-1970 reference period mean) on a 5 degree latitude by 10 degree longitude global grid. The data were derived primarily from the World Weather Records and the archives of the United Kingdom Meteorological Office. This long term temperature anomaly record may be used in studies addressing possible $\mathrm{CO} 2$ induced climate changes. To date, the data have been employed in generating hemispheric and global time series for determining whether recent (post-1900) warming trends have taken place.

All data have been assessed for quality (gross accuracy and consistency, temporal variability, and spatial and temporal completeness of record), and for long-term homogeneity. Although the period of record is from 1851 to 1988, few grid point locations have contributed data for the entire period of record.

The NDP consists of this document and a magnetic tape containing machinereadable files. This document provides sample listings of temperature anomalies, station numbers, mean inverse distance data, as well as a complete listing of the gridded surface air temperature anomalies on microfiche (Appendix B). This document also offers retrieval program listings (in FORTRAN and SAS languages), furnishes graphical summaries and information on sampling methods and data selection, defines limitations and restrictions of the data, and provides reprints of pertinent literature.

NDP-021/R1 (Rev. 1991)

HISTORICAL SUNSHINE AND CLOUD DATA IN THE UNITED STATES P. M. Steurer and T. R. Karl

National Oceanic and Atmospheric Administration

National Climatic Data Center

This data base presents monthly sunshine data from 240 U.S. stations (including Puerto Rico and nine Pacific Islands) and monthly cloud amount data from 197 U.S. stations. The longest periods of record are 1891 through 1987 for the sunshine data and 1871 through 1987 for the cloud data. The sunshine data were derived from measurements taken by a variety of sunshinerecording instruments. The cloud data were derived from land-based estimates of fractional cloud amount, which were made with observation practices that have varied during the period of record. Station number, station name, latitude, and longitude are given for all stations in each network. The sunshine data include monthly and annual total hours of recorded sunshine, monthly and annual maximum possible hours of sunshine, monthly and annual percentages of possible sunshine (hours recorded/hours possible), and dates of use for specific types of sunshine recorders at each station. The cloud data contain monthly and annual cloud amount (in percent of sky cover). The sunshine data are in four files: one station inventory (34.1 kB), one monthly and annual hours of measured sunshine ( $1.6 \mathrm{MB})$, one monthly and annual maximum possible hours of sunshine $(21.5 \mathrm{kB})$, and one monthly and annual percentage of possible sunshine $(2.1 \mathrm{MB})$. The cloud data are in two files: one station inventory $(20.4 \mathrm{kB})$ and one monthly and annual cloud amount $(2.4$ MB). All files are available on 9-track magnetic tape only.

NDP-026 (1988)

CLIMATOLOGICAL DATA FOR CLOUDS OVER THE GLOBE FROM SURFACE OBSERVATIONS 
C. J. Hahn

University of Colorado

S. G. Warren

University of Washington, Seattle

$\mathrm{J}$. London

University of Colorado

$R$. I. Jenne and $R$. M. Chervin

National Center for Atmospheric Research

With some data from as early as 1930, global long-term monthly and/or seasonal total cloud cover, cloud type amounts and frequencies of occurence, low cloud base heights, harmonic analyses of annual and diurnal cycles, interannual variations and trends, and cloud type co-occurrences have been compiled and presented in two atlases (Warren et al. 1988, 1990). These data were derived from land and ship synoptic weather reports from the spoT archive of the Fleet Numerical Oceanography Center (FNOC) and from Release 1 of the Comprehensive Ocean-Atmosphere Data set (COADS) for the years 19301979. The data are in 12 files (one containing latitude, longitude, landfraction, and number of land stations for grid boxes; four containing total cloud, cloud types, harmonic analyses, and interannual variations and trends for land; four containing total cloud, cloud types, harmonic analyses, and interannual variations and trends for oceans; one containing first cloud analyses for the first year of the GARP Global Experiment (EGGE); one containing cloud-type co-occurrences for land and oceans; and one containing a FORTRAN program to read and produce maps). These files range in size from $12.5 \mathrm{kB}$ to $5.67 \mathrm{MB}$ and are available on 9-track magnetic tape and CD-ROM only.

NDP-026A (1994)

CLIMATOLOGICAL DATA FOR CLOUDS OVER THE GIOBE FROM SUREACE OBSERVATIONS, 1982-1991

C. J. Hahn

University of Colorado

S. G. Warren

University of Washington, Seattle

J. London

University of Colorado

This database presents global coverage of anaylzed cloud data. The data were obtained from routine, surface synoptic weather reports from ships and land stations over the entire globe, for the ten-year period December 1981 through November 1991. The data were processed for total cloud cover and frequencies of occurrence of clear sky, precipitation, and sky obscured due to fog. Archived data, consisting of various annual, seasonal and monthly averages, are provided in grid boxes that are typically $2.5 \times 2.5$ degrees for land and $5 \times 5$ degrees for ocean. Day and nighttime averages are also given separately for each season. Several derived quantities, such as interannual variations and annual and diurnal harmonics, are provided as well. This data set incorporates an improved representation of nighttime cloudiness by utilizing only those nighttime observations for which the illuminance due to moon- light exceeds a specified threshold. This reduction in the nightdetection bias increases the computed global average total cloud cover by about 2\%. The impact on computed diurnal cycles is even greater, particularly over the oceans where it was found, in contrast to previous surface-based climatologies, that cloudiness is often greater at night than during the day. 
The database contains 17 files including a descriptive file (file01), a FORTRAN code that may be used to read data files, and 15 data files. The organization of data into files is based on similarity of content and data format. Total cloud data are generally separated from weather type data. The 15 data files include one file that provides the location, land fraction, and number of stations for grid boxes; one file that provides total cloud and weather types (ocean and land combined); four files containing total cloud cover (separate files for land and ocean); two files containing weather types (separate files for ocean and land); six files containing clear-sky frequencies, precipitation frequencies, and fog (sky-obscured) frequencies (separate files for land and ocean); and one file that contains the results of the analysis of the diurnal harmonics and interannual variations (land and ocean, total cloud and weather types). These files range in size from $2.2 \mathrm{kB}$ to 55.4 MB, totaling $410.4 \mathrm{mB}$. The data are available on 9-track magnetic tape, $8 \mathrm{~mm}$ tape, $1 / 4$ inch tape cartridge and through our anonymous ftp area.

NDP026B (May 1996)

EDITED SYNOPTIC CLOUD REPORTS FROM SHIPS AND LAND STATIONS OVER THE GLOBE, $1982-1991$

Carole J. Hahn

University of Arizona

Stephen G. Warren

University of Washington

Julius London

University of Colorado

Surface synoptic weather reports for the entire globe for the 10-year period from December 1981 through November 1991 have been processed, edited, and rewritten to provide this database designed for use in cloud analyses. The information in these 3 - and 6-hourly reports relating to clouds, including the present weather information, was extracted and put through a series of quality control checks. Reports not meeting certain quality control standards were rejected, as were reports from buoys and automatic weather stations. Correctable inconsistencies within reports were edited for consistency, so that the "edited cloud report" can be used for cloud analysis without further quality checking.

This database contains 124 million reports from land stations and $15 \mathrm{million}$ reports from ships. The archive consists of 241 files, 240 data files (one file for each month of data for land and ocean separately) and a README file. These files range in size from 5.0 to $8.4 \mathrm{MB}$ for the ocean data and from 49.8 to $63.5 \mathrm{MB}$ for the land data. The complete database requires approximately 8 gigabytes of storage space (2 gigabytes in the UNIX compressed form used by CDIAC).

NDP-039 (1991)

TWO LONG-TERM INSTRUMENTAL CLIMATIC DATA BASES OF THE PEOPLE' S REPUBLIC OF CHINA

Tao Shiyan, Fu Congbin, Zeng Zhaomei, Zhang Qingyun Chinese Academy of Sciences (Beijing) 
Two long-term instrumental data bases containing meteorological observations from the People's Republic of China (PRC) are described. These data sets were compiled in accordance with a joint research agreement signed by the United States Department of Energy (DOE) and the PRC Chinese Academy of Sciences (CAS) on August 19, 1987. CAS has provided records from 265 stations, partitioned into networks of 60 and 205 stations which each provide good geographical coverage of the PRC. The 60-station network data contain monthly measurements of barometric pressure, air temperature, precipitation amount, relative humidity, sunshine duration, cloud amount, wind direction and speed, and number of days with snow cover. Detailed station histories are presented for all 60 stations. The 205-station network data contain monthly mean temperatures and monthly precipitation totals; however, station histories are not currently available. Sixteen stations from these data sets (13 from the 60-station, 3 from the 205-station) have temperature and/or precipitation records which begin prior to 1900 , whereas the remaining stations began observing in the early to mid 1900s. Records from 262 stations extend through 1988; the remaining three station records extend through the early $1980 \mathrm{~s}$.

These data can be used in defining regional climate changes, establishing relationships between regional and large-scale climates, and in studying the climatic impacts of urbanization and increased concentrations of greenhouse gases. Additional uses could include examining impacts of periodic events such as volcanic eruptions or the El Nino/Southern Oscillation (ENSO). These data sets represent the most comprehensive, long-term instrumental Chinese climate data presently available.

NDP-040 (1993)

DAILY TEMPERATURE AND PRECIPITATION DATA FOR 223 U.S.S.R. STATIONS V. $N$. Razuvayev, E. G. Apasova, and R. A. Martuganov (contributors)

Under an international agreement, the National Climatic Data Center (NCDC) in Asheville, N.C., is exchanging climatological information with the Research Institute of Hydrometeorological Information in Obninsk, Russia. To expedite the dissemination of these data, CDIAC, with funding provided by NCDC, is distributing one of the more useful archives acquired through this exchange: a 223-station daily data set covering from 1881 to 1989. The data set contains (1) minimum, mean, and maximum daily temperatures; (2) daily precipitation; (3) station inventory information (i.e., WMo number, name, coordinates, and elevation); (4) station history (i.e., station relocation and rain-gage replacement information); and (5) quality-assurance information (i.e., flag codes that were assigned as a result of various data checks). The data are in 18 files.

NDP-041 (1992)

THE GLOBAL HISTORICAL CIIMATOLOGY NETWORK: LONG-TERM MONTHLY TEMPERATURE, PRECIPITATION, SEA LEVEL PRESSURE, AND STATION PRESSURE DATA RusSell S. VOSE Carbon Dioxide Information Analysis Center/Oak Ridge National Laboratory

Richard L. Schmoyer

Statistical Computing office/Oak Ridge National Laboratory

Peter M. Steurer, Thomas C. Peterson, Richard Heim, Thomas R. Karl National Climatic Data Center/NOAA

Jon K. Eischeid

Cooperative Institute for Research in Environmental Sciences 
Interest in global climate change has risen dramatically during the last several years. In a similar fashion, the number of data sets available to study global change has also increased. Unfortunately, these data sets have been compiled by many different organizations/researchers, making it confusing and time consuming for individual researchers to acquire the "best" data.

In response to this rapid growth in the number of global data sets, the Carbon Dioxide Information Analysis Center (CDIAC) and the National Climatic Data Center (NCDC) commenced the Global Historical Climatology Network (GHCN) project. The purpose of this project is to compile an improved global baseline data set of long-term monthly mean temperature, precipitation, sea level pressure, and station pressure for a dense network of worldwide meteorological stations. Specifically, the GHCN project seeks to consolidate the numerous pre-existing national-, regional-, and global-scale data sets into a single global climate data base that can be updated, enhanced, and distributed at regular intervals.

The first version of the GHCN data base was completed during the summer of 1992. It contains 6039 temperature, 7533 precipitation, 1883 sea level pressure, and 1873 station pressure stations. All stations have at least 10 years of data, $40 \%$ have more than 50 years of data, and $10 \%$ have more than 100 years of data. The majority of stations have fairly complete records (72\% are missing less than $10 \%$ of their data). Furthermore, $80 \%$ of all station records continue into the $1980 \mathrm{~s}$ or $1990 \mathrm{~s}$. Spatial coverage is good over most of the globe, particularly for the united states and central Europe. In comparison to other major global data sets, dramatic improvements are evident over South America, Africa, and Asia.

The GHCN data base has been subjected to a large amount of quality control. For example, all impossibly extreme values have been set to missing. In addition, all stations (some 17,000) were plotted and visually inspected for "gross" data processing errors and discontinuities, all of which are documented in the data base itself.

At this point, the GHCN data base is considered to be one of the best longterm climate data sets available for the study of global climate change. Furthermore, the data base will continue to evolve in the coming years. Planned improvements entail the inclusion of additional data, the correction of erroneous data, the adjustment of data inhomogeneities, the addition of new variables, and the production of gridded data sets.

NDP-042 (1992)

UNITED STATES HISTORICAL CLIMATOLOGY NETWORK DAILY TEMPERATURE AND PRECIPITATION DATA

Pamela Y. Hughes, Elaine H. Mason, Thomas R. Karl, and William A. Brower National Oceanic and Atmospheric Administration

National Climatic Data Center

This package consists of a data base containing daily observations of maximum and minimum temperature and precipitation amounts at 138 U.S. stations. These stations are a specially chosen subset of the 1219-station U.S. Historical Climatology Network (HCN), which was compiled by the National Climatic Data Center (Asheville, North Carolina) and is contained in NDP- 
019/R1. The daily data network (referred to as the HCN/D) consists of stations considered to be the best of those in the HCN, selected to provide effective coverage of the contiguous U.S. after considering the temporal homogeneity of each station's observing times, instrument positioning, and surroundings. The data for each station extend through 1987, and most station records are complete for at least 80 years. The daily resolution of these data lends maximum flexibility for studies attempting to detect and monitor long-term climatic changes on a regional scale. The data are contained in seven files (one station-inventory file, one station-history file, and five temperature and precipitation data files). The files range in size from 10 kB to approximately $31 \mathrm{MB}$ and are available via FTP and on 9-track magnetic tape only.

NDP-048 (1995)

Six- and Three-Hourly Meteorological Observations from 223 USSR Stations

V. N. Razuvaev

E. B. Apasova

R. A. Martuganov

All-Russian Research Institute of Hydrometeorological Information

Obninsk, Russia

This database contains six- and three-hourly meteorological observations from a 223 station USSR network.

The data records cover the period 1936-1983 [i.e., 6-hourly observations (1936-1965); 3-hourly observations (1966-1983)] and some extend through 1984, 1985, or 1986. Each record provides 24 types of meteorological observations. These observations appear in each record of the database in the order given below.

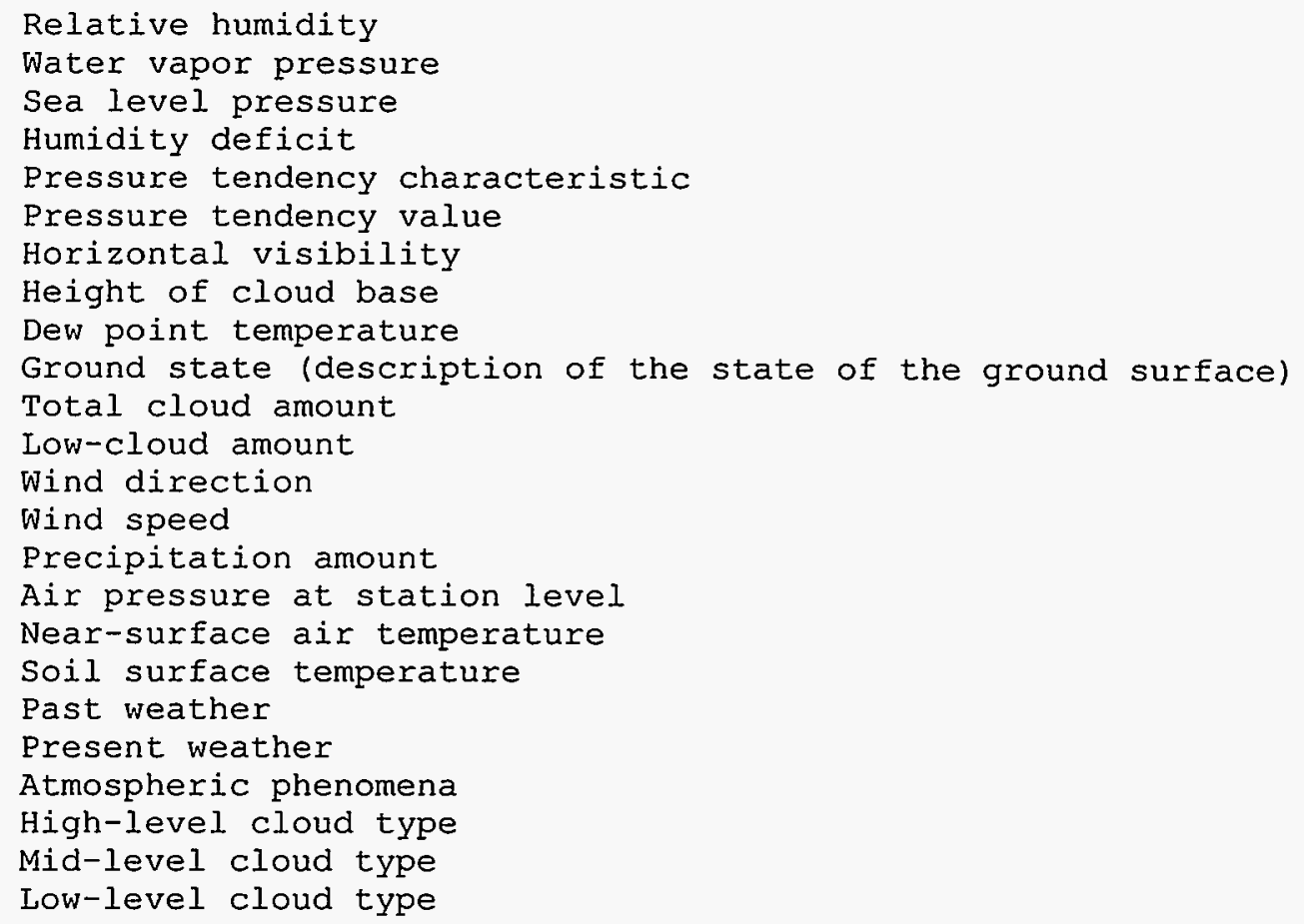




\section{observations)}

Characteristic of wind irregularity (only present in 6-hourly

The database is quite large requiring $557 \mathrm{Mb}$ of disk storage in a compressed form! The 25 data files average about $20 \mathrm{Mb}$ each.

TRENDS 193: A COMPENDIUM OF DATA ON GLOBAL CHANGE (1994)

Boden, T.A., D.P. Kaiser, R.J. Sepanski, and F.W. Stoss (eds.). Carbon Dioxide Information Analysis Center

Oak Ridge National Laboratory

oak Ridge, Tennessee 37831-6335

This document provides synopses of frequently used global-change data. This third issue of the Trends series presents historical and modern records of atmospheric concentrations of carbon dioxide (CO2), methane (CH4), nitrous oxide (N2O), two chlorofluorocarbons (CFC-11 and CFC-12), a hydrochlorofluorocarbon (HCFC-22), and two halons (H-1301 and H-1211) from an expanded number of globally distributed data sets. Virtually all of the modern records extend into the 1990s, some into 1994. Additional trace gas data presented in Trends 193 include historical atmospheric $\mathrm{CO} 2, \mathrm{CH} 4, \mathrm{and} \mathrm{N} 2 \mathrm{O}$ records derived from ice cores. Trends ' 9 '3 also includes revised and updated estimates through 1991 for global, regional, and national co2 emissions produced from the burning of fossil fuels, gas flaring, and the production of cement. Updated global emissions estimates through 1992 are also presented for CFC-11 and CFC-12. In addition, Trends '93 updates and expands the presentation of long-term temperature records, whose spatial coverage ranges from an individual Antarctic (ice core) site to the entire globe and from the Earth's surface to the lower stratosphere. New subject matter appearing in Trends '93 includes a chapter for long-term regional precipitation records, several time-series records for atmospheric aerosols, and isotopic carbon-14 measurements for atmospheric $\mathrm{CO} 2$ from several sites.

These files are found in the subdirectory /pub/trends93. Within '/pub/trends93' are additional subdirectories called 'co2', 'ch4', 'trace', 'emiss', 'precip', and 'temp'. The files range in size from $0.46 \mathrm{kB}$ to 35.97 kB, totaling $1.28 \mathrm{MB}$.

TR051 (1991)

A COMPREHENSIVE PRECIPITATION DATA SET FOR GLOBAL LAND AREAS

Jon K. Eischeid and Henry F. Diaz

CIRES, University of Colorado

and Environmental Research Laboratorịes

NOAA

Boulder, Colorado

Raymond S. Bradley

University of Massachusetts

Amherst, Massachusetts

Philip D. Jones

Climatic Research Unit

University of East Anglia

Norwich, United Kingdom 
This data base offers an expanded and updated compilation of long-term station precipitation data, together with a new set of gridded monthly mean fields for global land areas. This data set contains 5328 station records of monthly total precipitation, covering the period from the mid-1800s to the late 1980s. The station data were individually tested and visually inspected for the presence of spurious trends, jumps and other measurement biases. The quality control procedure which was used to check the station records for non-climatic discontinuities and other biases are detailed in a technical report that accompanies this data base.

The station data were interpolated onto a 4 degree latitude by 5 degree longitude uniform grid. Comparisons of these data with two other globalscale precipitation climatologies were done and are discussed in the technical report that accompanies this data base.

DB1003

\section{A COMPUTER-BASED ATLAS OF GLOBAL INSTRUMENTAL CLIMATE DATA}

Raymond S. Bradley, Linda G. Ahern, Frank T. Keimig Department of Geology and Geography

University of Massachusetts

Amherst, MA 01003

Color-shaded and contoured images of global, gridded instrumental data have been produced as a computer-based atlas. Each image simultaneously depicts anomaly maps of surface temperature, sea-level pressure, 500-mbar geopotential heights, and percentages of reference-period precipitation. Monthly, seasonal, and annual composites are available in either cylindrical equidistant or northern and southern hemisphere polar projections. Temperature maps are available for 1854 to 1991 , precipitation from 1851 to 1989, sea-level pressure from 1899 to 1991, and 500-mbar heights from 1946 to 1991. The source of data for the temperature images is Jones et al.'s global gridded temperature anomalies. The precipitation images were derived from Eischeid et al.'s global gridded precipitation percentages. Grids from the Data Support Section, National Center for Atmospheric Research (NCAR) were the sources for the sea-level-pressure and 500-mbar geopotential-height images. All images are in GIF files (1024 x 822 pixels, 256 colors) and can be displayed on many different computer platforms. Each annual subdirectory contains 141 images, each seasonal subdirectory contains 563 images, and each monthly subdirectory contains 1656 images. The entire atlas requires approximately $340 \mathrm{MB}$ of disk space, but users may retrieve any number of images at one time.

Users should have monitors with the capability of displaying 256 colors (SVGA, 8-bit RGB color) and software for viewing GIF files. The monitor is necessary to take advantage of the high-resolution color images and to display them correctly. For users needing a GIF viewer, three shareware viewers are provided - one for an IBM-compatible PC, one for a Macintosh, and one for a workstation.

A CD-ROM version of the atlas is presently being prepared by the Climatology Lab at the University of Massachusetts and will be distributed by them at a cost of $\$ 30.00$. 
This work is scheduled to be published in the Bulletin of the American Meteorological Society in January 1994.

These files can be found in the subdirectory 'images'.

DB1004

ALASKAN HISTORICAL CLIMATOLOGY NETWORK (HCN) SERIAL TEMPERATURE AND PRECIPITATION DATA

T.R. Karl, R.G. Baldwin, M.G. Burgin, D.R. Easterling, R.W. Knight, and P.Y. Hughes (contributors)

National Oceanic and Atmospheric Administration

National Climatic Data Center

Asheville, North Carolina 28801

This database is a companion to the Historical Climatology Network (HCN) database for the contiguous United States [CDIAC Numeric Data Package (NDP) 019/R1]. The database contains monthly temperature (minimum, maximum, and mean) and total monthly precipitation data for 47 Alaskan stations. These data were derived from a variety of sources including the National climatic Data Center archives, the state climatologist for Alaska, and published literature. The period of record varies by station. The longest record is for the Sitka Magnetic observatory (beginning in 1828), and most records extend through 1990 .

Unlike the HCN database for the contiguous U.S., adjustments have not been made to these climate records for time-of-observation differences, instrument changes, or station moves. Because such occurrences may result in inhomogeneous time series, users of these data are urged to review the information given in the station history file in order to identify the stations most suitable for their particular applications.

The data are contained in two files:

(1) "ak_hcn.dat" ( a $1.64 \mathrm{mB}$ data file containing all four climate variables: monthly minimum, maximum, and mean temperatures, and total monthly precipitation):

(2) "ak_hcn.his" (a $148 \mathrm{kB}$ station history file).

Before accessing these data files, users should first read the information contained in the file "ak_hcn.des" (a $48 \mathrm{kB}$ descriptive file).

These files can be found in the subdirectory /pub/db1004. 


\section{Appendix B}

Information from the National Center for Atmospheric Research (NCAR)

\section{B.2 - B.5 About NCAR's research data}

(source: http://www.scd.ucar.edu/docs/dss_brochure/brochure.html)

B.6 - B.13 List of all NCAR datasets

(source: http://www.scd.ucar.edu/dss/catalogs/dstitles.html)

B.14 - B.15 NCAR dataset reference numbers

(source: http://www.scd.ucar.edu/dss/catalogs/decimal.html)

B.16 List of all NCAR datasets containing minimum and maximum temperture data

(source: http://www.scd.ucar.edu/dss/catalogs/tmaxtmin.html)

B.17 sci.geo.meteorology data sources FAQ

(source: http://www.scd.ucar.edu/dss/faq) 



\section{NCAR's Research Data: A Rich Resource}

The National Center for Atmospheric Research provides a computer-accessible archive for use by scientists, teachers, and students. The archive contains over 400 datasets of observations and analyses. NCAR staff in the Data Support Section of the Scientific Computing Division add new datasets and update existing ones to support the needs of the research community.

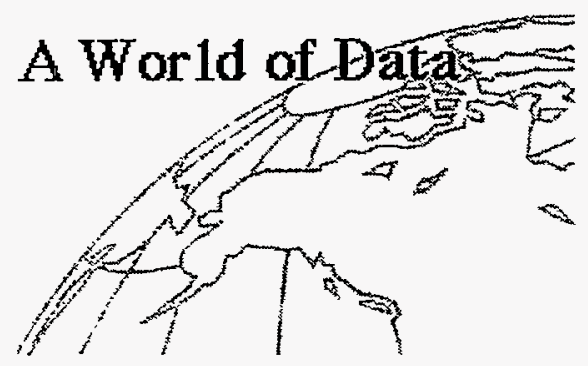

A major strength of NCAR's data archives is the variety and versatility of its data collection. Frequently used datasets include

* Gridded Atmospheric Analyses. Major datasets include gridded representations of such atmospheric elements as temperature, pressure, and wind that are derived from observational data by the National Meteorological Center and the European Centre for Medium-range Weather Forecasts.

* Satellite Data. The archive includes Global Area Coverage data and TIROS Operational Vertical Sounder data from the National Oceanic and Atmospheric Administration as well as other sets of satellite data.

NOAA GOES Satellite

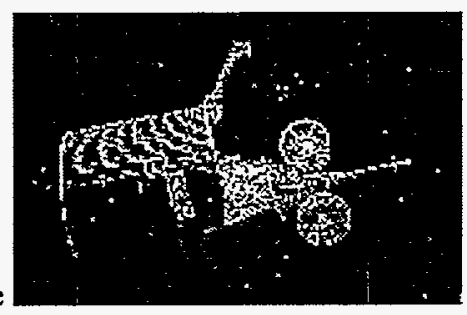

* Climate Model Data for Assessment Studies. NCAR has been acting as a center for climate model data for assessment studies since 1987. The studies include the effects of climate change on crops, forests, grasslands, and rivers.

* Long-Term Climate, Climate Trend, and Variability Data. Climate data over time are useful for verifying the accuracy of computer climate simulations, as well as to provide the initial boundary data for climate predictions using computer models. Scientists can access these data to study climate trends as far back as the mid-1800s. 




Global temperature variations between 1854 and 1991.

* Reanalysis of World Data. Existing gridded datasets for the 1950 to 1990 period were derived using primitive techniques at first, and went through many changes while evolving to current methods. Many desirable output products are not available in the existing datasets, and there is now more data available for input to the analysis. NCAR is collaborating with the National Meteorological Center to reanalyze the world's atmospheric data, starting with data from 1957. By reanalyzing old data with new models, the effect of the changes in models is removed. Consistent data over a long time span are essential for global climate studies.

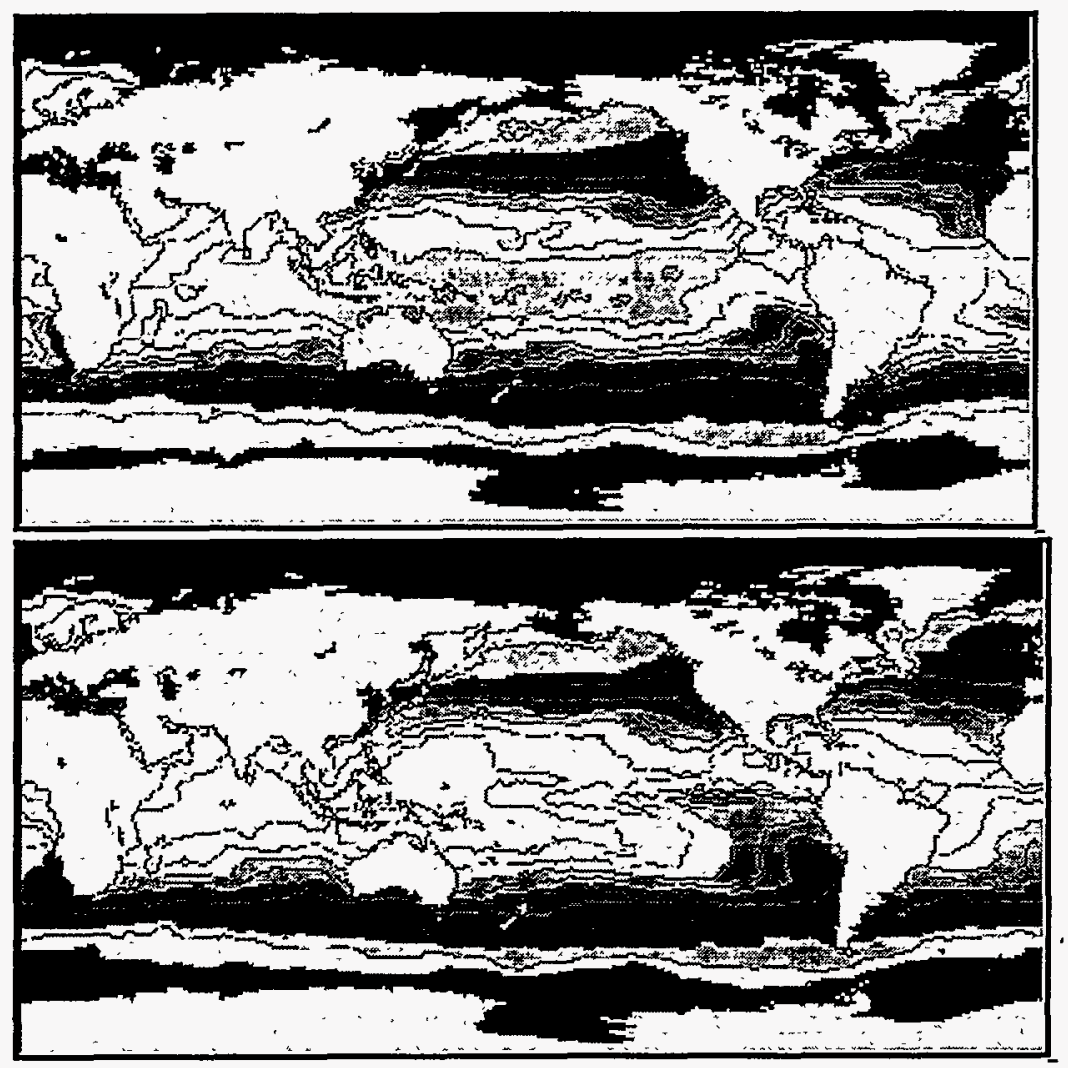

Sea-surface temperatures in the tropical oceans.

* Ocean Data. NCAR maintains a suite of ocean datasets to support modeling, climate, and observational research. The Comprehensive Ocean-Atmosphere Dataset combines many marine surface datasets, including observations from merchant ships, research ships, and ocean buoys. This cooperative effort between NCAR and NOAA has produced the best available global dataset for the long period 1854-1992. Continuing work will extend and improve this dataset. 


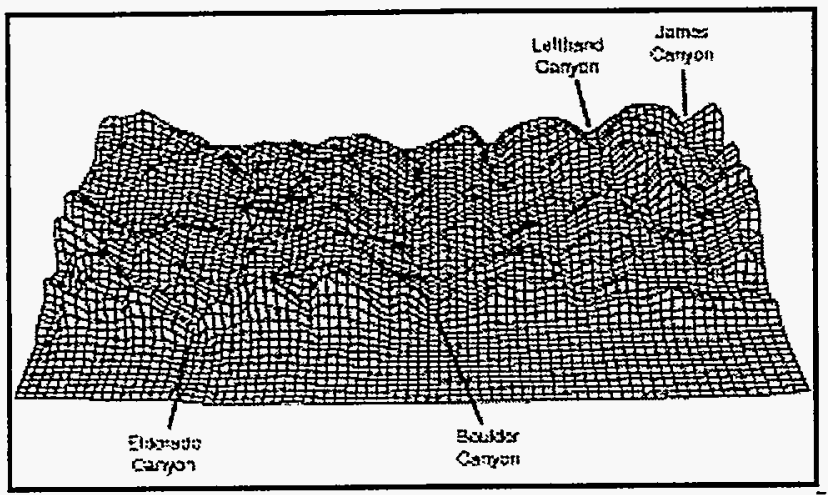

Map of Boulder, Colorado.

* Geoplyysical Datasets. NCAR obtains data from a variety of sources as needed by the research community. Examples include global elevation datasets provided by the U.S. Navy, the National Geophysical Data Center, the National Meteorological Center, Rand Corp., and the Defense Mapping Agency. Vegetation data are provided from a variety of sources. Users often use geophysical data for projects that involve agriculture, forests, rivers, or lakes, and for model boundary conditions.

* Datasets for Science Education. NCAR has supplied datasets to secondary schools for school projects. Some sets are available for Internet access, and more will be added. NCAR will also contribute data and expertise to the Global Learning and Observations to Benefit the Environment project, an ambitious initiative that would have all school children assist in monitoring the earth's environment by taking atmospheric measurements and using the data they collect in their own experiments.

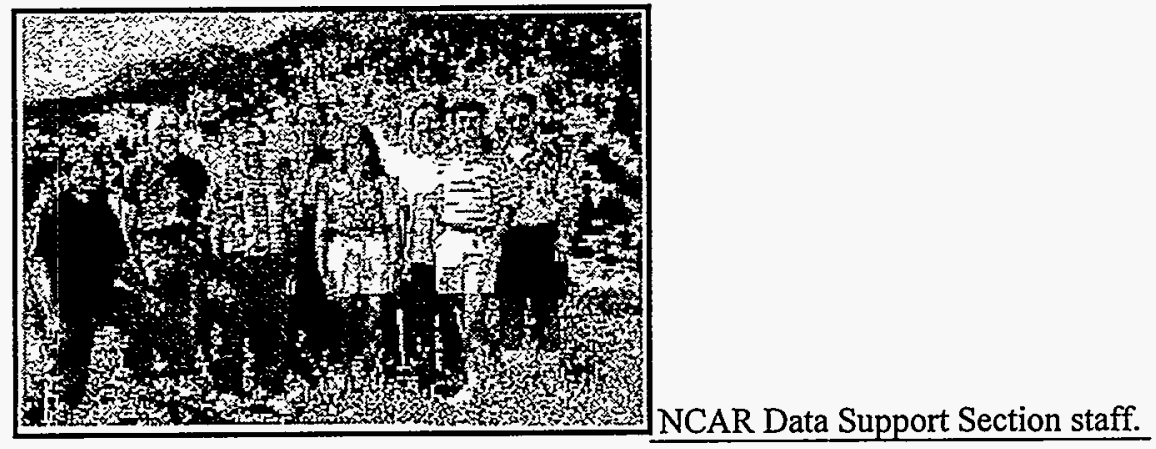

\section{Access to the Datasets}

Many small datasets are accessible over the Internet at no charge. The entire archive is stored on the NCAR Mass Storage System (MSS). For a fee based on data volume, requested data can be moved from the MSS to disk for Internet access or copied to various media for distribution. Users of the NCAR computer systems may use data directly from the MSS.

* Internet Data Services. Internet access to archive documentation, software, and data is provided by anonymous FTP and on the World Wide Web. The FTP address is ncardata.ucar.edu. FTP to this address and look at the file README for an introduction to the system. To access the hypertext online service, use the following Uniform Resource Locator:

http://www.ucar.edu/dss

* Data on CD-ROM. Northern Hemisphere National Meteorological Center gridded analyses, 1946-1989, are available on a CD-ROM produced by the University of Washington and NCAR. NCAR plans to make several additional collections of data available on CD-ROM, including a series of National Meteorological Center 2.5-degree global analyses and a series containing North American rawinsonde data and hourly surface observations.

* Personalized Services. NCAR staff are available to help you locate data appropriate for your research 
needs. They can also help you use the data, and provide supporting software and a variety of additional documentation.

For assistance or further information on ordering and pricing, contact

NCAR, Scientific Computing Division

Data Support Section

P.O. Box 3000

Boulder, CO $80307-3000$

Voice: (303) 497-1219

FAX: (303) 497-1298

E-mail: datahelp@ncar.ucar.edu

Datasets illustrated in this brochure were rendered using the NCAR Graphics package. Satellite photo courtesy of National Oceanic and Atmospheric Administration. All other photos: NCAR Photographics. Design: NCAR Graphic Services.

NCAR is operated by the University Corporation for Atmospheric Research, a consortium of universities with graduate programs in atmospheric science, under the sponsorship of the National Science Foundation. NCAR is an equal opportunity employer. 


\section{List of all datasets}

This is a hypertext list of all datasets in the NCAR Data Support Section archive. Follow the link on a dataset reference number for more information on that dataset, including links to the MSS file names, software, format references, and data files if available.

If you're feeling lost (there are over 470 datasets here!) check the guide to the dataset numbering scheme, which can be used as an index to go quickly to the desired section of this list. You can also search the dataset descriptions.

- ds001.0 General Routines

- ds010.0 NCAR N.Hem Sea Level Press, daily monthly seasonal 1899-con

- ds010.1 Trenberth's N.Hem Sea Level Press, monthly (from DSS sets)

- ds011.0 M.I.T. N.Hem Sea Level Press, daily 1.939Jul-1944Nov

- ds012.0 U.S.S.R. N.Hem Sea Level Press, daily 1880-1979

- ds015.0 NMC N.Hem Sea Level Press \& 700mb Ht, daily 1947-1967Aug

- ds018.0 U.S. Navy N.Hem Sea Level Press \& 500mb Ht, daily 1945 Nov-con

- ds018.1 Pazan's U.S. Navy N.Hem Sea Level Press, daily (from DSS sets)

- ds020.0 U.K. N.Hem 500mb Ht, daily 1949-1961Jan

- ds020.1 U.K. N.Hem Sea Level Press \& 500mb Ht, daily 1945-1946

- ds024.0 NCAR N.Hem 300mb Ht, daily 1958Feb-1959Mar

- ds025.0 Univ Wisconsin N.Hem 300mb Ht, daily 1950-1958Mar

- ds026.0 ESSPO N.Hem Tropo Anals, daily 1955Apr-1960Mar (ds018.0 gap)

- ds027.0 IGY N.Hem Strato Anals, daily 1957Jul-1959Jun

- ds035.0 U.S. AFGWC N.Hem Tropo Anals, daily 1959Apr-1965

- ds036.0 U.S. AFGWC N.Hem Dewpoint \& Nephanals, daily 1963-1972

- ds037.0 U.S. AFGWC N.Hem Boundary Layer Anals, 1973 (April)

- ds038.0 U.S. AFGWC Global Multi-layer Nephanals, 1971-1979 (irreg)

- ds038.5 U.S. AFGWC Global Multi-layer Nephanals, 1979 (repacked by DSS)

- ds060.0 NMC B-3 47x51 N.Hem Tropo Anals, daily 1959-1972

- ds060.1 Gelhard's NMC B-3 47x51 N.Hem 500mb Gap Fillers, 1960-1977

- ds061.0 NMC 47x51 N.Hem Strato Anals, daily 1964-1980

- ds061.1 Madden's Global Wave Anals, daily 1964-1986 (from DSS sets)

- ds061.5 NMC B-3 47x51 N.Hem Anals, daily 1962Mar-1972

- ds061.6 NMC B-3 47x51 N.Hem Anals, daily 1962-1963 (DSS subset)

- ds062.0 NMC B-3 47x51 N.Hem Forecasts, daily 1967Nov-1971 (DSS subset)

- ds063.0 NMC B-3 47x51 N.Hem Anals, daily 1963Aug-1972 (DSS subset)

- ds065.0 NMC B-3 47x51 N.Hem Vert Motion Anals, daily $19580 c t-1972$

- ds066.0 NCEP $65 \times 65$ N.Hem Tropo Anals, daily 1973-con ( $\& 47 \times 51$ by DSS)

- ds067.0 NCEP 65x65 N. \& S.Hem Strato Anals, daily 1981Jun-1997Mar

- ds067.1 Gelman's CAC 65x65 N. \& S.Hem Anals, daily 1978Sep-con

- ds067.3 NCEP 65x65 N. \& S.Hem Strato Anals, daily 1997May-con

- ds067.6 Randel's Spectral Height Fields, derived from ds067.1

- ds068.0 NMC Eta Model Anals, 3-hrly, 1994Jul1 1-1994Aug31

- ds069.0 NMC LFM N.America Tropo Anals, daily 1971 Oct-1995Dec

- ds069.5 NMC NGM N.America Tropo Anals, daily 19840 ct-con

- ds075.0 NMC Tropical Anals, daily 1968-1985

- ds080.0 NMC Global Tropo Anals, daily 1972Nov-1974Sep (from Flattery)

- ds081.0 NMC Global Tropo Anals, daily 1974Dec-1976Jun (from Flattery)

- ds082.0 NCEP Global Tropo Anals, daily 1976Jul-1997Mar

- ds082.1 NCEP Global Boundary Layer Anals, daily 1976Jul-con (DSS subset)

- ds082.2 NMC Global Tropopause Anals, daily 1976Jul-con (DSS subset)

- ds082.5 NMC Global Tropo Anals, daily 1991Jan-Jun (DSS CD-ROM)

- ds083.0 NCEP Global Tropo Anals, daily 1997May-con

- ds083.I NCEP Global Boundary Layer Anals, daily 1997May-con

- ds084.0 NMC MRF Global 10 Day Forecasts, daily 1990-con

- ds084.2 NCEP Global T80 Sigma Analyses, daily 1990Sep-con (from Kistler)

- ds084.5 NMC MRF Global Flux, daily 1990Mar-con

- ds085.0 N.Hemis 47x51 Tropo Anals, monthly 1955Apr-con (DSS built)

- ds085.1 N.Hemis 72x19 Tropo Anals, monthly 1947Apr-con (DSS built)

- ds086.0 CAC Global Anals, monthly 19780ct-con

- ds087.0 Gelman's $72 \times 19$ N.\& S.Hem Strato Anals, monthly 1978 oct-1988dec

- ds090.0 NCEP/NCAR Global Reanalysis Products, 6-hrly, monthly

- ds090.1 NCEP/NCAR Global Reanalysis 8-day Forecast Products 
- ds090.2 NCEP/NCAR Reanalysis Monthly Mean Subsets (from DS090.0)

- ds100.0 NOTOS S.Hem Sea Level Press, daily 1951-1958

- $\mathrm{ds102.0}$ NOTOS IGY S.Hem Sea Level Press \& 500mb Ht, daily 1957Jun-1958

- ds103.0 Jenne's IGY S.Hem 500mb Ht, daily 1957Jun-1958

- ds106.0 German IGY Tropical Sea Level Press, daily 1957Jun-1958

- ds107.0 S.African S.Hem Tropo Anals, daily 1977Aug-1981Mar

- ds108.0 Australian S.Hem Tropo Anals, daily 1972Apr-con

- $\frac{\mathrm{ds} 108.3}{3}$ Trenberth's S.Hem 500mb Ht, 1968Jun-1977Aug

- ds109.0 New Zealand Area Sea Level Press, daily 1957Jun-1978Feb

- ds110.0 ECMWF WMO Global Tropo Anals, daily 1980-1989

- $\frac{\mathrm{ds} 110.1}{10}$ Trenberth's Global Ocean Wind Stress Anals, monthly 1980-1986

- ds110.3 Trenberth's ECMWF WMO Global Tropo 5 \& 10 Year Mean Analyses

- ds111.0 ECMWF TOGA Global Advanced Oper Spectral Anals, daily 1985-con

- ds111.1 ECMWF TOGA Global Sfc Anals, daily 1985-con

- ds111.2 ECMWF TOGA Global Sfc \& Upper Air Anals, daily 1985-con

- ds111.3 ECMWF TOGA Global Supplementary Fields, 1985-con

- ds111.4 ECMWF TOGA Global Hybrid Tropo Anals, daily 1990jul-1991jun

- ds111.5 ECMWF TOGA Global Tropo Anals, monthly 1985jan-con (DSS built)

- ds112.0 U.S.S.R. Various Global \& Hempheric Anals, 1880-1985

- ds115.0 ECMWF Re-analysis level III-B global surface data

- ds115.1 ECMWF Re-analysis level III-B global upper air data

- ds115.2 ECMWF Re-analysis level III-B global supplementary fields

- ds115.3 ECMWF Re-analysis advánced global surface data

- ds115.4 ECMWF Re-analysis advanced global upper air data

- ds115.5 ECMWF Re-analysis advanced global supplementary fields

- ds115.6 ECMWF Re-analysis advanced global upper air moisture data

- ds188.0 Labitzke's Daily N.Hem Strato Anals, 1964-1996

- $\mathrm{ds190.0}$ NCDC W.N.Hem Rocket Strato Anals, wkly Jan,Apr,Jul,Oct 1964-66

- ds190.3 Gelman's NMC N.Hem Strato Anals, wkly 1976Jul-1977Apr

- ds191.0 Newell's N.Hem Strato Anals, wkly 1972Jan-1973Jun

- ds195.0 N.Hem 47x51 Time Series Tropo Anals, 1899-con (DSS built)

- ds195.1 N.Hem 72x19 Time Series Tropo Anals, 1946-con (DSS built)

- ds195.5 CDROMs of N.Hem Gridded Anals, 1946-1994Dec

- ds196.0 Jenne's N.Hem 500mb Ht, 15-day 19620 ct-1971 (from NMC B-3)

- ds200.0 Jenne's S.Hem Climatology, monthly 1950-1966

- ds201.0 Australian S.Hem Climatology, monthly 1973-1982

- ds205.0 Jenne's N.Hem Climatology, monthly 1950-1964

- ds206.0 Van de Boogard's Climate Anals, Jan \& July

- ds207.0 Rand's Global Climatology, Jan Apr Jul Oct

- ds208.0 Sadler's Tropical Wind Climatology, 1960-1973

- ds208.1 Sadler's Tropical 250mb Wind Anals, monthly 1966-1973

- $\frac{\mathrm{ds} 209.0}{\mathrm{~d} 20.0}$ Oregon St. CRI Global Ocean Heat Flux \& Wind Stress, monthly

- ds209.1 Weare's Tropical Pacific Heat Budget, monthly 1957-1976

- ds209.2 Bunker Climate Atlas of the N.Atlantic Ocean

- ds209.3 Hastenrath's Tropical Atlantic Heat Budget, monthly

- ds210.0 Labitzke's N.Hem Strato Climatology, 1951-1971

- ds210.1 Labitzke's N.Hem Strato Anals, 1957-1988 \& Sunspots 1951-1972

- ds212.0 Solot's N.Hem Sea Level Press \& 500mb Ht, monthly 1899-1939

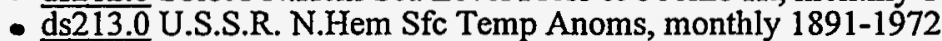

- ds213.1 U.S.S.R. N.Hem Sfc Temp Anals, monthly 1891-1981

- ds215.0 Jones' U.K. Global Sfc Temps, monthly 1851-1993

- ds217.0 GFDL Atmospheric Circulation Anals, monthly 1958May-1973Apr

- ds217.1 Oort's GFDL Atmos. Circulation Anals, monthly 1958May-1989Dec



- ds218.1 Chellia's CAC Global Tropo Climate Diagnostics, 1979-1988

- ds219.0 Masutani's ECMWF Global Tropo Climate Anals, 1979Mar-1989Feb

- ds220.0 U.S.A.F. ETAC Global Tropo \& Strato Anals, monthly 1956-1960

- ds222.0 Walsh's Arctic Sfc Temp Anals, monthly 1946-1975

- ds228.0 Hulme's Gridded Global Land Precipitation Climatology

- ds230.0 FSU/COAPS Pacific \& Indian Ocean Pseudo Wind Stress

- ds231.0 Wyrtki's NORPAX Pacific Wind Stress, monthly 1947-1973

- ds232.0 Hellerman's GFDL Global Ocean Wind Stress Anals, monthly

- ds232.1 Harrison's Climatological Mean Wind Global Wind Stress

- ds233.0 Walsh's Arctic and Antarctic Sea Ice Concentration Analyses

- ds233.5 Arctic Sea Ice Thickness Climatology 
- ds234.0 Ropelewski's CAC Antarctic Ice Anals, monthly 1973-1990Mar

- ds235.0 U.S.S.R. N.Hem Sfc Press \& Precip Anoms, monthly 1873-1979

- ds236.0 Legates\&Willmott's Global Air Temp \& Precip Anals, monthly

- ds237.0 Willmott's Terrestrial Water Budget, monthly

- ds238.0 Diaz' Global Precip Anals, monthly 1851-1989

- ds239.0 Rudolf's WCRP Global Precip Prelim Anals, monthly 1987-1988

- ds240.0 U.S. Navy FNOC N.Hem Sea Sfc Temp Anals, daily 1961Nov-con

- ds240.1 U.S. Navy FNOC N.Hem Sfc Anals, daily 1969Sep-con

- ds240.5 U.S. Navy FNOC S.Hem Sea Sfc Temp Anals, daily 1974Aug-con

- ds240.6 U.S. Navy FNOC S.Hem Tropo Anals, daily 1974Aug-con

- ds241.0 U.S. Navy FNOC Anals (all types), daily 1990May-con

- ds242.0 U.S. Navy FNOC Global \& Tropical Anals, daily 1973Jul-1984Jul

- ds250.0 Pacific Sea Level Ht Station Obs, daily 1901-1987

- $\frac{d s 251.0}{d s}$ Equatorial Pacific Ocean Climate Anals, monthly 1950-1979

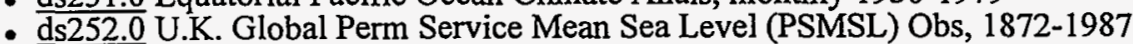

- $\mathrm{ds253.0}$ CDIAC Sfc Water \& Atmospheric CO2 \& N2O Obs, 1977-1990

- ds254.0 Najjar's NODC PO4, NO3, \& SIO2 Nutrient Ocean Anals

- ds255.0 Hansen's NODC EPOCS Drifting Buoy Obs, daily 1979-1984

- ds256.0 Canadian MEDS Drifting Buoy Observations

- ds256.1 PMEL ATLAS \& EPOCS Buoy Obs for TOGA/COADS, daily 1980-1989

- ds256.2 NSIDC Univ Wash. PSC ARGOS Buoy Obs, 1987Jan-Jun,Oct-Dec

- ds257.0 Canadian MEDS W. \& E. Coast Seawater data, daily 1914-1985

- ds258.0 Scripps Pier \& W.Coast Seawater Temp \& Salin, daily 1916-1990

- ds258.1 Woods Hole Lightship Data

- $\mathrm{ds} 259.0$ Woods Hole Improved METeorological (IMET) Marine Obs, 1992

- $\frac{d 2560.0}{d s}$ White's Ocean Temperature Climatology 1950-1993

- ds270.0 Washington\&Thiel's Global Sea Sfc Temp Climatology

- ds270.2 Rand's Global Sea Sfc Temp \& Ice Climatology

- ds271.0 GFDL COADS Global Sea Sfc Temp Anals, monthly 1870-1979

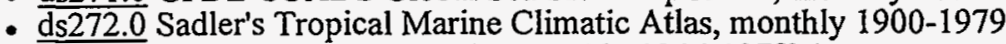

- $\frac{\mathrm{ds} 273.0}{\mathrm{~d} 227 \mathrm{O}}$ Fletcher's Sea Sfc Anals, monthly 1946-1978May

- ds274.0 Rasmussen's Pacific Sea Sfc Temp \& Wind, monthly 1946-1976

- ds275.0 Sette's Pacific Sea Sfc Temp Anals, monthly 1949-1962

- ds276.0 U.K. Sea Sfc Temp Anals, monthly 1854-1968, (by Lawes)

- ds277.0 Reynolds' CAC Global Sea Sfc Temp Anals, monthly 1970-1990Jun

- ds277.1 NCEP ODAS Tropical Pacific Ocean Analyses

- $\frac{\mathrm{d} \mathrm{d} 277.2}{\mathrm{~d} 278}$ GISST UK Met. Office Global Ice and SST

- $\frac{\mathrm{ds} 278.0}{\mathrm{~d} 227.0}$ Bauer\&Robinson's Sea Water Temp Climatology, 1969-1981

- ds279.0 Samuels\&Cox' GFDL Global Oceanographic Data Set Atlas

- ds280.0 Noo's Global Ocean Sfc Currents, seasonal 1901-1978

- $\mathrm{ds281.0}$ NCDC U.S. Navy TD9757 Marine Climatic Atlas, monthly 1850-1970

- ds283.0 Hansen\&Lebedeff's Global Sfc Temp Anals, monthly 1880-1987

- ds285.0 Levitus' Climatological Atlas of the World Ocean

- ds285.1 NODC Southern Ocean Atlas Obs \& Anal

- ds286.0 M.I.T. Hydrography of N.Atlantic, 1981Jun-1985Apr (by Fukumori

- ds287.0 GFDL MOM Climatological Ocean Initialization Anals

- $\frac{d 2289.0}{d s}$ Shea \& Trenberth's Global Monthly Sea Sfc Temp Climatology

- ds289.1 Global Ocean Sfc Temp Atlas (GOSTA), and Land Surface Atlas

- ds290.0 Shea's Climatology Atlas, 1950-1979 (from DSS sets)

- ds292.0 Warren's Global Climatological Cloud Data, 1930-1983Nov

- $\frac{\mathrm{ds} 292.1}{\mathrm{~d} 229}$ Warren's Global Climatological Cloud Data, by Sfc Obs 1982-91

- ds295.0 Baker's Global Ocean Soundings, (empty,reserved)

- ds302.0 Krishnamurti's Tropical 200mb Wind, summers 1967 \& 1972

- ds302.1 Krishnamurti's GATE Tropical 300mb-200mb Wind, summer 1974

- $\frac{\mathrm{ds} 302.2}{\mathrm{~d}}$ Krishnamurti's MONEX Tropical Tropo Wind Anals, spring 1979

- ds302.3 Krishnamurti's Tropical Tropo Wind Anals, monthly 1965-1974

- ds302.4 Krishnamurti's MONEX Region Precip Anals, 1979May-Jul

- ds302.5 Krishnamurti's ECMWF FGGE IIIb Vert Velocity Anals, 1978-1979

- ds303.0 NCAR GCM Model Output, 1968Jan

- ds304.0 GARP DST III Global Tropo \& Strato Anals, some 1974May-1976Mar

- ds305.0 Shea's N.Hem Selected Blocking Cases, 1962Dec-1977Feb .

- ds306.0 NMC Error Anals, 1979Mar-Apr

- ds307.0 ECMWF FGGE Global Anals, daily 1978Dec-1979Nov

- ds307.1 ECMWF FGGE IIIB Spectral Anals, daily 1979Jan-Mar

- $\underline{\mathrm{ds} 307.3}$ ECMWF FGGE TD101 Global Reanals, SOP1\&2 1979 
- ds307.5 ECMWF FGGE Global Anals, daily 1978Dec-1979Nov (DSS subset)

- ds307.7 ECMWF FGGE Global Anals for ALPEX, spring 1982

- ds307.9 ECMWF FGGE T63 Tropo, Sfc \& Tendency Anals, daily 1979

- ds308.0 GFDL Global Anals for FGGE, SOP1\&2 \& 1978Dec-1979Nov

- ds309.0 Goddard's IIIb Anals for FGGE, SOP1\&2 1979

- ds310.0 GATE Anals by Ooyama, Chu, \& Esbensen, 1974Aug-Sep

- ds312.0 NMC Global Anals \& Spectral Anals for FGGE, 1979Jan-Mar,Jun

- ds315.0 Dewey\&Heim's Snow Cover, wkly monthly 1966 Nov-1988

- ds318.0 GISS \& GFDL Climate Model Outputs for EPA CO2 Studies

- ds318.1 GFDL Climate Model Outputs for CO2 Studies

- ds318.2 UK Climate Model Outputs for CO2 Studies

- ds318.3 CCC Climate Model Outputs for CO2 Studies

- ds318.4 GISS Climate Model Outputs for CO2 Studies

- ds318.6 German Climate Model Tropo Anals for EPA CO2 studies

- ds319.1 Climate Model Products from Canada, CCC

- $\mathrm{ds} 319.2$ Climate Model Products from UK, Hadley Center

- ds319.3 Climate Model Products from Germany,MPI

- ds353.0 NMC B-3 ADP Global Upper Air Data Obs, daily 1962Mar-1972

- ds353.1 NCEP ADP Global Upper Air Obs (Mixed), daily 1985-con

- ds353.2 NMC Global Upper Air \& Sfc Obs for GATE, 1974Jun-Sep

- $\frac{\mathrm{ds} 353.3}{\mathrm{~d}}$ NMC DST II data for GARP, 1974May-1976May

- ds353.4 NCEP ADP Global Upper Air Obs Subsets, daily 1973-con

- ds354.0 Swedish Level IIb Upper Air \& Sfc Obs for FGGE, 1978Nov-1979

- ds354.1 ECMWF DST IIb Upper Air \& Sfc Obs for ALPEX, spring 1982

- ds355.0 U.S.A.F. Global Upper Air Obs, daily 1966Jul-1969Aug

- ds358.0 Ptarmigan Dropsondes, irreg 1950-1961

- ds359.0 NOAA FSL Wind Profiler Obs, hourly 1992May-con

- ds360.0 U.S.A.F. ETAC DATSAV TD57 Global Aircraft Obs, 1976-1985

- ds361.0 Australian Aircraft Obs, daily 1971Dec-1989.

- ds362.0 New Zealand Aircraft Data, 1978Dec22-1988Jun30

- ds365.0 Sadler's Global Aircraft Obs, daily 1960-1973

- ds368.0 NASA GASP Aircraft Obs, 1975Mar-1979Jul

- ds381.0 Kennedy's ALPEX Aircraft Obs, spring 1982

- ds383.0 FSU's BOMEX Raobs, daily 1969May-Sep

- ds385.0 Fankhauser's N.America Severe Storms Cases (8), spring 1966-67

- ds388.0 GATE Global Upper Air \& Sfc Obs, 1974Jun-Sep

- ds388.1 CEDDA GATE Global Upper Air \& Sfc Obs, 1974Jun-Sep

- ds389.0 Portable Automated Mesonet (PAM) Obs, 1977Apr-1982Nov

- ds390.0 Global Time Series Raobs, daily 1948-con

- ds390.1 U.S. Control TD56 Time Series Raobs, daily 1948-con

- ds390.2 General Inventory (TD54) of Time Series Raobs

- ds390.3 India Time Series Raobs, 1951-1978Jun

- ds390.4 U.S.A.F. TD9014 Raobs, daily 1948-1965

- ds390.5 U.S.A.F. TDF54 Time Series Raobs, daily 1943Jan-1974Dec

- ds391.0 Monthly Time Series Raobs, 1948-con

- ds392.0 Shea's Strato Zonal Wind \& Temp Profiles, monthly 1953-1988

- ds393.0 U.S.A.F. TDF52 Pibals \& Winds Aloft

- ds393.1 U.S.A.F. TDF53 Pibals \& Winds Aloft

- ds398.0 M.I.T. Raobs, daily 1958May-1963Apr (thru Kung,Univ Missouri)

- ds400.0 Ascension Island Raobs, 1968-1977Mar

- ds402.0 U.S.S.R. Raobs, 1961-1970

- ds430.0 Global (spotty non-U.S.) Monthly Mean Raobs, 1950-con

- ds431.0 Monthly Mean RAOB data by Bram Oort, GFDL

- ds460.0 U.S.A.F. ETAC TD9600 Sfc Obs, 1967Feb-Apr \& 1976Aug

- ds462.0 U.S.A.F. AFGWC, Sfc Obs, 1967Dec

- ds462.1 U.S. AFGWC Global Sfc Obs, 1975Apr-May

- ds462.2 U.S. AFGWC Global Sfc Obs for SESAME, few days 1977Apr-Sep

- ds463.0 NCDC U.S.A.F. DATSAV TD9685 Global Sfc Obs, daily 1967-1980

- ds464.0 NCEP ADP Global Sfc Obs, daily Jul1976-con

- ds464.1 NMC ADP Global Sfc Obs subsets (by DSS from ds464.0)

- ds466.0 Sadler's Pacific Island Precip, monthly 1965-1972

- ds467.0 NCDC TD13 Global Sfc Obs, daily 1899-1970

- ds467.1 U.S.A.F. DATSAV TD13 Global Sfc Obs, daily 1949-1970

- ds469.0 Canadian Sfc Obs, daily 1963jan-1976dec, 95 stations

- $\underline{\mathrm{ds} 470.0}$ NCDC TD14\&TD3280 U.S. Sfc Airway Hourly Obs, 1938(1948)-cont 
- ds472.0 TDL U.S. \& Canada Sfc Hourly Obs, daily 1976Dec-cont

- ds473.0 Univ Wisconsin Antarctic Sfc Obs, daily 1980-1991Oct

- $\mathrm{ds473.5}$ Univ Wisconsin Greenland Sfc Obs, daily 1987-19910ct

- ds474.0 Univ Washington Russian Ice Station Obs, daily 1950-1990

- $\mathrm{ds475.0}$ U.S.S.R. surface 6- and 3-hourly sfe synoptic obs 1936-1983

- ds480.0 India Precip, daily monthly 1901-1970

- ds480.1 Kanpur,India Precip, daily 1975-1984

- $\mathrm{ds481.0}$ India Precip, wkly 1979-1985

- $\mathrm{ds482.0}$ Australia Precip, daily monthly 1939-1982

- ds482.1 Australia Precip, daily monthly 1840Jan-1990Dec

- ds483.0 Malaysia,Thailand \& Indonesia Sfc Obs, daily 1951-1985

- $\mathrm{ds484.0}$ Shafer's Pacific Rainfall Data, daily 1971Jan-1993Jul

- $\mathrm{ds485.0}$ China Precip, daily 1951-1982

- ds486.0 Brazil Sfc Obs, hrly, 1951Jan-1980Dec

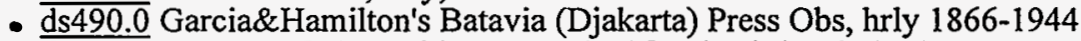

- $\frac{\mathrm{ds} 491.0}{\mathrm{ds} 010}$ Denver,CO \& Buckley U.S.A.F. Sfc Obs, hrly 1948-1972

- ds501.0 Boulder,CO Sfc Obs (precip \& max-min temps), daily 1897-1976

- ds501.5 Boulder,CO Sfc Wind Obs, cases 1969

- ds503.0 NCDC SOLMET TD9724 Solar \& Sfc Obs, daily 1952-1976

- $\mathrm{ds504.0}$ NCDC TD9734 Typical Meteorological Year, Solar \& Sfc

- ds505.0 NCDC TD3240 U.S. Control Coop Hourly Precip, daily 1948-cont

- ds507.0 Hourly Gridded Precipitation for North America, Higgins Janowiak

- ds508.0 Amos Eddy's U.S. Sfc Anals, daily 1881-1985

- ds509.0 NCDC TD3210 U.S. 1st Order Summary of Day, 1884(1948)-1987Jul

- ds510.0 NCDC TD3200 U.S. Control Summary of Day, 1890(1948)-cont

- ds510.1 NCDC U.S. Pan Evaporation, daily 1948-1978

- ds510.2 Texas Sfc Obs, daily monthly 1900-1973

- $\mathrm{ds510.4}$ NCDC U.S. Summary of Day, various stations 1890-1970

- $\frac{\mathrm{ds} 511.0}{\mathrm{~d} 512.0}$ CDIAC U.S. HCN Temp \& Precip Obs, daily 1880-1987

- ds512.0 CAC Global CEAS Summary of Day/Month Obs, 1979-cont

- ds513.0 May's Global Sfc Temp Climate Anals, daily 1979-1989Jun

- ds514.0 China Summary of Day 1979May-Sep

- ds515.0 GATE ASECNA Africa Precip, daily 1974

- ds516.0 Canada Summary of Day, 1890-1979

- $\frac{\mathrm{ds} 517.0}{}$ Brazil Precip, daily 1910-1974 (thru Geisler)

- ds518.0 Japan Summary of Day, 1951-1989

- $\mathrm{ds520.0}$ NMC U.S. WBAN-3 Summary of Day, 1948-1963

- $\mathrm{ds} 520.1$ NCDC U.S. WBAN Sfc Obs, 1948-1978

- ds521.0 U.S. Summary of Day \& 3- \$ 6-hrly 1969-1976

- $\mathrm{ds522.0}$ Shea's Summary of Day Collection (from DSS sets)

- ds523.0 Australia Summary of Day \& Sfc Obs, 1939(1957)-1982

- ds524.0 Russian Summary of Day, 1880(1935)-1989



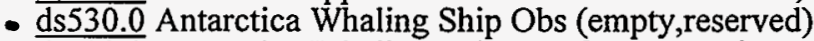

- $\mathrm{ds532.0}$ Antarctica Whaling Ship Obs from So. Africa

- ds533.0 MORMET (Russian) Marine Surface Observations

- ds535.0 NCDC Observations from Ocean Station Vessels, 1945-1987

- ds536.0 Pazan's NORPAX TD11 Sfc Ship Obs

- $\mathrm{ds540.0}$ COADS Global Marine Observations, 1854-continuing

- $\frac{\mathrm{ds} 540.1}{\mathrm{~d}}$ COADS Global Marine Statistics, 1850-199x

- ds540.2 COADS Release 1a

- $\mathrm{ds541.0}$ Oberhuber's COADS Atlas

- ds541.1 da Silva \& Young's Surface Marine Atlas derived from COADS

- ds541.2 Petty's Ocean Precip. Characteristics from COADS

- $\mathrm{ds542.0}$ NODC Oceanographic Expendable Bathythermograph (XBT),1966-1987

- ds542.1 NODC Oceanographic Mechanical Bathythermograph (MBT),1941-1980

- $\mathrm{ds542.2}$ NODC Oceanographic Station Data (OSD), 1900-1990

- $\mathrm{ds542.3}$ NODC Compressed (Low-resolution) CTD/STD CO22, 1969-1990

- $\mathrm{ds542.4}$ NODC Selected Level Expendable Bathythermograph (SBT) Data

- $\mathrm{ds543.0}$ Reid's NODC Deep Ocean Station Obs, 1900-1987

- ds544.0 Woods Hole N.Atlantic TTO, 1981 (from Woods Hole)

- $\mathrm{ds545.0}$ Woods Hole Hydrographic Data from Warm Core Ring 1982-B

- ds545.1 URI Gulf Stream Crest Anatomy Hydrograhic Survey - Fall 1988

- $\overline{\mathrm{ds} 546.0}$ Woods Hole Position Lotus Current Meter, 1982-1983

- $\underline{\mathrm{ds547.0}}$ Inter-American Tropical Tuna Commission Ship Observations 
- ds548.0 UK Marine Data Bank

- ds550.1 USGS River Flow Data

- ds552.0 UNESCO Flow Rates of Selected World Rivers, monthly 1800-1972

- ds553.0 Russian River Flow Data

- $\frac{\mathrm{d} 5560.0}{\mathrm{~d}}$ NCDC TD3220 U.S. Control Summary of Month, 1851(1931)-cont

- ds564.0 Global Historical Climatology Net (GHCN) Temp,Precip,Pressure

- ds565.0 U.S. Historical Climatology Net (HCN) Temp \& Precip, 1880-1987

- ds565.1 CDIAC U.S. Historical Sunshine Obs, 1891-1984

- ds569.0 U.S. DOE Global Monthly Station Temp \& Precip, 1738-1980

- ds570.0 World Monthly Sfc Station Climatology, 1738-cont

- ds570.1 World Weather Records, 1961-1970, 1971-1980

- ds570.2 NCDC U.S. Monthly Sfc Station Climatology, 1961-1970

- ds570.3 CAC TD9643 U.S. Station Temp \& Precip, monthly 1981-1983

- ds571.0 Nicholson's Africa Precip, monthly 1901-1975

- ds572.0 Harnack's S.American Precip, monthly 1891-1983

- ds573.0 CAC Ctrl.Pacific Island Precip, monthly 19-1980 (thru Shea)

- ds574.0 U.S. Sfc Monthly Station Normals and Sequential Data

- ds575.0 India Monthly Station Precip, 1901-1970

- ds576.0 Canadian Monthly Station Temp \& Precip (thru Shea)

- ds577.0 Shea's Australia Monthly Station Precip, 19-1983 (from DS483

- ds578.0 China Monthly Station Precip, 1951-1980 (thru Shukla)

- ds578.1 China Monthly Station Precip \& Temp, 1951-1990 (thru Zhang)

- ds578.2 China Monthly Station Precip \& Temp, 1951-1984, for 50 stns

- ds578.3 China Monthly Station Tmax Tmin Precip, 1965-1975, for 89 stns

- ds578.5 China Monthly Station Temp and Precip, thru 1988, 205 stns

- ds579.0 Jones' Mongolia Summary of Month, 1936-1983

- ds580.0 Malaysian ASEAN Climatic Atlas, 19 -1975 (thru Krishnamurti)

- ds582.0 Univ Wisconsin Antarctica Sfc Obs, monthly 1980-1989

- ds600.0 GARP Global Upper Air \& Sfc Obs, pre-GARP 1970Jun

- $\mathrm{ds602.0}$ Line Island Experiment Sfc \& Upper Air Obs, 1967Mar-Apr

- ds602.1 Line Island Experiment Aircraft Obs, 1967Mar-Apr

- ds603.0 NCAR Natl Hail Research Experiment Raobs, 1972-1978 summers

- ds605.0 MONEX Monsoon-77, Somalia Pibals; Indian \& U.S.S.R. Ships

- ds605.2 Winter Monsoon Experiment (WMONEX), 1978Dec

- ds605.5 Summer Monsoon Experiment (SMONEX), 1979May-Jul

- ds606.1 TOGA/COARE air-sea fluxes

- ds606.2 TOGA/COARE large scale atmospheric data

- ds606.3 TOGA/COARE convection mesoscale data

- $\mathrm{ds606.4}$ TOGA/COARE large scale ocean data

- ds606.5 TOGA/COARE ocean mixing data

- ds609.1 GCIP FSL MAPS mords and molts data, 1-hrly

- ds609.2 GCIP NCEP Eta model output

- ds609.3 GCIP Canadian Meteorological Centre (CMC) GEM model output

- ds610.0 FGGE Dropwindsondes, 1978Dec-1979Jul (thru Shea)

- ds611.0 ALPEX Dropwindsondes, spring 1982 (thru Julian)

- ds615.0 TWERLE S.Hem Drifting Balloon Data, 75Jun13-76Aug09 (thru Shea

- ds617.0 Hildebrand's HAPEX King Air Flux \& Soundings, 1986May-Jul

- ds618.0 ECMWF AMEX Global Tropo \& Strato Anals, daily 1987Jan

- ds620.0 Kuwait Oil Fires Archive

- ds670.0 NESS Global Brightness Anals, 1967-1972Aug

- ds671.0 NESS NOAA-1 Longwave Anals, 1971Apr-Jul

- ds672.0 Sadler's Equatorial Nephanals, daily 1965Feb-1973Jul

- ds672.5 Sadler's N.Pacific Nephanals, monthly 1965Feb-1978Feb

- ds673.0 NMC Nimbus-5 Sea Ice \& Rain Rate (ESMR) data, 1975Jan-Feb

- ds674.0 Bristor's NESS ESSA-7 Brightness, 1968-1969Mar

- $\frac{d}{d s 676.0}$ NESS Visual \& Infrared Brightness Anals SRVIS\&SRIR, 1974-1995

- ds676.1 Weickmann's NESS Infrared Brightness Anals, 5-day 1974-1986

- ds677.0 NESS ITOS Visual \& Infrared Brightness Anals SRVIS\&SRIR, 1973

- ds678.0 NESS TIROS-M Visual \& Infrared Brightness Anals, 19730ct

- ds679.0 Rodger's Nimbus-5 Selective Chopper Radiometer (SCR) 1972-1974

- $\frac{\mathrm{ds} 680.0}{}$ VonderHaar's Nimbus-3 Minimum Albedo Anals, 1969Apr-1970Feb

- ds681.0 EDIS TIROS-N 1024 Mosaic Data for FGGE, 1979Jan-Jun

- $\frac{d s 684.0}{d s}$ Waliser's Tropical Monthly OLR and HRC Anomalies

- ds685.0 Kleespies' Nimbus-3 Infrared Spectrometer (SIRSA\&B), 1969-1971

- ds686.0 EDIS TIROS-N Operational Vert Sounder (TOVS) Obs, 1979-1980 
- ds691.0 NESS NOAA Vert Temp Profile Radiometer (VTPR) Obs, 1974Sep

- $\frac{\mathrm{d} 6692.0}{\mathrm{~d}}$ NESS NOAA Vert Temp Profile Radiometer (VTPR) Obs, 1972-1979

- ds695.0 Koenig's NESDIS Subtarget Radiance Obs, 1978Nov

- ds698.0 NESS NOAA Polar Orbiter Global Area Coverage (GAC), 1981-1982

- ds700.0 NESS NOAA Polar Orbiter Obs (TBM), $19780 \mathrm{ct}-1989$

- ds701.0 NASA Global Tropo Temp Anals from MSU data, 1979-1991Jan

- ds701.5 Spencer's Global Oceanic Precip Anals, 1979-1992Apr

- ds703.0 NOAA Polar Orbiter Global (GAC) Data, 1989Jan-1991Dec

- ds709.0 NASA SAMS Experiment Zonal Mean Methane \& N2O, 1979-1981

- ds710.0 NASA Nimbus-7 Orbital Total Ozone Obs, 19780ct-1986Sep

- ds710.5 Campbell's Nimbus-7 THIR, CMATRIX, 1979Apr-1985Mar

- ds711.0 NASA Nimbus-4 Total Ozone Obs, 1970Apr-1977May

- ds712.0 E.Smith's SMS Hourly Brightness Data for GATE, 1974Jun-Aug

- ds716.0 India INSAT Visual \& Infrared Images, 1984Apr-1989Mar

- ds718.0 Arkin's GOES 1/2 Monthly Temp Distrib Histograms, 1982-19890ct

- ds718.5 CAC OLR, monthly means and half month means

- ds719.0 Arkin's Monthly Tropical Wind \& Outgo LW Radia (OLR) 1968-1984

- ds720.0 NESS GOES Wind data, 19740ct-1984Feb

- ds722.0 GEWEX NASA Water Vapor Project (NVAP)

- ds724.0 METEOSAT Data from Garrett Campbell, CSU

- ds725.0 Campbell's Internat'l Satell Cloud Climat Proj (ISCCP) Bl

- ds725.1 Campbell's Internat'l Satell Cloud Climat Proj (ISCCP) CX

- ds725.2 Campbell's Internat'l Satell Cloud Climat Proj (ISCCP) B1, B2

- ds726.0 GFDL SEASAT Scatterometer Derived Winds, 1978Jul-Oct

- ds726.1 Chelton's SEASAT Wind Stress Anals, 1978Jul-Oct

- ds727.0 NODC GEOSAT Altimeter Wind \& Wave Data, 1985Mar-1986Sep

- ds727.1 JPL GEOSAT Sea Level Ht Anals, 1986Nov-1988

- ds728.0 Global Precipitation Climatology Project (GPCP) Products

- ds728.1 Xie and Arkin Merged Monthly Precipitation Estimates

- ds729.0 Chang's SSM/I Precip, monthly estimates

- ds730.0 Campbell's Earth Radia Budget Exper (ERBE), 1978Nov-1983Oct

- ds732.0 Barkstrom's Earth Radia Budget Exper (ERBE), 1984Nov-1986Oct

- ds733.0 Nimbus 7 ERBE Matrix Data, daily 1978 Nov-1987Nov

- ds740.0 Naegele's NOAA Highly Reflective Cloud (HRC) Anals, 1971-1987

- ds740.1 NOAA Highly Reflective Cloud (HRC) Anals, monthly 1971-1985

- ds741.0 Bishop's Surface Solar Irradiance derived from ISCCP

- ds742.0 NASA Internat'1 Satell Cloud Climat Proj (ISCCP) C1, 1983-1987

- ds742.1 NASA Internat'l Satell Cloud Climat Proj (ISCCP) C2, 1983-1991

- ds742.3 NASA Internat'1 Satell Cloud Climat Proj (ISCCP) B3, 1987-1988

- ds742.5 NASA Internat'l Satell Cloud Climat Proj (ISCCP) D1

- ds742.6 NASA Internat'l Satell Cloud Climat Proj (ISCCP) D2

- ds743.0 Japan GMS Satell Data (ISCCP) B1, 1983-con

- ds744.0 ESA ERS-1 and ERS-2 Scatterometer wind data

- ds744.1 NSCAT Scatterometer Ocean Winds

- ds745.0 Australian GMS McIDAS Archive for TOGA COARE

- ds746.0 Nimbus 7 CZCS Pigment Concentration

- ds750.0 Scripps Global Elevation \& Depth Data

- ds750.1 Rand's Global Elevation \& Depth Data (derived from Scripps)

- ds754.0 U.S. Navy Global Elevation Data, 10-Min (1984Dec)

- ds755.0 U.S.A.F. Global Average Elevation Data, 1-Degr, 30-Min, 5-Min

- ds756.0 Defense Mapping Agency (DMA) Global Elevations (empty,reserved

- ds756.1 Defense Mapping Agency (DMA) U.S. 30-Sec Elevations

- ds756.5 USGS Selected 3-sec Elevations (CO, HI, Great Plains)

- ds757.0 NMC Global Elevation Data, 2.5-Degr \& Spectral

- ds758.0 USGS 30-sec Global Elevation Data, GTOP030

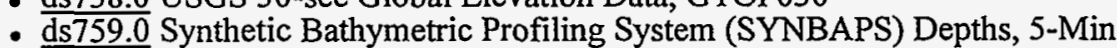

- ds759.1 NGDC ETOPO5 Global Ocean Depth \& Land Elevation, 5-Min

- ds759.2 TerrainBase Global 5-minute Ocean Depth and Land Elevation

- ds760.0 Berkovsky\&Bertoni U.S.A.F. AFCRL Global Elevation Data, 1-Deg

- ds761.0 S.African Area Elevation Data, 1-Min

- ds762.0 USGS Land Use and Land Cover, $200 \mathrm{~m}$

- ds765.0 Matthew's GISS Global Vegetation, Land-use, \& Albedo, 1-Degr

- ds765.5 Matthew's GSFC Global Wetlands \& Methane Emission, 1-Degr

- ds766.0 Argonne Land-use \& Deposition Data, 0.2-Degr

- $\underline{\mathrm{ds} 767.0}$ Wilson, Henderson-Sellers' Global Vegetation \& Soils, 1-Degr 
- ds768.0 Cogley\&Briggs' Global Precip Climatology \& Topography, 1-Degr

- ds769.0 Olson's CDIAC World Ecosystems by Carbon Vegetation, 30-Min

- ds770.0 Staub\&Rosenweig's GISS Soil \& Sfc Slope, 1-Degr

- ds780.0 NCAR Continental Outline Data

- ds800.0 French EOLE S.Hem Balloon Obs, 1971Aug-1972 (thru NASA)

- ds800.1 FGGE Constant Level Balloon Obs, 1979Jan-Jul (thru Shea)

- ds800.2 French MONEX Low-level Drifting Balloon Obs, 1979 (thru Cadet)

- ds801.0 Japan AMTEX Obs, daily 1974-1975 Feb-Mar

- ds804.0 NCDC TD9518 Daily Ozone Soundings, 1963Sep-1969May

- ds805.0 Canadian Total Ozone Obs \& Anals, daily monthly 1951May-1975

- ds805.1 London's Global Total Ozone Anals, monthly 1957Jul-1976

- ds805.2 Canadian Ozonesondes \& Total Ozone, 1957Jul-1985

- ds806.0 London's Global Ozone from OGO-4, 1967Sep-1969Jan

- $\frac{\mathrm{ds} 808.0}{\mathrm{~d}}$ NSSFC Severe Local Storms Log (SELSLOG), 1955-1972Jun

- ds812.0 Oklahoma City KTVY Tower Obs, 1976 Oct-1977Nov

- ds814.0 Feiber's Global 500mb \& 300mb Vorticity Indices, 1946-1979Feb

- ds816.0 Batelle's Wind Energy Summaries, various stations

- ds820.0 Lau's N.Hem Circulation Statistics, winters 1965-1976

- ds820.1 White's N.Hem Circulation Statistics, summers 1966-1977

- ds824.0 NCDC Global Tropical Cyclone Position Data, 1886-1991

- ds824.1 NCDC Revised Global Tropical Cyclone Position Data, 1877-1995

- ds825.0 Central England Temperatures, Manley, 1659-con

- ds830.0 U.S.C.G.S. Geomagnetic Data for 3 stations, 1947-1969

- ds832.0 NOAA WDCA Magnetic Indices \& Sunspots, 1932-1981Jun

- ds834.0 Sunspots and 10.7cm Flux, 1610-current (from Clark \& NGDC)

- ds836.0 Jack Eddy's Compilation of Auroral Observation Catalogues

- ds839.0 Incoherent Scatter Database (CEDAR), 1969-con

- ds840.0 NMC TDL Manually Digitized Radar (MDR), 1973Nov-1977Sep

- ds840.1 NMC TDL Manually Digitized Radar (MDR), hrly 1973Nov-cont

- ds845.1 GATE Ship Radar, 1974Jun-Sep

- ds845.2 GATE Ship Radar/ Quadra Full Resolution, 1974Jun-Sep

- ds850.0 U.S. Army Panama Meteorological \& Biological Data, 1965-1970

- ds855.0 NCDC TD5850 Global Rocketsondes 1969-1988

- ds856.0 NCDC Rocketsondes, monthly 1961-1972

- ds860.0 U.S.A.F. TD9703 AFCRL Atmospheric Lines for Radiation Calcs

- ds861.0 Earth Insolation for 1.1 Million Years (from Belgium)

- ds862.0 CLIMAP Climatic Boundary Conditions for 18,000 years BP

- ds863.0 Duffy\&Imbrie's SPECMAP Ocean Cores with 400,000 years BP

- ds865.0 Limpert's GSFC Precip Temp \& Derived Soil Moisture Anals

- ds866.0 GISS Methane \& Livestock Distribution, 1-Degr

- ds867.0 Matthew's GISS Methane from Rice Cultivation

- ds870.0 Sacramento Peak 9.1 cm Solar Anals, 1964-1973Jul (from Stanford

- ds875.0 GATE Aircraft Obs, 1974Jun-Sep

- ds880.0 GATE Commercial Aircraft Obs, 1974Jun-Sep

- ds885.0 NCDC TD9658 U.S. Palmer Drought Indices, monthly 1931-1982

- ds885.1 NCDC TD9640 U.S. Palmer Drought Indices, monthly 1895-1987

- ds887.0 Lethbridge's Thunderstorm Indices

- $\mathrm{ds888.0}$ World Weather Disk Data (parts selected by DSS)

- ds890.0 Los Angeles Pollution (empty,reserved)

- ds891.0 U.S.S.R. Various Anals \& Obs, 1891-1986

- ds895.0 Various Data from Data Exchange with China, LASG/IAP

- ds900.0 U.S.A.F. AFGWC Station (Sfc \& Upper Air) Library (1990Aug)

- ds900.1 NCDC WBAN Station Library

- ds901.0 NCDC COOP Station Library for Summary of Day \& Hourly Precip

- ds902.0 NCAR ADP Upper Air Station History (DSS built)

- ds904.0 Various Station Libraries and Histories

- ds905.0 W.M.O. Station (Sfc \& Upper Air) Library (1995Nov)

- ds950.0 Univ Arizona Tree Ring Data



updated $8 / 27 / 98$ 


\section{Dataset reference numbers}

Datasets archived by the Data Support Section are assigned reference numbers in the format ds $x x x . y$. Usually, datasets with the same whole number $x x x$ but different fractional $y$ are related; for example, they may be different products from the same model, or one may be a subset of, or derived from, another.

Links go to the referenced section in the list of all datasets. If this chart is too hard to read on your browser, use the plaintext version instead.

\begin{tabular}{|c|c|}
\hline number & description \\
\hline $000-009$ & general information \\
\hline $010-039$ & various northern hemisphere daily gridded analyses \\
\hline $060-069$ & nmc northern hemisphere daily gridded analyses \\
\hline$\underline{070-079}$ & nmc daily tropical grids \\
\hline$\underline{080-084}$ & nmc daily global grids \\
\hline $085-089$ & monthly mean grids \\
\hline $100-109$ & southern hemisphere (and tropical) daily gridded analyses \\
\hline $110-119$ & ecmwf (and u.s.s.r.) daily global grids \\
\hline $180-192$ & stratospheric grids \\
\hline 193-195 & time series grids \\
\hline $196-199$ & special climatological analyses \\
\hline $200-239$ & climatological and monthly mean grids \\
\hline $240-249$ & u.s. navy daily hemispheric and global grids \\
\hline $250-269$ & oceanographic observations and analyses \\
\hline $270-299$ & climatological and monthly mean grids \\
\hline $300-349 ;$ & special meteorological analyses \\
\hline $350-369$ & upper air observations \\
\hline $360-369$ & aircraft observations \\
\hline $370-389$ & special meteorological observations \\
\hline $390-409$ & time series raobs \\
\hline $430-439$ & mean monthly raobs \\
\hline $460-479$ & surface synoptic observations \\
\hline $480-508$ & surface hourly and precipitation \\
\hline $509-524$ & surface summary of day \\
\hline$\underline{525-529}$ & climatological \\
\hline $530-549$ & ship data \\
\hline $550-559$ & streamflow \\
\hline $560-589$ & mean monthly surface data \\
\hline $600-629$ & meteorological projects or experiments \\
\hline $670-673$ & satellite data \\
\hline $674-680$ & mesoscale brightness \\
\hline $681-704$ & miscellaneous satellite \\
\hline
\end{tabular}




\begin{tabular}{|c|c|}
\hline 705-711 & satellite observed ozone data \\
\hline $712-749$ & miscellaneous satellite \\
\hline $750-799$ & geophysical data \\
\hline $800-802$ & miscellaneous \\
\hline $803-807$ & ozone data \\
\hline $808-839$ & miscellaneous \\
\hline $840-849$ & radar data \\
\hline $850-899$ & miscellaneous data \\
\hline $900-909$ & station library information \\
\hline $950-959$ & paleoclimatology \\
\hline $990-999$ & special sets supporting ncar scientists \\
\hline
\end{tabular}

\begin{tabular}{|c|c|c|c|c|c|}
\hline 表男 & Datasets & Aword of Difx & DSS home & $\frac{\$ 18}{30}$ & NCAR home \\
\hline
\end{tabular}

updated 10/15/96 


\section{Datasets containing minimum and maximum temperature}

- Global

- North America

- $\underline{\text { Other }}$

\section{Global}

- ds463.0 7500 stations, 1967-1980, daily, synoptic order, large

- $\frac{\mathrm{ds} 467.0}{7-10,000 \text { stations, 1899-1972, daily, time order, large }}$

- $\underline{\mathrm{ds} 512.0} 7500$ stations, 1979-7/93, daily and monthly, time and station order, medium

\section{North America}

- ds469.0 Canada, 95 stations, 1963-1972, daily, time order, small

- ds508.0 USA, 137 stations, 1881-1985, daily, time and synoptic order, small

- ds509.0 USA controlled, 1600 stations, 1884-1990, daily, time and station order, large

- $\frac{\mathrm{ds} 510.0}{\mathrm{USA}}$, 11,000 stations, 1888-1992, daily, time order, large

- ds516.0 Canada, 780 stations, 1874-1989 (mostly 1950-79), daily, time order, large

- $\underline{\mathrm{ds} 522.0}$ daily, time order, small

- USA, 372 stations, $1888-1976$

- Canada, 127 stations, 1874-1979

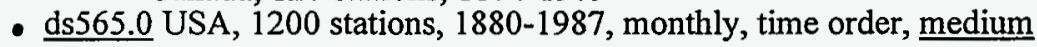

\section{Other}

- $\underline{\text { ds483.0 }} 1951-1985$, daily, time order, small

- Malaysia, 111 stations

- Thailand, 52 stations

- ds510.0 US Pacific and Caribbean, 11,000 stations, 1888-1992, daily, time order, large

- ds518.0 Japan, 100+ stations, 1951-1989, daily, time order, small

- ds523.0 Australia, 10,000 stations, 1939-1982, daily, time order, medium

- ds524.0 Russia, 223 stations, 1880-1989, daily, time order, small

- $\underline{\mathrm{ds} 582.0}$ Antarctica, 47 stations, 1980-1989 daily and monthly, time order, small

Notes: Many of these data sets also contain daily precipitation.

Dataset volume:

- small -- under $120 \mathrm{MB}$

- medium -- between $120 \mathrm{MB}$ and $1 \mathrm{~GB}$ (1000 MB)

- large -- over $1 \mathrm{~GB}$

Based on a compilation by Dennis Shea, August, 1993

\begin{tabular}{|c|c|c|c|c|c|}
\hline Inta & Datasets & A word of patid & DSS home & $\frac{1}{x=10}$ & NCAR home \\
\hline
\end{tabular}

updated 10/15/96 


\section{sci.geo.meteorology data sources FAQ}

This is the introduction to a series of FAQ postings for the Usenet newsgroup sci.geo.meteorology. "FAQ" stands for Frequently Asked Questions: these postings are intended to answer the general question, "Where can I get $\langle X>$ ?" for just about any value of $\langle X>$ which has anything to do with meteorology.

This FAQ series grew out of a FAQ which was much smaller in scope, the "Sources of Meteorological Data FAQ" which identified Internet and other sources of meteorological data for both the hobbyist and the researcher. The bulk of this FAQ series is still about data sources, but a lot of other information has been added.

The following postings comprise the FAQ series:

Meteorology FAQ Part $1 / 6$ : Intro

Overview of FAQ series, where to find the FAQ series, how to use the file retrieval methods.

Meteorology FAQ Part 2/6: Sources of weather data

$A$ list of sites with weather information, organized by region of the globe. Includes satellite images, current weather observations, forecasts, radar, and severe weather information. Also includes lists of state climatologists and regional climate centers.

Meteorology FAQ Part 3/6: Sources of research data

A list of sites with meteorological data and metadata other than current weather information. Includes major data centers, plus sites which have satellite data, hydrology and glaciology data, environmental chemistry data, geophysical and map data, oceanography data, and relevant software.

Meteorology FAQ Part 4/6 : Sources of CD-ROMs

$A$ list of CD-ROMs containing data for the atmospheric sciences, and where to get them.

Meteorology FAQ Part 5/6 : Internet resources

A list of Internet resources for researchers, students, teachers, and nonscientists interested in discussing or learning about meteorology and related disciplines. Includes newsgroups, mailing lists, institutional home pages, curriculum materials, and sites containing information on meteorology topics.

Meteorology FAO Part 6/6: Print and other resources

A list of non-Internet resources for researchers, students, teachers, and nonscientists. Includes books and magazines for the nonprofessional, textbooks, journals, and professional societies.

This FAQ series is posted to sci.geo.meteorology, news.answers, and sci.answers every two weeks; it also appears on the mailing lists CLIMLIST and met-stud.

Current copies of this FAQ series can be obtained by anonymous FTP at

<URL:ftp://ncardata.ucar.edu/other resources/meteorology-faq/> or in hypertext form via WWW at

$<U R L:$ http://www.scd.ucar.edu/dss/faq/>.

If you have corrections or suggested additions to any section of the FAQ, please email them to Ilana Stern at ilana@ncar.ucar.edu.

faq-intro | weather-data | research-data | cdroms | net-resources | print-resources

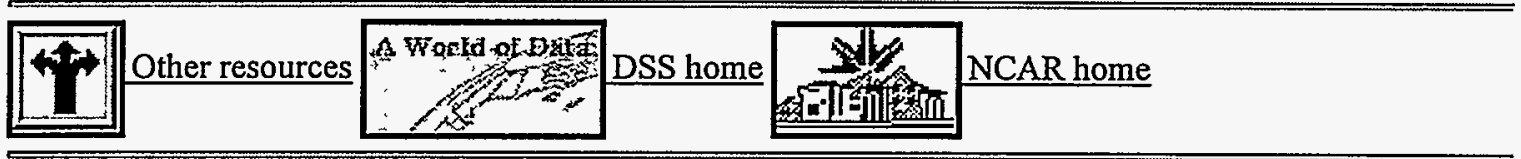

updated 10/15/96 


\section{Appendix C}

\section{Information about the National Climatic Data Center (NCDC)}

\section{C.2 - C.3 NCDC Climate Data Inventories home page}

(source: http://www.ncdc.noaa.gov/ol/climate/climateinventories.html)

\section{C.4 - C.8 NCDC Surface Data Inventories home page}

(source: http://www.ncdc.noaa.gov/ol/climate/surfaceinventories.html) 


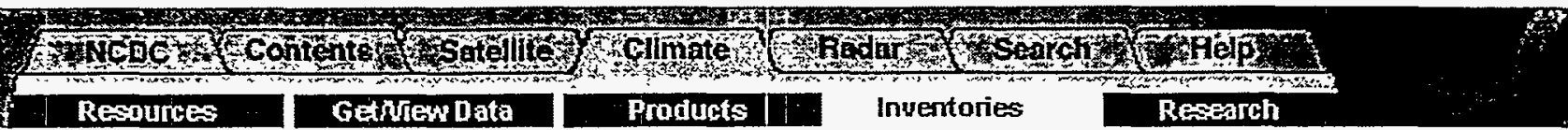

\title{
Climate Data Inventories
}

\author{
(Browse, Then Order by Phone/Email)
}

- About NCDC's Data

- NCDC Datasets

- Locate Weather Observation Station (U.S. Controlled Stations Only)

- Inventories/Station Lists (.txt Files) for U.S. and Global Surface Data

- Inventories/Station Lists for U.S. and Global Upper Air Data

NCDC | Contents | Satellite | Climate | Radar | Search | Help

Resources $\mid$ Get/View Data $\mid$ Products $\mid$ Inventories | Research

\section{About NCDC's Data}

The National Climatic Data Center (NCDC) is the largest and most diverse environmental data center in the world containing more than 90 percent of NOAAs data. Data archives at NCDC hold a treasure trove of meteorological/ climatological information, environmental satellite data, and NEXRAD weather radar data. These data are a cornerstone for the prediction of future events which affect the world's environment and economy. The data have become critical to the scientific community and policy makers in regard to global climate variability and trends.

In many regards, this collection represents this nation's heritage in that it contains the history of meteorological observations since the 1700 s. The collection is so extensive that it has been estimated that the large majority of all meteorological records ever taken in the United States are available in some form in NCDC's archives.

NCDC's data are available in both digital and non-digital form on many different media types (paper, 35mm and $16 \mathrm{~mm}$ film, microfiche, magnetic tape, $8 \mathrm{~mm}$ tape, optical). The Center's digital holdings contain over million media units, contain almost 300 terabytes of information, and grow almost 80 terabytes each year. Non-digital holdings comprise more than 200 million paper records, two million microfiche, and almost 100,000 rolls of microfilm.

From this vast collection of data, the following list has been developed which represents some of the more popular environmental data sets available at NCDC.

More Popular Digital Data Sets at NCDC ,

$\begin{array}{lll}\text { Type } & \text { DS ID Description } \\ \text { Climate } & \text { TD3200 Daily Summary Obs - Cooperative U.S. and Possessions } \\ \text { Climate } & \text { TD3210 Daily Summary Observations - First Order U.S. } \\ \text { Climate } & \text { TD3220 Monthly Summary Observations } \\ \text { Climate } & \text { TD3240 Precipitation - Hourly } \\ \text { Climate } & \text { TD3260 Precipitation - } 15 \text { Minute }\end{array}$




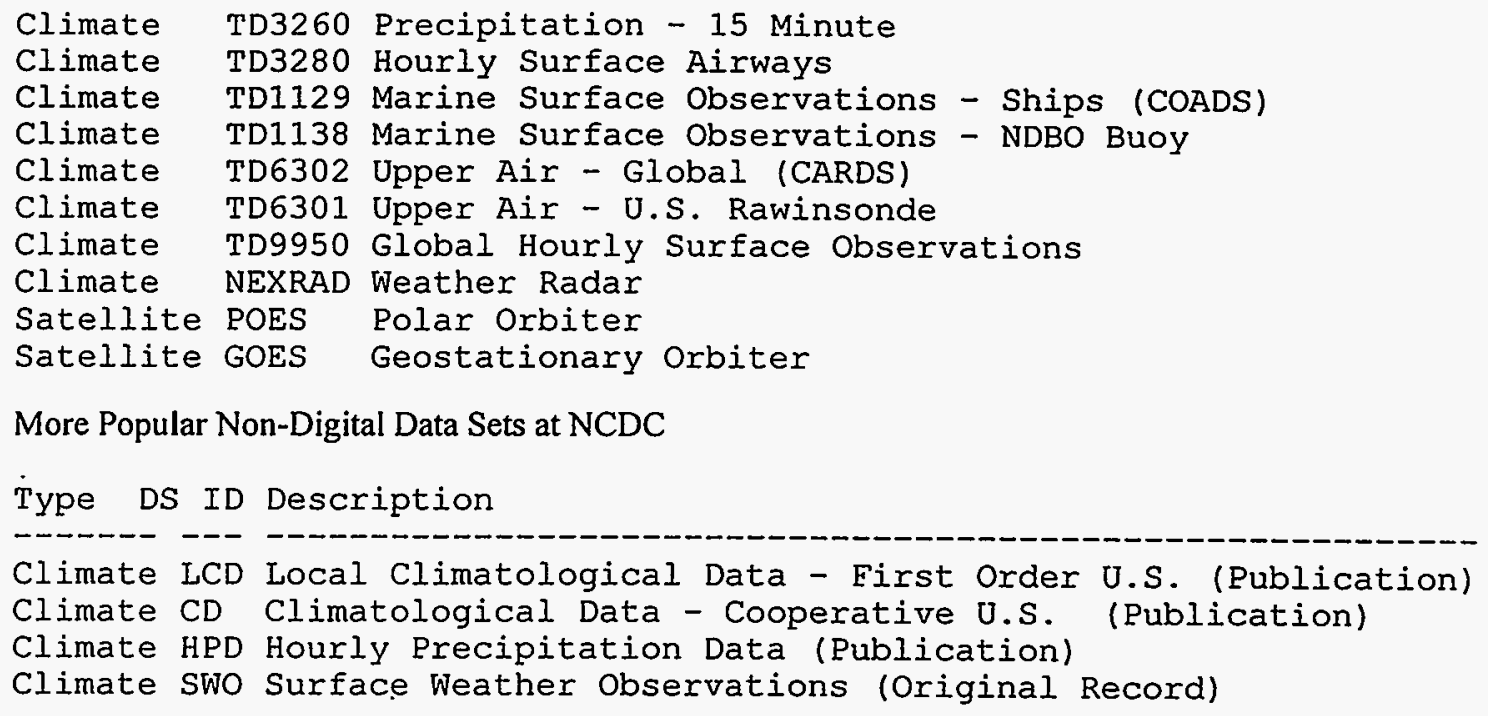

More Popular Non-Digital Data Sets at NCDC

Type DS ID Description

Climate LCD Local Climatological Data - First Order U.S. (Publication)

Climate CD Climatological Data - Cooperative U.S. (Publication)

Climate HPD Hourly Precipitation Data (Publication)

Climate SwO Surface Weather Observations (Original Record)

\section{圈 Top of Page}

http://www.ncdc.noaa.gov/ol/climate/climateinventories.html

Last updated 27 Jan 98 by webmaster@ncdc.noaa.gov

Please see the NCDC Contact Page if you have questions or comments. 


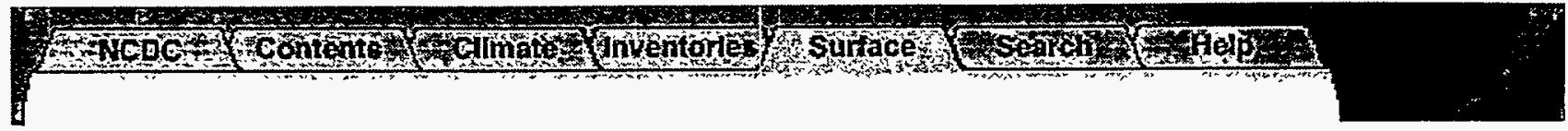

\title{
Inventories/Station Lists
}

\section{For U.S. and Global Surface Data}

\author{
(Updated August 21, 1998)
}

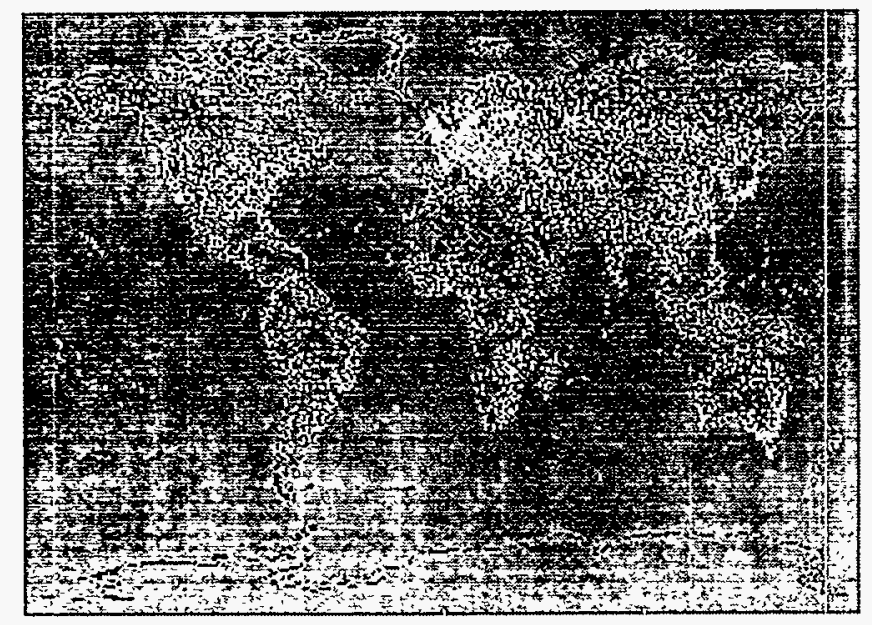

- Introduction

- Surface Data Inventories \& Station Lists

- NEXRAD Inventories \& Information

- Other Inventories \& Information

- Anonymous FTP Instructions

- Notes

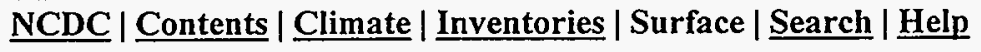

\section{Introduction}

Quick access to NCDC inventories and information is provided below (just click on any file listed below to download). Instructions are also provided at the bottom of this page for accessing these files through anonymous $\mathrm{ftp}$. Some of these files are rather large so special attention to the size is recommended before accessing them through your browser. Additional notes are also available.

\section{Surface Data Inventories \& Station Lists}

\section{ASOS STATION LIST}

ftp://ftp.ncdc.noaa.gov/pub/data/inventories/ASOSLST.TXT (36.0Kbytes)

$A$ list of all U.S. ASOS stations for which NCDC receives and processes data.

\section{COOPERATIVE STATIONS INDEX}

ftp://ftp.ncdc.noaa.gov/pub/data/inventories/COOP.TXT (10.2Mbytes)

Historical cooperative station index through 1998. Cooperative stations are U.S. stations operated by local observers which generally report max/min temperatures and precipitation. National Weather Service (NWS) data are also included in this dataset. The data receive extensive automated + manual quality control. Data are available through 1998 , and the index includes a county location cross-reference. Over 8000 stations are currently active across the country. $* * *$ Due to file size, users should 'load to local disk' (right mouse button on many browsers) instead of attempting to read entire file into memory. See cooperative active stations index below for smaller file with only the currently active stations included. Both files have header record to identify columns for: Cooperative, WBAN, and WMO station numbers; FAA, NWS, and ICAO call letters; country, state, county, time zone, station name, latitude (degrees-minutes-seconds, north=positive, south=negative), longitude (degrees-minutes-seconds, 
east=positive, west=negative), and elevation (in feet).

COOPERATIVE STATIONS INDEX (COMPRESSED)

ftp://ftp.ncdc.noaa.gov/pub/data/inventories/COOP.TXT.Z (1.6Mbytes)

Same as above but compressed for quicker download.

COOPERATIVE STATIONS INDEX-ACTIVE STATIONS

$\mathrm{ftp} / / \mathrm{ftp}$.ncdc.noaa.gov/pub/data/inventories/COOP-ACT.TXT (1.4Mbytes)

Same as Index above but only includes stations that are still active, thereby providing a much smaller file for downloading.

COOPERATIVE STATIONS MAP

ftp://ftp.ncdc.noaa.gov/pub/data/inventories/COOP-MAP.GIF (35.0Kbytes)

A 'gif' image map with locations of all currently active cooperative stations in the continental U.S. plotted.

COOPERATIVE STATIONS STATE CODES

$\mathrm{ftp}: / / \mathrm{ftp}$.ncdc.noaa.gov/pub/data/inventories/COOP-STATE-CODES.TXT ( 772 bytes)

The 2-digit numbers for each state which correspond to the first 2 digits of the cooperative station numbers.

\section{U.S. CLIMATE DIVISIONS}

ftp://ftp.ncdc.noaa.gov/pub/data/inventories/DIV-AREA.TXT ( 4174bytes)

The square mileage in each climate division, by state (i.e., the individual area weights applied to each division for climatological summaries).

GLOBAL HOURLY SURFACE DATA INFORMATION: Use the global country list to identify the countries (including U.S.) of interest. Then use one of the global station lists to identify the station(s) of interest. Finally, use the global surface inventories to obtain month-by-month inventories showing the volume of data available for each station.

\section{GLOBAL COUNTRY LIST}

ftp://ftp.ncdc.noaa.gov/pub/data/inventories/COUNTRX-LIST.TXT (12.6Kbytes)

Reference showing country names and the associated station number ranges assigned for each country. Use with global inventories.

\section{GLOBAL STATION HISTORY}

ftp://ftp.ncdc.noaa.gov/pub/data/inventories/GLOBAL-STATION-LIST-HISTORY.TXT (1.6Mbytes) Similar to 'GLOBAL STATION LIST \#1' (see below) but also shows inactive stations and a chronology of stations since the early 1970's. Updated annually.

\section{GLOBAL STATION LIST \#1}

ftp://ftp.ncdc.noaa.gov/pub/data/inventories/GLOBAL-STATION-LIST.TXT (784Kbytes)

$A$ list of active worldwide surface and/or upper-air stations sorted by country and state (for the U.S.), and includes latitude/longitude/elevation information. The 'GLOBAL COUNTRY LIST' file provides corresponding country names and station number ranges for each country. The global surface inventories provide month-by-month inventories of data available from the surface database. Updated quarterly.

\section{GLOBAL STATION LIST \#2}

ftp://ftp.ncdc.noaa.gov/pub/data/inventories/MSC-ABB.TXT (816Kbytes)

Same as 'GLOBAL STATION LIST \#1' but sorted by station number. Updated quarterly.

\section{GLOBAL SURFACE INVENTORY (WMO BLOCKS 01-19)}

ftp://ftp.ncdc.noaa.gov/pub/data/inventories/GLOBAL-SFC-1900-1996A.TXT (4.3Mbytes)

RECENTLY UPDATED--reflecting addition of more historical data to database. Monthly inventory of worldwide surface observations for the TD9950 (AWS DATSAV2) database from 1900-1996. TD9950 includes all U.S. and worldwide hourly and synoptic observations, and the data receive extensive automated quality control. These 5 files cover WMO blocks 01-19, 20-39, 40-59, 60-79, and 80-99 respectively; with this file (blocks 01-19) covering all of Europe. These files contain the most complete inventory in this directory for these data. They can be used in conjunction with other files described in this directory, such as 'GLOBAL STATION LIST \#1'. Inventories are updated periodically, and data will be available approximately one month after the end of the data month (e.g., January available by first of March). ${ }^{* *}$ Due to file size, users should 'load to local disk' (right mouse button on many browsers) instead of attempting to read the entire file into memory. 
GLOBAL SURFACE INVENTORY (WMO BLOCKS 20-39)

ftp://ftp.ncdc.noaa.gov/pub/data/inventories/GLOBAL-SFC-1900-1996B.TXT (5.9Mbytes)

See above. These blocks cover the former USSR region.

GLOBAL SURFACE INVENTORY (WMO BLOCKS 40-59)

$\mathrm{ftp} / / / \mathrm{ftp}$.ncdc.noaa.gov/pub/data/inventories/GLOBAL-SFC-1900-1996C.TXT (3.9Mbytes)

See above. These blocks cover the remainder of Asia.

GLOBAL SURFACE INVENTORY (WMO BLOCKS 60-79)

ftp://ftp.ncdc.noaa.gov/pub/data/inventories/GLOBAL-SFC-1900-1996D.TXT (5.4Mbytes)

See above. These blocks cover Africa and North America (including U.S.)

GLOBAL SURFACE INVENTORY (WMO BLOCKS 80-99)

$\mathrm{ftp}: / / \mathrm{ftp} . n c d c . n o a a . g o v / p u b / d a t a / i n v e n t o r i e s / G L O B A L-S F C-1900-1996 \mathrm{E} . T X T$ (2.4Mbytes)

See above. These blocks cover South America, Antarctica, Pacific Islands (including Hawaii), Australia and nearby regions.

GLOBAL SURFACE INVENTORY FOR 1996

ftp://ftp.ncdc.noaa.gov/pub/data/inventories/GLOBAL-SFC-1996.TXT (800Kbytes)

Monthly inventory of worldwide (U.S. and abroad) surface observations for 1996 from the TD9950 database.

GLOBAL SURFACE INVENTORY FOR 1997

ftp://ftp.ncdc.noaa.gov/pub/data/inventories/GLOBAL-SFC-1997.TXT (700Kbytes)

Monthly inventory of worldwide (U.S. and abroad) surface observations for 1997 from the TD9950 database.

GLOBAL SURFACE INVENTORY FOR 1998

ftp://ftp.ncdc.noaa.gov/pub/data/inventories/GLOBAL-SFC-1998.TXT (700Kbytes)

Monthly inventory of worldwide (U.S. and abroad) surface observations for 1998 from the TD 9950 database.

NATIONAL WEATHER SERVICE (NWS) STATION HISTORIES

ftp://ftp.ncdc.noaa.gov/pub/data/inventories/STATION-HIST.WP5 (5.1Mbytes)

A Wordperfect-5 file with station history summaries for all NWS locations--includes exact station location, anemometer height, etc. *** Use 'load to local disk' (right mouse button on many browsers) due to file size.

NATIONAL WEATHER SERVICE STATION HISTORIES-ZIPPED

ftp://ftp.ncdc.noaa.gov/pub/data/inventories/STATION-HIST.ZIP (880Kbytes)

PK-zipped version of the NWS station histories file.

NWS-NAVY SURFACE DATA INVENTORY

ftp://ftp.ncdc.noaa.gov/pub/data/inventories/TD3280.TXT (2.1Mbytes)

TD3280 (U.S. Navy, National Weather Service first-order stations) inventory through 1998--historical index of stations/periods of record included in TD3280. Some of the stations which have partial periods of record shown here have full periods of record shown in the global TD9950 inventories mentioned above. (TD9950 includes additional U.S. stations as well.) TD3280 data receive extensive automated + manual quality control. Data are available through 1998. Generally, NCDC services requests for NWS/Navy hourly data from this tapedeck, and requests for other hourly/synoptic data from TD 9950 (global surface shown above).

NWS-USAF-NAVY STATION LIST

ftp://ftp.ncdc.noaa.gov/pub/data/inventories/WBAN.TXT (5.0Mbytes)

Historical WBAN index through 1998. WBAN's are forms received here at NCDC for National Weather Service and U.S. military stations. This is an index of these locations--many of which have hourly data in digital form. Additional hourly type stations are included in the global surface inventories above. See format file below for format documentation.

NWS-USAF-NAVY STATION LIST (COMPRESSED)

ftp://ftp.ncdc.noaa.gov/pub/data/inventories/WBAN.TXT.Z (820Kbytes)

Same as above but compressed for quicker download.

NWS-USAF-NAVY STATION LIST FORMAT

ftp://ftp.ncdc.noaa.gov/pub/data/inventories/WBAN-FMT.TXT (1.0Kbytes) 
Format layout for the NWS-USAF-Navy station list.

WBAN-WMO CROSS REFERENCE

ftp://ftp.ncdc.noaa.gov/pub/data/inventories/WBAN-MSC.TXT (125Kbytes)

WBAN-AWSMSC-WMO cross reference--the WBAN index and TD9950 (both mentioned above) cross-referenced with World Meteorological Organization (WMO) numbers. These are the 3 numbering systems used by NCDC for national/international locations. Cross-reference is based on corresponding call letters for the station.

\section{NEXRAD Inventories \& Information}

\section{NEXRAD REVIEW AND INFORMATION}

$\mathrm{ftp}: / / \mathrm{ftp}$.ncdc.noaa.gov/pub/data/inventories/NEXRAD-DESCRIPTION.TXT (27.9Kbytes)

Descriptive information about NEXRAD level II and level III data/products. Includes a list of all stations planned for the network, and details concerning the types of data available. Go to "Radar Resources" on our homepage for level II and level II inventories, along with much additional information.

\section{国 Other Inventories \& Information}

PRODUCTS AND SERVICES GUIDE (WORDPERFECT 6.1)

ftp://ftp.ncdc.noaa.gov/pub/data/inventories/COMPLETE-GUIDE.WP6 (17 mbytes)

A products and services guide for NCDC in Wordperfect 6.1 format-17 megabytes in size.

\section{UPPER AIR STATION INDEX}

ftp://ftp.ncdc.noaa.gov/pub/data/inventories/UPPERAIR.TXT (372Kbytes)

Historical index of NCDC's new Comprehensive Aerological Reference Dataset (CARDS)--a dataset of worldwide upper air soundings collected from numerous sources. This index includes each stations' latitude, longitude, elevation, and beginning/ending date for data.

\section{国 Anonymous FTP Instructions}

a) Enter: open ftp.ncdc.noaa.gov

b) Login is: ftp or anonymous

c) Password is: your email address

d) You are now logged onto a UNIX workstation. Enter help if you'd like a list of available commands.

e) To move to the correct subdirectory, enter: $\mathrm{cd} / \mathrm{pub} / \mathrm{data} /$ inventories

f) To get a copy of the file descriptions, enter: get README.TXT destination (destination is your output location and name)...e.g.--get README.TXT c:README.TXT - copies to hard drive c: Note that file names are in all CAPITAL letters.

g) Then, to get a copy of any of the inventory files, use the same procedure, such as--get COOP.TXT c:COOP.TXT

h) To logoff the system when finished, enter: bye

\section{Notes}

These files are updated periodically as resources/information allow. To read any of the files (after downloading), you can use Wordperfect or any other editor. In Wordperfect, the 'TEXT IN' command (CTRL-F5) will read in a large file rather quickly, and the 'SEARCH' command (F2) will locate a character string (e.g., a station name).

Of course, Fortran or any other language may be used to access any of the data.

If you have any technical questions about these inventories, please contact:

Neal Lott: Ph. 828-271-4995 ext 182; email nlottencdc.noaa.gov or 
Tom Ross: Ph. 828-271-4994 ext 181; email trossencdc.noaa.gov or Fax: $828-271-4876$

The data to which these inventories pertain (e.g., hourly surface data) are not available on-line (internet, etc). To place orders for data (magnetic tape, cartridge tape, $8 \mathrm{~mm}$ tape, diskette, paper copy), please contact our Climate Services Branch (Phone 828-271-4800, Fax 828-271-4876, Internet orders@ncdc.noaa.gov).

\section{囯 Top of Page}

http://www.ncdc.noaa.gov/ol/climate/surfaceinventories.html Last Updated 26 Aug 98 by the NCDC Research Customer Service Group

Please see the NCDC Contact Page if you have questions or comments. 


\title{
Appendix D
}

Information about the Aerometric Information Retrieval System (AIRS)

\author{
D.2 AIRS Home Page \\ (source: http://www.epa.gov/airs) \\ D.3 - D.5 AIRS General Information \\ (source: http://www.epa.gov/airprogm/airs/airs2.html) \\ D.6 - D.7 AIRSWeb \\ (source: http://www.epa.gov/airsweb) \\ D. 8 \\ AIRS Database Products \\ (source: $h$ ttp://www.epa.gov/airs/products.html)
}

D. 1 


Drils of
Air \&
Badiation
About OAR
Contact onR
What's New
PolicylGuidanc
AIRsWeb
TTNWeb
Comments
EPA Locator
Other EpA orftes
Water
Solid Waste
Pesticides
R \& D
Enforcement
Administrator

1 1

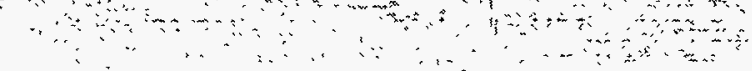

\begin{tabular}{|c|c|c|c|c|}
\hline $\begin{array}{l}\text { AIRS Database } \\
\text { Basic Facts }\end{array}$ & $\begin{array}{l}\text { Publications } \\
\text { usingalrsData }\end{array}$ & $\begin{array}{l}\text { AIfSData } \\
\text { Wehsites }\end{array}$ & $\begin{array}{l}\text { AIRS Data } \\
\text { Gontacts }\end{array}$ & $\begin{array}{l}\text { Atrus Database } \\
\text { Products }\end{array}$ \\
\hline \multicolumn{4}{|c|}{ 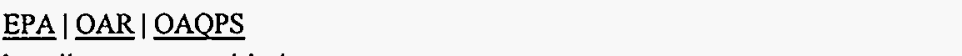 } & Search / Comments \\
\hline \multicolumn{4}{|c|}{ http://www.epa.gov/airs/ } & August 17, 1998 \\
\hline
\end{tabular}




\section{Orico of
Air \&
Aactation}

,

About OAR

Contact OAR

What's New

Palicy/Guidance

AIRSWEb

TTNWeh

Comments

EPA Locator

Othar EPA OIfleas

Water

Solid Waste

Pesticides

$R \mathbb{R} \mathrm{D}$

Enforcement

Administrator

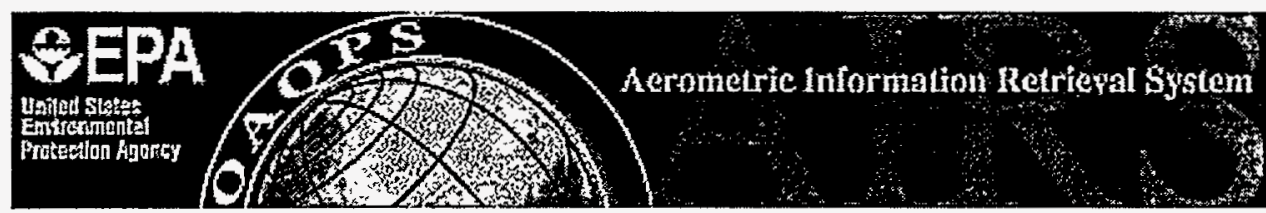

\section{AIRS General Information}

AIRS (Aerometric Information Retrieval System) is a computer-based repository of information about airborne pollution in the United States and various World Health Organization (WHO) member countries. The system is administered by the U.S. Environmental Protection Agency (EPA), Office of Air Quality Planning and Standards (OAQPS), Information Transfer and Program Integration Division (ITPID), located in Research Triangle Park, North Carolina. AIRS is installed on the IBM computer system at the EPA's National Computer Center (NCC) in Research Triangle Park, North Carolina. Any organization or individual with access to the EPA computer system may use AIRS to retrieve air pollution data.

\section{Purpose of AIRS}

The Office of Air Quality Planning and Standards manages EPA programs to improve air quality in areas where the current quality is unacceptable and to prevent deterioration in areas where the air is relatively free of contamination. To accomplish this task, OAQPS establishes national ambient air quality standards for pollutants that are proven detriments to public health. These pollutants are known as criteria pollutants. The states implement regulatory and enforcement procedures to meet national ambient air quality standards. OAQPS tracks each state's progress toward achieving and maintaining these standards, and reports status to Congress. AIRS provides the information OAQPS needs to carry out these functions.

OAQPS monitors the states' progress in meeting air quality standards by measuring concentrations of criteria pollutants. The Clean Air Act requires every state to establish a network of air monitoring stations for these pollutants, using criteria set by OAQPS for their location and operation. The monitoring stations in this network are called the State and Local Air Monitoring Stations (SLAMS). The states must provide OAQPS with an annual summary of monitoring results at each SLAMS monitor, and detailed results must be available to OAQPS upon request. To obtain more timely and detailed information about air quality in strategic locations across the nation, OAQPS established an additional network of monitors: the National Air Monitoring Stations (NAMS). NAMS sites, which are part of the SLAMS network, must meet more stringent monitor siting, equipment type, and quality assurance criteria. NAMS monitors also must submit detailed quarterly and annual monitoring results to OAQPS.

According to provisions of the Clean Air Act, each state must provide the EPA with a State Implementation Plan (SIP). Implementation plans define what actions a state will take to improve the air quality in areas that do not meet national ambient air quality standards (Non-Attainment Areas). The Clean Air Act also stipulates that the SIP include a comprehensive inventory of existing sources of air pollution and an accurate estimate of the amount of pollutants emitted by each source. OAQPS and the states need this emissions inventory to evaluate the effects on air quality of planned new sources of pollution and to satisfy other analysis and reporting requirements of the Clean Air Act.

AIRS contains all air quality, emissions, compliance, and enforcement information that OAQPS and state agencies need to carry out their respective programs for improving and maintaining air quality. Reporting capabilities allow states to access and use their data. It eliminates the need for individual states to maintain their own databases of air pollution information and to reformat or reorganize data for submission to the EPA's database. AIRS provides standard information requirements and information handling procedures, which enables OAQPS to compare and to use data from different states.

\section{AIRS Subsystems and Applications}


Air Quality Subsystem (AQS) contains measurements of ambient concentrations of air pollutants and meteorological data from thousands of monitoring stations operated by EPA, state and local agencies. The Air Quality Subsystem contains descriptive information about each monitoring station, including its geographic location and who operates it.

AIRS Facility Subsystem (AFS) contains both emissions and compliance data on air pollution point sources regulated by the U.S. EPA and/or state and local air regulatory agencies. AFS contains data on industrial plants and their components: stacks, the points at which emissions are introduced into the atmosphere; points, the emission point or process within a plant that produces the pollutant emissions; and segments, which are components of the processes that produce emissions. Compliance data is maintained at the plant and point levels, tracking classification status, inspections, and compliance actions. AFS also includes data for management of operating permit applications and renewals.

Geographic, Common, and Maintenance Subsystem (GCS) is a repository of reference data shared by the AQS, AFS, and AMS subsystems. The data includes codes and code descriptions used to identify places, pollutants, and processes, geographic information, and values such as air quality standards and emission factors.

AIRS Graphics (AG) integrates data from multiple AIRS subsystems into maps and charts that enable users to identify patterns, trends, and anomalies in air pollution data. AIRS Graphics has interactive menus that make it easy to choose "graphical reports", and to select options that control their contents. AG software takes care of all the details and displays color graphics on your 3270 graphics terminal. You may then save the graph, request color prints, export the graph and/or data in PC format, and browse the data used to create the graph.

AIRS Executive (AE) is an IBM PC program that contains a select subset of data extracted from the AIRS database. Its user-friendly format guides you to air pollution information on ambient air and plant emissions sources.

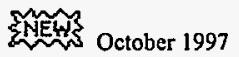

AIRSWeb provides access from the Web to the same subset of AIRS data included in AIRS Executive. AIRSWeb has summaries of air monitoring data for the current and five prior years, the latest available estimates of air pollutant emissions from major point sources, the overall regulatory compliance status of those sources, and names of contacts in EPA and state/local air pollution agencies. All these data pertain to the criteria pollutants (carbon monoxide, nitrogen dioxide, sulfur dioxide, ozone, particulate matter, lead). AIRSWeb includes data for the 50 States plus the District of Columbia, Puerto Rico, and Virgin Islands.

\section{AIRS Section of EPA's Technology Transfer Network (TTN)}

The Technology Transfer Network is a group of Websites that provide technical and regulatory information about air pollution. The TTN has information ranging from emissions test methods to regulatory air pollution models. There are tools for estimating air pollutant emissions, computer code for regulatory air models, Title by Title summaries of the Clean Air Act, and discussion forums where you can ask questions and share ideas. The TTN's primary audience is environmental professionals, but the Websites are open to anyone who wishes to visit them. The TTN/AIRS Technical Website has been designed for use by State and Local Air Pollution Control Program professionals to assist them with their day to day work of collecting, validating and storing air pollution data in the AIRS Database.

The TTN Websites evolved from a collection of electronic bulletin boards developed and operated by EPA's Office of Air Quality Planning and Standards. Although the bulletin boards are being phased out, they will remain available through most of 1998. Information about accessing the bulletin board system is available elsewhere.

Access to the AIRS Database 
The AIRS database resides on EPA's private mainframe computer system. It is not a publicly available database that can be accessed from the Web (although we're trying to make that happen in 1998). To retrieve information directly from AIRS, you need to obtain an account on the EPA mainframe computer system and pay the applicable computer usage charges. Information about obtaining a computer account is available from the Customer Call Center (help desk) at the EPA National Computer Center, telephone 800-334-2405 (toll free) or 919-541-7862.

If your information requirements are fairly specific, a request under the Freedom of Information Act (FOIA) may be an easier way to to get AIRS data than establishing a computer account. See Obtaining Additional AIRS Data for details about submitting a FOIA request.

\section{AIRSLetter}

The AIRSLetter is a quarterly publication that covers emerging issues and information related to all of the AIIRS subsystems and applications mentioned above. The current AIRSLetter is available, as well as archived issues, in Adobe Acrobat ${ }^{8}$ format.

\section{AIRS Support Contacts}

The AIRS Contacts page lists individuals and organizations you may contact to get more information about AIRS and related collections of air pollution data.

\begin{tabular}{lr}
\hline EPA $\mid$ OAR $\mid$ OAQPS $\mid \frac{\text { AIRS Home }}{\mathrm{http}: / / \text { www.epa.gov/airs/airs2.html }}$ & $\frac{\text { Search } / \text { Comments }}{\text { August } 17,1998}$
\end{tabular}




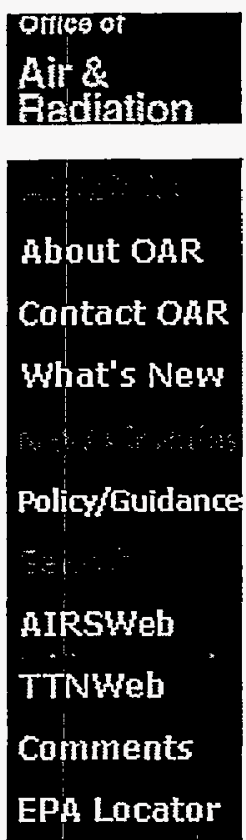

Olhar Exh OHices
Water
Solid Yaste
Pesticides
R \& $\mathrm{D}$
Enforcement
Administrator

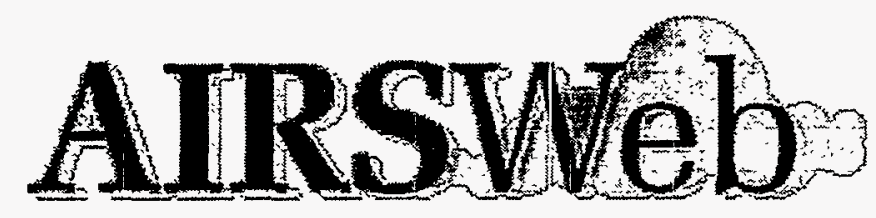

United States Environmental Protection Agency

Office of Air Quality Planning \& Standards

Information Transfer \& Program Integration Division

Information Transfer Group

Research Triangle Park, NC 27711

Air pollution...



Purpose AIRSWeb gives you access to air pollution data for the entire United States. Want to know the highest ozone level measured in your state last year? Ever wonder where air pollution monitoring sites are located? Are there sources of air pollution in your town? This is the place to find out! AIRSWeb creates custom reports using criteria that you specify, displays standard maps of the United States, and provides names of people to contact.

AIRSWeb does have limitations, though. It can't tell you where the air is cleanest, and it doesn't include some types of air pollution sources. Nevertheless, we think you will find it useful.

Data AIRSWeb gets its information from EPA's massive air pollution database, which goes by the name Aerometric Information Retrieval System, or the acronym AIRS. Containing billions of pollution values and related data, AIRS is the most extensive collection of air pollution data on earth. (Visit the main AIRS Website for more information about the AIRS database.) AIRSWeb is a collection of the most significant AIRS data elements, presented clearly.

The AIRSWeb data collection is refreshed monthly, usually on the first Tuesday. The last update was September 1, 1998. 
Features I Here are the main types of information in AIRSWeb. Choose one and learn more about air pollution!

Sources are the major point sources of air pollution. Source Reports display the estimated annual emissions of air pollutants from individual sources (plants, factories, etc.), and indicate whether the sources are complying with applicable regulations. The reports also list the number of sources and total pollutant emissions in each type of industry.

Monitors tell how much pollution is in the air. Monitor Reports provide annual summaries of air pollution measurements at individual monitoring stations, and tell where monitoring stations are located. Monitor Queries provide direct access to an interim AIRS database which has more detailed information. Complete monitor descriptions and summary data are available now, and individual readings of air pollution levels (raw data) will be added.

Maps show the locations of major air pollution sources, monitoring sites, and areas of the country where air pollution levels exceed health-based EPA standards.

Contacts gives the names, addresses, and phone numbers of people in EPA and state environmental agencies to contact about air pollution data.

Info explains AIRS data, and describes AIRSWeb reports and maps.

What's New summarizes the new features and changes in AIRSWeb. 

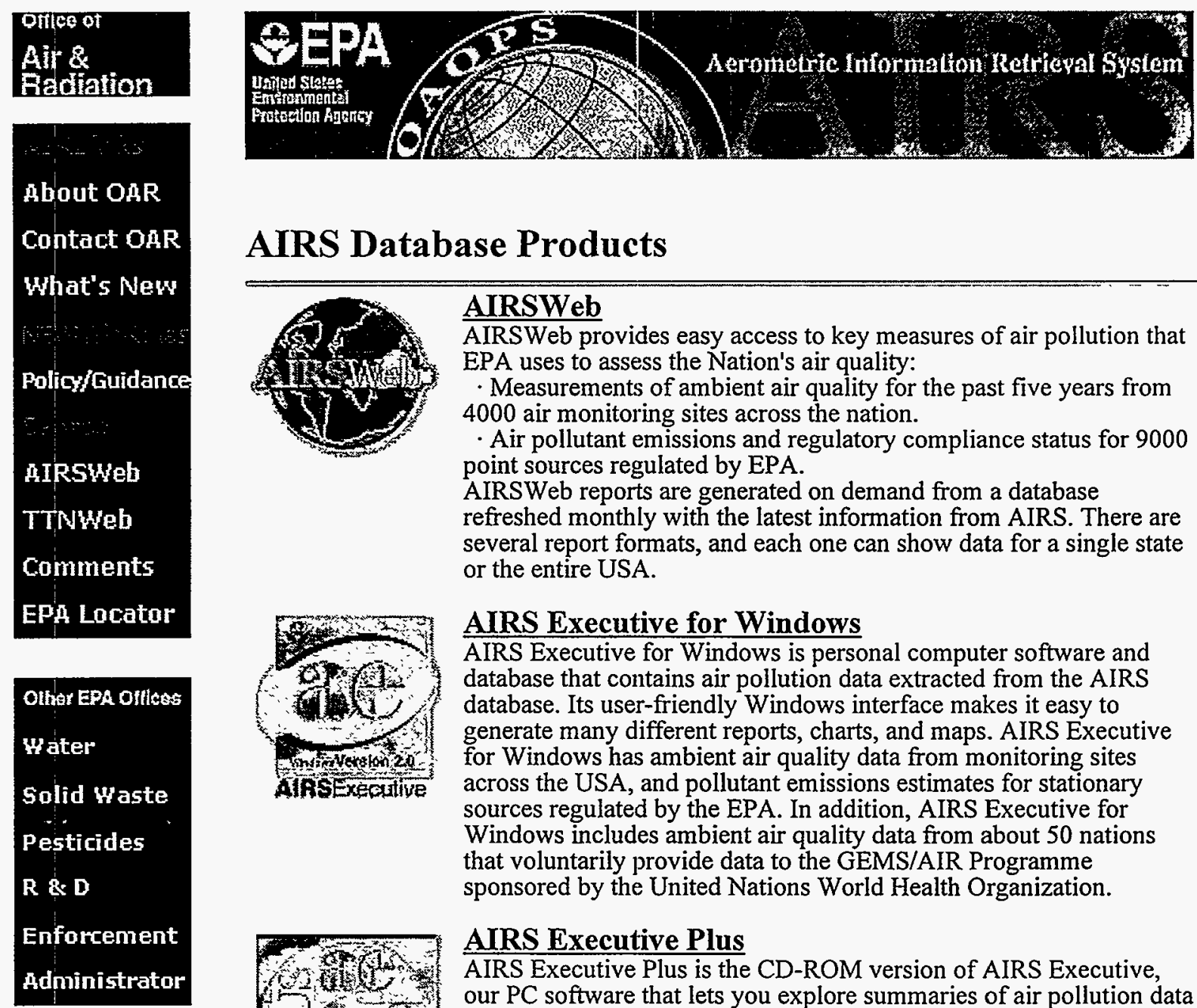

\section{AIRS Database Products}
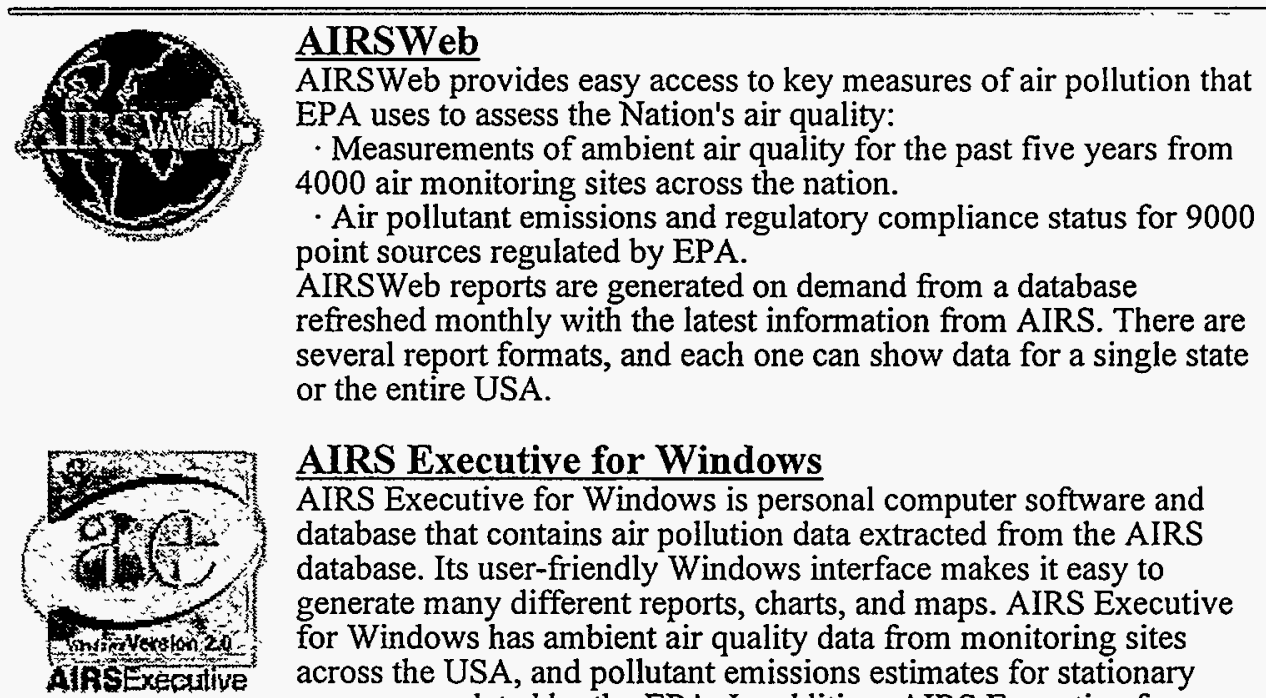

\section{AIRS Executive for Windows}

AIRS Executive for Windows is personal computer software and database that contains air pollution data extracted from the AIRS database. Its user-friendly Windows interface makes it easy to generate many different reports, charts, and maps. AIRS Executive for Windows has ambient air quality data from monitoring sites across the USA, and pollutant emissions estimates for stationary sources regulated by the EPA. In addition, AIRS Executive for Windows includes ambient air quality data from about 50 nations that voluntarily provide data to the GEMS/AIR Programme sponsored by the United Nations World Health Organization.

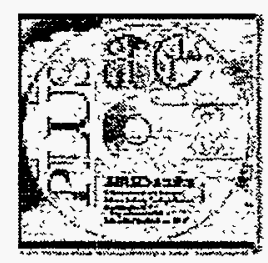

\section{AIRS Executive Plus}

AIRS Executive Plus is the CD-ROM version of AIRS Executive, our PC software that lets you explore summaries of air pollution data for the United States and 50 nations.

Like AIRS Executive, AIRS Executive Plus is designed to provide quick access to a subset of air pollution information. Managers, supervisors, and non-technical staff will find it especially helpful in obtaining easy-to-read summaries of air pollution data. Take a laptop to a meeting, for example, and air pollution data is readily at your fingertips. Non-technical users also will find AIRS Executive to be an invaluable resource in obtaining air pollution information regarding their communities.

You must be running Windows 95 or Windows NT to use AIRS Executive Plus.



\section{AIRS Graphics on the Web}

Coming Soon: AIRS Graphics on the Web (AGWeb) brings reports, charts, and maps for the AIRS database to the web, which can be accessed by many people. AGWeb creates an advanced user interface on the Web by taking advantage of powerful web technologies. AGWeb also allows download of maps and charts to the local client for publishing and printing.

EPA I OAR | OAQPS I AIRS Home

http://www.epa.gov/airs/products.html
Search I Comments August 17, 1998 


\section{Appendix E}

Some individual sources of prepared climate data

E.2 - E.25 Some individual sources of prepared climate data

E.1 


\section{Name of data base AWIS Climate Database}

Who assembled the data base Agricultural Weather Information Service, Inc.

Who supports the data base Agricultural Weather Information Service, Inc.

How to locate http://www.awis.com

Organization Agricultural Weather Information Service, Inc.

Web Page Title Agricultural Weather Information Service (AWIS), Inc.

Why the data base exists To make money for Agricultural Weather Information Service, Inc.

\section{Time period covered}

Sample of data Agricultural Weather Information Service, Inc.

Daily Weather Observations for: Dublin, GA Year $=96$

AIR TEMPERATURE 4 INCH SOIL

DATE MAX MIN AVG DFN PRECP MAX MIN AVG OBS ADJ CHL

$\begin{array}{lllllllllllll}2 / 1 & 67 & 35 & 51 & 6 & 0.35 & 60 & 50 & 55 & 36 & 35 & 10\end{array}$

$\begin{array}{lllllllllllll}2 / 2 & 55 & 36 & 46 & 1 & 0.10 & 56 & 47 & 52 & 51 & 36 & 15\end{array}$

$\begin{array}{llllllllllll}2 / 3 & 51 & 36 & 44 & -3 & 0.60 & 53 & 44 & 49 & 36 & 36 & 17\end{array}$

$\begin{array}{lllllllllllll}2 / 4 & 37 & 15 & 26 & -20 & 0.00 & 50 & 41 & 46 & 15 & 15 & 24\end{array}$

$\begin{array}{llllllllllll}2 / 5 & 33 & 11 & 22 & -24 & 0.00 & 42 & 34 & 38 & 12 & 11 & 24\end{array}$

About AWIS is a commercial database for the states of Alabama, Florida, and Georgia. 
Name of data base

Who assembled the data base Alaska Climate Research Center

Who supports the data base Alaska Climate Research Center

How to locate http://climate.gi.alaska.edu/climatology/data.html

Organization Alaska Climate Research Center, University of Alaska - Fairbanks

Web Page Title Alaskan Climatology Data

Why the data base exists

Time period covered 1949

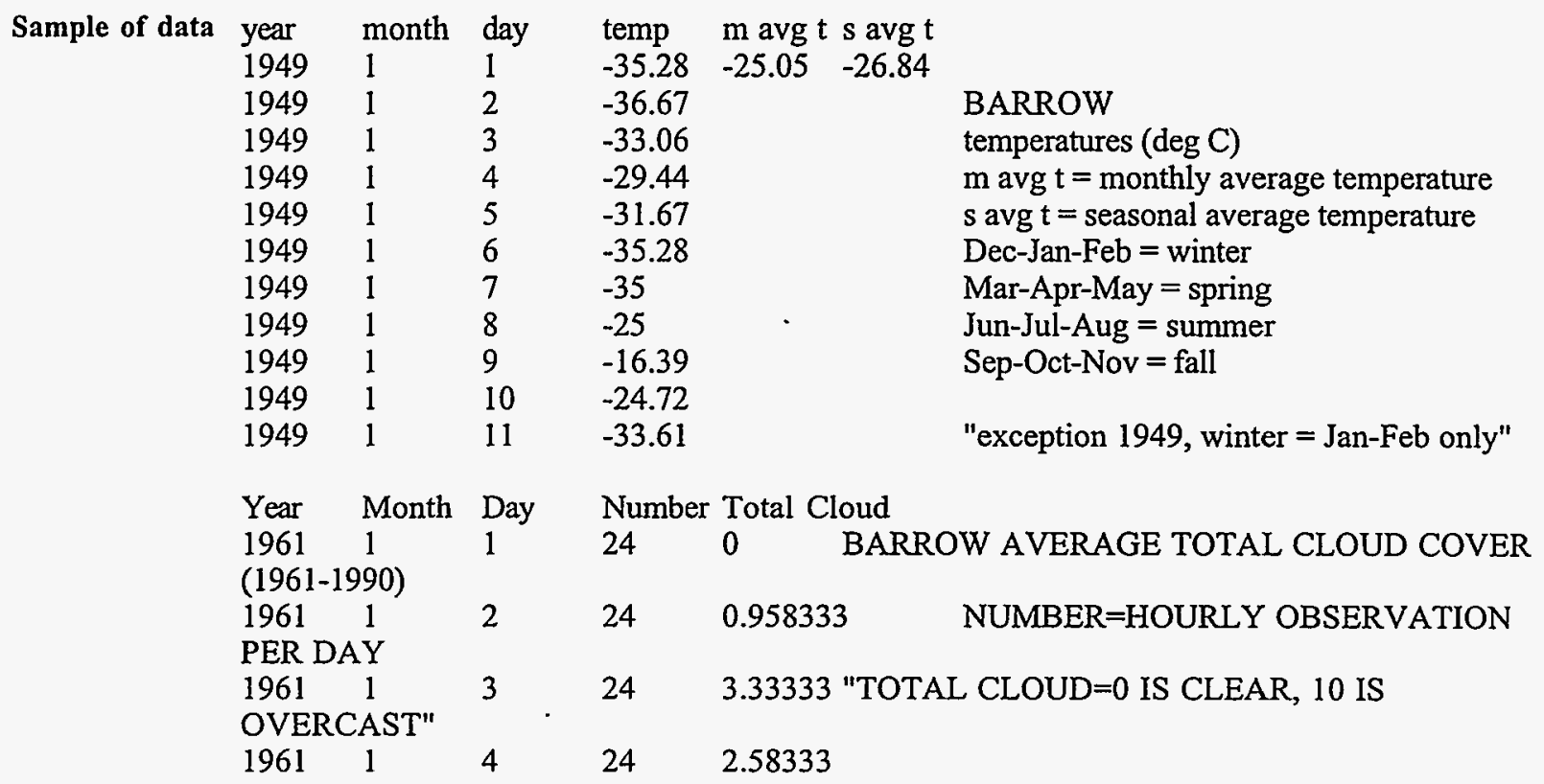

About Temperature and Precipitation data for Barrow and Barter Island can be found on a linked ftp server

Fairbanks data is also available in HTML format

Weather records by month for over 20 Alaskan cities are available via the web:

Temperature records by month including:

Highest temperature

Lowest Temperature

Mean number of days with minimum temperature $32 \mathrm{~F}$ or less

Average heating degree days

Average cooling degree days

Other Records by month including:

Normal monthly precipitation

Average number of day with .01 inches of precipitation or more

Average snowfall

Average percent of possible sunshine

Mean number of day of cloudiness

Average relative humidity

Average wind speed

Sunrise - Sunset data 
Name of data base Model and Climate Products

Who assembled the data base Catherine Smith, Cooperative Institute for Research in Environmental Sciences, University of CO

Who supports the data base Catherine Smith, Cooperative Institute for Research in Environmental Sciences, University of CO

How to locate http://www.cdc.noaa.gov/products.html

Organization Climate Diagnostics Center, National Oceanic and Atmospheric Administration

Web Page Title Products and Services at CDC

Why the data base exists These high-quality data sets significantly improve NOAA's capabilities for monitoring climatic trends, particularly in surface temperatures and precipitation.

Time period covered $1893-1997$

Sample of data Boulder Daily Weather data from the NOAANWS

Cooperative Site

Temperatures are in degrees Fahrenheit

Precipitation, snowfall and snow depth are in inches

Max and min temperatures are for the $6 \mathrm{pm}-6 \mathrm{pm}$ time period

1948-1990 Data

June 1990

\begin{tabular}{|c|c|c|c|c|c|}
\hline Day & high $T$ & low $\mathrm{T}$ & Precip & Snow & Snow \\
\hline 1 & 76 & 46 & $\mathbf{T}$ & 0 & 0 \\
\hline 2 & 73 & 40 & 0 & 0 & 0 \\
\hline 3 & 75 & 46 & 0 & 0 & 0 \\
\hline 4 & 94 & 50 & 0 & 0 & 0 \\
\hline 5 & 89 & 56 & 0 & 0 & 0 \\
\hline
\end{tabular}

About The mission of the Climate Diagnostics Center (CDC) is to identify the nature and causes for climate variations on time scales ranging from a month to centuries.

The goal of this work is to develop the ability to predict important climate variations on these time scales. Short-term climate variations of interest include major droughts and floods over the continental U.S., and the global anomalies associated with El Niño-Southern Oscillation (ENSO).

This web page has links to detailed monthly data for U.S. cities, very detailed data for Boulder, Colorado, and links to other data. 
Name of data base Data \& Indices

Who assembled the data base Climate Predication Center, National Oceanic and Atmospheric Administration

Who supports the data base Climate Predication Center, National Oceanic and Atmospheric Administration

How to locate http://nic.fb4.noaa.gov/data/altindex.html

Organization Climate Predication Center, National Oceanic and Atmospheric Administration

Web Page Title Climate Prediction Center - Data \& Indices

Why the data base exists The Climate Prediction Center maintains a continuous watch on short-term climate fluctuations and to diagnose and predict them as quickly as possible.

Time period covered six months ago-present

Sample of data

HEATING DEGREE DAY DATA WEEKLY SUMMARY

CLIMATE PREDICTION CENTER-NCEP-NWS-NOAA

LAST DATE OF DATA COLLECTION PERIOD IS JAN 31, 1998

ACCUMULATIONS ARE FROM JUL 1, 1997 TO JAN 31, 1998

-999 = NORMAL LESS THAN 100 OR RATIO INCALCULABLE

STATE CITY

$\begin{aligned} & \text { CALI WEEK } \text { WEEK WEEK } \\ & \text { TOTAL DEV DEV } \\ & \text { FROM FROM } \\ & \text { NORM L YR }\end{aligned}$

$\begin{array}{lllll}\text { CUM } & \text { CUM } & \text { CUM } & \text { CUM } & \text { CUM } \\ \text { TOTAL DEV } & \text { DEV } & \text { DEV } & \text { DEV } \\ \text { FROM } & \text { FROM } & \text { FROM } & \text { FROM } \\ \text { NORM } & \text { L YR } & \text { NORM } & \text { L YR } \\ & & \text { PRCT } & \text { PRCT }\end{array}$

$\begin{array}{lllrrrrrrr}\text { AL BIRMINGHAM } & \text { BHM } & 152 & -8 & 9 & 1875 & 13 & 232 & 1 & 14 \\ \text { AK ANCHORAGE } & \text { ANC } & 297 & -49 & -17 & 5937 & -355 & -647 & -6 & -10 \\ \text { AZ DOUGLAS } & \text { DUG } & 117 & -17 & 8 & 1687 & -27 & 168 & -2 & 11 \\ \text { AR EL DORADO } & \text { ELD } & 122 & -31 & -17 & 1811 & 59 & 273 & 3 & 18 \\ \text { CA BAKERSFIELD } & \text { BFL } & 110 & 2 & 36 & 1351 & -66 & 27 & -5 & 2\end{array}$

About The Climate Prediction Center's (CPC) real-time data base is the most timely climate data base in the world. Because of CPC's emphasis on providing data as quickly as possible, many values are only preliminary. CPC cannot guarantee the overall quality and reliability of such preliminary data and does not encourage its use for research purposes; data in final form are available from the National Climatic Data Center. (www.ncdc.noaa.gov)

Good source of historical data for heating and cooling degree days on many cities around the country. There are also data on temperature and precipitation. 
Name of data base Georgia Automated Environmental Monitoring Network

Who assembled the data base College of Agriculture and Environmental Sciences, University of Georgia

Who supports the data base College of Agriculture and Environmental Sciences, University of Georgia

How to locate http://www.griffin.peachnet.edu/bae

Organization College of Agriculture and Environmental Sciences, University of Georgia

Web Page Title Georgia Weather - Automated Environmental Monitoring Network Page

Why the data base exists To collect reliable weather information for agricultural and environmental applications, such as air and soil temperature, relative humidity, rainfall, solar radiation, wind speed, and wind direction.

Time period covered 1996 - present

Sample of data Historical Data

\begin{tabular}{|c|c|c|c|c|c|}
\hline \multicolumn{6}{|c|}{$\begin{array}{l}\text { JONESBORO, Atlanta Beach } \\
\text { Jonesboro - Clayton County, GA }\end{array}$} \\
\hline Date: & & Max. Temp. $\left({ }^{\circ} \mathrm{F}\right)$ & Min. Temp. & $\left({ }^{\circ} \mathrm{F}\right)$ & Rain (in) \\
\hline $\operatorname{Jan} 1$, & 1998 & $48.0^{\circ}$ & 17.1 & & 0.00 \\
\hline $\operatorname{Jan} 2$ & 1998 & 60.4 & 18.9 & & 0.00 \\
\hline $\operatorname{Jan} 3$ & 1998 & 66.9 & 29.3 & & 0.00 \\
\hline $\operatorname{Jan} 4$ & 1998 & 68.4 & 36.9 & & 0.00 \\
\hline $\operatorname{Jan} 5$ & 1998 & 65.7 & 51.3 & & 0.04 \\
\hline $\operatorname{Jan} 6$ & 1998 & 69.6 & 59.2 & & 0.51 \\
\hline
\end{tabular}

About The Georgia Automated Environmental Monitoring Network was established in 1991 by the College of Agriculture and Environmental Sciences of the University of Georgia. The objective of the AEMN is to collect reliable weather information for agricultural and environmental applications. Each station monitors air temperature, relative humidity, rainfall, solar radiation, wind speed, wind direction, and soil temperature at 2,4 , and 8 inch depths every 1 second. Data are summarized at 15 minute intervals and at midnight a daily summary is calculated. A microcomputer at the Georgia Experiment Station initiates telephone calls to each station periodically and downloads the recorded data. 


\section{Name of data base Colorado Climate Data Access}

Who assembled the data base Colorado Climate Center

Who supports the data base John Kleist, Colorado Climate Center

How to locate http://ulysses.atmos.colostate.edu/Access.html

Organization Colorado Climate Center

Web Page Title Colorado Climate Data Access

Why the data base exists These data have been collected as a part of the National Weather Service's Cooperative Program.

Time period covered 1948 - present.

\begin{tabular}{|c|c|c|c|c|c|c|c|c|}
\hline \multirow[t]{2}{*}{ Sample of data } & \multicolumn{2}{|c|}{ station = } & \multicolumn{2}{|c|}{ DENVER WSFO AP } & Year $=1950$ & \multicolumn{2}{|c|}{ Month $=1$} & \multirow[b]{2}{*}{$(f t)$} \\
\hline & $I d=$ & 20 & $t=3946$ & (ddmm) & Lon $=1$ & 453 (dddmm) & Elev $=5290$ & \\
\hline & Day & Tmax & Tmin & Tobs & $\mathrm{HDD}$ & Prec & & \\
\hline & & $\operatorname{deg} F$ & $\operatorname{deg} F$ & $\operatorname{deg} F$ & base 65 & In. $* 100$ & & \\
\hline & 1 & 58 & 29 & & 21 & 0 & & \\
\hline & 2 & 54 & 5 & & 35 & 1 & & \\
\hline & 3 & 5 & -12 & & 68 & 4 & & \\
\hline & 4 & 8 & -14 & & 68 & $t$ & & \\
\hline & 5 & 28 & -5 & & 53 & 0 & & \\
\hline
\end{tabular}

About Through its threefold program of Climate Monitoring (data acquisition, analysis, and archiving), Climate Research and Climate Services, the Colorado Climate Center is responding to many climate related questions and problems affecting the state today. 
Name of data base Global Change Master Directory (GCMD)

Who assembled the data base NASA

Who supports the data base NASA

How to locate http://gcmd.gsfc.nasa.gov

Organization NASA

Web Page Title THE GLOBAL CHANGE MASTER DIRECTORY

Why the data base exists The GCMD assists the scientific community in the discovery of and linkage to Earth science data and provides data holders a means to advertise their data to the Earth Science Community.

Time period covered unknown. changes as they locate more data

Sample of data Daily, Monthly, Annual Climate Data Including Temperature, Wind, Rainfall, Sunshine, and Precipitation for the British Isles (1803-1910)

The temperature, rainfall, and sunshine data resides in a book containing tables and maps of monthly and annual normals for surface temperature, rainfall, and sunshine for the British Isles averaged over the period 1871 to 1910 . Monthly and annual variables incorporated in the tables are the following: mean maximum, minimum, and mean temperature; number of days of rainfall, sunshine, and humidity; mean maximum and minimum temperature; total rainfall; temperature ranges; daily mean sunshine; and percent possible sunshine. There are maps of monthly and annual mean maximum and minimum temperature, rainfall, and monthly sunshine hours per day.

Hourly and 5-day weather data resides in 14 books containing tables, maps, and graphs of hourly, five-day, and monthly surface pressure, temperature, rainfall, and winds for the British Isles. These are for each month of the period 1869 to 1879 . Some of the years contain daily weather maps of pressure and wind. Hourly data include continuous traces of temperature, pressure, and rainfall. These are displayed in the form of graphs only. Daily parameters incorporated in these data are five-day means of temperature and pressure, and records of gale force winds and their duration for a particular speed. Monthly parameters include the following: mean pressure and temperature; maximum and minimum pressure and temperature; and number of hours during the month when strong winds occurred.

About The Global Change Master Directory is a multidisciplinary on-line information system containing descriptions of Earth and space science data holdings available to the science community. These include data from NASA, NOAA, NCAR, USGS, DOE (CDIAC), EPA, NSF and over 470 government agencies, research institutions, archives and universities worldwide.

The GCMD is not a data repository. The GCMD is a database of descriptions of data sets, not the data sets themselves. It is more like a card catalog of data. It will help in locating the proper data set, what the data set includes, and who has it. If the data set is on-line, there will be a link to it. 
Name of data base High Plains Climate Center Data Holdings

Who assembled the data base High Plains Climate Center, University of Nebraska-Lincoln

Who supports the data base High Plains Climate Center, University of Nebraska-Lincoln

How to locate http://hpccsun.unl.edu

Organization High Plains Climate Center, University of Nebraska-Lincoln

Web Page Title High Plains Climate Center Home Page

Why the data base exists The mission of the High Plains Climate Center is to increase the use and availability of climate data in the High Plains region.

Time period covered 1890 s - present

\begin{tabular}{|c|c|c|c|c|c|c|c|c|c|c|}
\hline \multirow[t]{9}{*}{ Sample of data } & \multirow{2}{*}{\multicolumn{2}{|c|}{$\begin{array}{r}\text { LINCOLNIANR } \\
2254809\end{array}$}} & \multicolumn{2}{|l|}{ NE } & \multirow[b]{2}{*}{ Rel Hum } & \multirow{2}{*}{\multicolumn{2}{|c|}{ Soil Tmp Hind Spd }} & \multirow[b]{2}{*}{ Solar } & \multirow[b]{2}{*}{ Precip } & \\
\hline & & & T-High & T-LoW & & & & & & \\
\hline & & $-\mathrm{NE}$ & & & & & & & & \\
\hline & & date/time & $\mathrm{F}$ & $\mathbf{F}$ & $q$ & $\mathrm{~F} Q 4$ in. & $\mathrm{mi} / \mathrm{hr}$ & langleys & inches & inches \\
\hline & 2 & 119982400 & 37.090 & 28.647 & 96.547 & 33.437 & 4.718 & 26.278 & 0.2721 & 0.002 \\
\hline & 2 & 219982400 & 33.712 & 26.589 & 97.861 & 33.046 & 4.253 & 47.377 & 0.009 & 0.002 \\
\hline & 2 & 319982400 & 29.383 & 16.052 & 85.396 & 33.048 & 4.865 & 158.043 & 0.009 & 0.023 \\
\hline & 2 & 419982400 & 28.276 & 7.898 & 88.830 & 32.819 & 3.296 & 147.177 & 0.000 & 0.018 \\
\hline & 2 & 519982400 & 32.801 & 24.197 & 84.066 & 32.721 & 3.970 & 140.969 & 0.020 & 0.022 \\
\hline
\end{tabular}

NWS :

\begin{tabular}{|c|c|c|c|c|c|c|c|}
\hline & & $\mathrm{LN} A$ & ORT & $\mathrm{NE}$ & & & \\
\hline & & 2547 & & $\mathrm{~T}-\mathrm{High}$ & T-Low & Precip & Snow \\
\hline & & $t e / t$ & & $F$ & F & inches & inches \\
\hline 2 & 1 & 1998 & 700 & 37.000 & 29.000 & 0.010 & 0.000 \\
\hline 2 & 2 & 1998 & 700 & 32.000 & 27.000 & 0.000 & 0.000 \\
\hline 2 & 3 & 1998 & 700 & 30.000 & 16.000 & 0.000 & 0.000 \\
\hline 2 & 4 & 1998 & 700 & 28.000 & 9.000 & 0.000 & 0.000 \\
\hline 2 & 5 & 1998 & 700 & 34.000 & 25.000 & 0.000 & 0.000 \\
\hline
\end{tabular}

About The High Plains Climate Center (HPCC) was formed in 1987 by charter members in the states of Colorado, lowa, Kansas, Nebraska, South Dakota, and Wyoming. North Dakota became a member of HPCC in 1988, bringing the number of affiliated universities to seven: Colorado State University, lowa State University, Kansas State University, University of Nebraska, North Dakota State University, South Dakota State University, and University of Wyoming.

The HPCC is well recognized as one of the centers of expertise in the use of automated weather stations to obtain near-real time climate data. Scientists from around the nation and from other countries have visited the HPCC to receive training in the collection, management, and summarization of near real-time data. HPCC also includes in its archive all relevant data from National Weather Service surface weather networks and participated in the preparation of special data sets that extend back to the 1890's. 
Name of data base The Ithaca Climate Page

Who assembled the data base Northeast Regional Climate Center, Cornell University

Who supports the data base Northeast Regional Climate Center, Cornell University

How to locate http://met-www.cit.cornell.edu/climate/ithaca

Organization Northeast Regional Climate Center, Cornell University

Web Page Title The Ithaca Climate Page

Why the data base exists The NRCC's mission is to facilitate and enhance the collection, dissemination and use of climate data.

Time period covered January 1995 - present

Sample of data Monthly Climate Summary for Ithaca, NY

January 1995

$\begin{array}{rrrrrrrrrrr}\text { DAY } & \text { MAX } & \text { MIN } & \text { AVG } & \text { DPT } & \text { HDD } & \text { CDD } & \text { GDD } & \text { PRECIP } & \text { SNOW } & \text { DEPTH } \\ 1 & 38 & 28 & 33 & 10 & 32 & 0 & 0 & 0.38 & 0.0 & 0 \\ 2 & 44 & 26 & 35 & 12 & 30 & 0 & 0 & 0.09 & 0.7 & \text { Tr } \\ 3 & 27 & 17 & 22 & -1 & 43 & 0 & 0 & 0.01 & 0.6 & 1 \\ 4 & 27 & 15 & 21 & -2 & 44 & 0 & 0 & \mathrm{Tr} & \mathrm{Tr} & 1 \\ 5 & 18 & 8 & 13 & -10 & 52 & 0 & 0 & 0.03 & 1.2 & 2\end{array}$

About Recent historical weater data for Ithaca, New York. 
Name of data base Kentucky Weather and Climate Information

Who assembled the data base Agricultual Weather Center, University of Kentucky

Who supports the data base Agricultual Weather Center, University of Kentucky

How to locate http://wwwagwx.ca.uky.edu/Kyagwx.html

Organization Agricultual Weather Center, University of Kentucky

Web Page Title Kentucky Weather and Climate Information

Why the data base exists The data is a free service of the University of Kentucky College of Agriculture

Time period covered 1978-1988

Sample of data Bardstown Climate Data

This weather data provided by the University of Kentucky

Agricultural weather Center (Phone 606/257-3000)

World Wide Web URI: http://wwwagwx.ca.uky.edu/

\begin{tabular}{|c|c|c|c|c|c|c|c|c|c|}
\hline \multirow[b]{2}{*}{ STATION } & \multirow[b]{2}{*}{ DATE } & \multicolumn{3}{|c|}{ AIR TEMP } & \multirow[b]{2}{*}{ PRECIP } & \multicolumn{2}{|c|}{$\mathrm{RH}$} & \multicolumn{2}{|l|}{$\begin{array}{l}\text { SOIL TEMP } \\
\text { GRASS BARE }\end{array}$} \\
\hline & & $\mathrm{MX}$ & $\mathbb{M N}$ & $\mathrm{AV}$ & & $\mathrm{MX}$ & $\mathrm{MN}$ & $M X M N M X M N$ & EVAP \\
\hline$n-m-n-m-n-m$ & ---n-. & $-\cdots$ & -- & -- & ----- & --- & -- & $-\ldots-\ldots$ & ---- \\
\hline Bardstown & $01-01-98$ & 41 & 10 & 26 & & 99 & 42 & 3736 & \\
\hline Bardstown & $01-02-98$ & 53 & 37 & 45 & & 56 & 24 & 4038 & \\
\hline Bardstown & $01-03-98$ & 62 & 47 & 54 & & 68 & 26 & $44 \quad 40$ & \\
\hline Bardstowm & $01-04-98$ & 66 & 49 & 58 & & 94 & 58 & $48 \quad 45$ & \\
\hline Bardstown & $01-05-98 E$ & 60 & 51 & 56 & 0.27 & 100 & 68 & 4945 & \\
\hline
\end{tabular}

About Good data and monthly climatology data for various locations in Kentucky. There are three years of precipitation reports for three cities.

There are also many agriculture-related statistics available, including growing degree days, insect degree days, and livestock stress. 
Name of data base Midwest Climate Information System (MICIS)

Who assembled the data base Midwestern Climate Center, University of Illinois at Urbana-Champaign

Who supports the data base Midwestern Climate Center, University of Illinois at Urbana-Champaign

How to locate http://mcc.sws.uiuc.edu

Organization Midwestern Climate Center, University of Illinois at Urbana-Champaign

Web Page Title Midwestern Climate Center

Why the data base exists The Midwestern Climate Center has a primary responsibility of delivering climate information, which it does primarily through MICIS.

Time period covered 1881 - present

Sample of data STATION: URBANA, IL (Station ID: 118740)

\begin{tabular}{|c|c|c|c|c|c|c|c|c|c|c|c|}
\hline \multirow{2}{*}{\multicolumn{3}{|c|}{ Year Mo Dy }} & \multirow{2}{*}{$\begin{array}{l}\text { Precip- } \\
\text { itation } \\
\text { (in) }\end{array}$} & \multicolumn{3}{|c|}{ |<--Temperature->| } & \multirow[b]{2}{*}{$\begin{array}{c}\text { Degree } \\
\text { Days }\end{array}$} & \multirow{2}{*}{$\begin{array}{l}\text { Snow } \\
\text { Fall } \\
\text { (in) }\end{array}$} & Snow & \multirow[b]{2}{*}{ Observe } & \multirow[b]{2}{*}{ Source } \\
\hline & & & & $\begin{array}{l}\text { High } \\
\text { (F) }\end{array}$ & $\begin{array}{l}\text { Low } \\
(F)\end{array}$ & $\begin{array}{l}\text { Mean } \\
\text { (F) }\end{array}$ & & & $\begin{array}{c}\text { Depth } \\
\text { (in) }\end{array}$ & & \\
\hline 1998 & 01 & 01 & 0.00 & 44 & 15 & 30 & 35 & 0.0 & 1 & MID & $\mathrm{P}$ \\
\hline 1998 & 01 & 02 & 0.00 & 49 & 35 & 42 & 23 & 0.0 & 0 & MID & $P$ \\
\hline 1998 & 01 & 03 & 0.10 & 56 & 49 & 53 & 12 & 0.0 & 0 & MID & $\mathrm{P}$ \\
\hline 1998 & 01 & 04 & 0.06 & 58 & 52 & 55 & 10 & 0.0 & 0 & MID & $\mathrm{p}$ \\
\hline 1998 & 01 & 05 & 0.59 & 57 & 52 & 55 & 10 & 0.0 & 0 & MID & $\mathrm{P}$ \\
\hline
\end{tabular}

About The Midwestern Climate Center has four primary responsibilities: delivery of climate information, monitoring of regional climate anomalies (droughts, floods, etc.) and preparation of specialized information relevant to the anomaly, preparation of specialized historical climate data sets, and applied research on climate issues.

The primary region of the Center include the states of Illinois, Indiana, Iowa, Kentucky, Michigan, Minnesota, Missouri, Ohio, and Wisconsin. Some data are available for the eastem two-thirds of the U.S. plus Ontario and Quebec. There is an detailed inventory of the weather stations used, including their location and years in service.

The Midwest Climate Information System (MICIS), for example, provides daily climate data for more than 3,200 reporting stations in the region. Data for most stations date back to the early 1900 s, and for some stations back to the early 1900's. Most data is available for a fee. 
Name of data base Climate Visualization (CLIMVIS)

Who assembled the data base National Climatic Data Center, National Oceanic and Atmospheric Administration

Who supports the data base National Climatic Data Center, National Oceanic and Atmospheric Administration

How to locate http://www.ncdc.noaa.gov/ol/climate/climatedata.html

Organization National Climatic Data Center, National Oceanic and Atmospheric Administration

Web Page Title NCDC: Get/View OnLine Climate Data

Why the data base exists NCDC's mission is to manage climatological data and information. This effort requires the dissemination of a vast array of climatological data.

Time period covered 1940s or earlier - June 1996

Sample of data January 1950

23271, CA SACRAMENTO WSO CITY , 195009-196312, ABCDE

(A) Daily Maximum Temperature

-Day--Value-

$01 \quad 42$

$02 \quad 46$

$03 \quad 43$

$04 \quad 44$

$05 \quad 48$

About NCDC is the world's largest active archive of weather data. NCDC produces numerous climate publications and responds to data requests from all over the world. NCDC operates the World Data Center-A, Meteorology which is collocated at NCDC.

Links to surface data, upper air data, and marine data. The above data is from the US Surface Data database. Parameters were chosen and a graph appeared. A link below the graph provides data. 


\section{Name of data base Climate Data}

Who assembled the data base National Weather Service Forecast Office, Norman, Oklahoma

Who supports the data base National Weather Service Forecast Office, Norman, Oklahoma

How to locate http://www.nssl.noaa.gov/ nws/f6.html

Organization National Weather Service Forecast Office, Norman, Oklahoma

Web Page Title NWSFO Norman WWW Home Page - Climate Data

Why the data base exists The National Weather Service's mission includes the preparation and dissemination of publich forecasts.

Time period covered January 1995 to present

Sample of data OKLAHOMA CITY

PRELTMINARY LOCAL CLIMATOLOGICAL DATA

LATITUDE: 35 DEG. $24^{\prime} \mathrm{N}$; LONGITUDE: 97 DEG. $3^{\prime} \mathrm{W}$ GROUND ELEVATION: 1215 FT. STANDARD TIM



About Daily summaries of temperatures and precipitation from observations taken at the Will Rogers World Airport in Oklahoma City, Oklahoma and at Sheppard AFB in Wichita Falls, Texas.

The data includes maximum and minimum temperatures, degree days, precipitation, average and peak wind speed, sunshine, and weather conditions.

Unfortunately, data only dates back to 1995 , so this data base may be of no use for heat island research. 


\section{Name of data base Climatology Monthly Data}

Who assembled the data base National Weather Service Office Denver, National Oceanic and Atmospheric Administration

Who supports the data base National Weather Service Office Denver, National Oceanic and Atmospheric Administration

How to locate http://www.crh.noaa.gov/den/climo.html

Organization National Weather Service Office Denver, National Oceanic and Atmospheric Administration

Web Page Title climo

Why the data base exists

Time period covered January 1995 - present

Sample of data

*****THIS FORM IS FOR UNOFFICIAL USE ONLY*****

Preliminary Local Climatological Data (WS Form: F-6)

Station: DENVER CO

Month: JAN

Year: 1995

Temperature in F : $\quad$ :Pcpn :Snow: Wind $\quad$ :Sunshine: Sky $\quad$ :Pk Wnd

$============================$ Columns

$\begin{array}{lllllllllllllllllll}1 & 2 & 3 & 4 & 5 & 6 \mathrm{a} & 6 \mathrm{~b} & 7 & 8 & 9 & 10 & 11 & 12 & 13 & 14 & 15 & 16 & 17 & 18\end{array}$

Dy Max Min Avg Dep HDD CDD Wtr Snw Dpth Avg Spd Dir Min Psbl S-S Wx Spd Dr

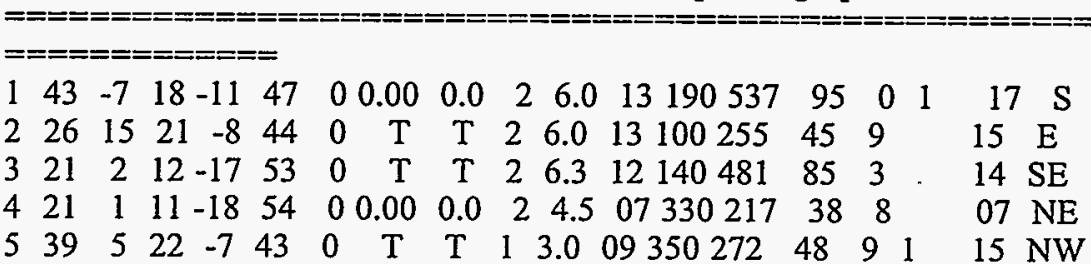

About Daily and monthly weather data from Denver, Colorado.

E.15 


\section{Name of data base NCAR Data Support Section Data Archive}

Who assembled the data base Data Support Section, Scientific Computing Division, National Center for Atmospheric Research

Who supports the data base Data Support Section, Scientific Computing Division, National Center for Atmospheric Research

How to locate http://www.scd.ucar.edu/dss

Organization Data Support Section, Scientific Computing Division, National Center for Atmospheric Research

Web Page Title NCAR Data Archive -- README

Why the data base exists To support the needs of the research community.

Time period covered some climatology data as early as 1738 -present

Sample of data 221481934212

59968356822681968076804681368006813681768216830683568406839684268386846684568386

84368406840684868426839683868376836683768396835

Character

Position

Description

1-2 Type of record flag: 1=library record; $2=$ data record

3 Type of station: $1=\mathrm{COOP} ; 2=\mathrm{WBAN}$

4-9 Station number: If COOP, characters 4-5 = state \#, characters 6-9 = station \# If WBAN, character $4=0$, characters $5-9=$ WBAN \#

10-12 Year minus 1600; e.g., 357 is equivalent to 1957

13-14 Month

15-16 Parameter: $1=$ Mean Temp; $2=$ Max Temp; $3=$ Min Temp; 4 = Precipitation

17-18 Units Code: 5 = degrees Fahrenheit (Temperatures)

$9=$ hundredths inches (Precipitation)

About The National Center for Atmospheric Research provides a computer-accessible archive for use by scientists, teachers, and students. The archive contains over 400 datasets of observations and analyses. NCAR staff in the Data Support Section of the Scientific Computing Division add new datasets and update existing ones to support the needs of the research community.

Frequently used datasets include gridded atmospheric analyses, satellite data, climate model data for assessment studies, long-term climate data (including trends and variability)

The above sample data can be located at the link Dataset information / dataset information | Titles and links to all DSS datasets $\mid \mathrm{ds} 508.0$ | sample.dly.ascii 


\section{Name of data base Climate Data}

Who assembled the data base New Mexico State University Climate Center, Department of Agronomy and Horticulture

Who supports the data base New Mexico State University Climate Center, Department of Agronomy and Horticulture

How to locate http://weather.nmsu.edu/convert.html

Organization New Mexico State University Climate Center, Department of Agronomy and Horticulture

Web Page Title NMSU Weather Data Conversion/Data Retrieval

Why the data base exists The duties of the State Climate Center include Disseminating climate data, information, advice and assessments to state agencies, local public bodies and the general public.

Time period covered $1976-$ present

Sample of data weather Summary From: C - T11868.CVT

Elevation: 1183 meters

\begin{tabular}{|c|c|c|c|c|c|c|c|c|c|c|c|c|c|c|}
\hline \multirow[t]{4}{*}{ Date } & \multicolumn{3}{|c|}{ Air } & $\operatorname{Rel}$ & \multicolumn{3}{|c|}{ |Soil|wind } & |Sol| & Rain| & \multirow{3}{*}{$\begin{array}{l}\text { PET } \\
\text { (In) }\end{array}$} & \multirow{2}{*}{$\begin{array}{l}\text { | Heat } \\
\text { |Corn }\end{array}$} & \multicolumn{3}{|c|}{ Units (F) } \\
\hline & Tem & p (F & & Humid| & Temp & Spe & & $|\operatorname{Rad}|$ & (In & & & Cotn & Genr| & \\
\hline & & & & $(\%)$ & (F) & (MP & & $j(L) \mid$ & & & 86 & 86 & $086<$ & $1 a x$ \\
\hline & & & & & & & & & & & 50 & 55 & $050<$ & $\Leftrightarrow=\operatorname{Min}$ \\
\hline$M / D D / Y Y$ & $\mathrm{MX}$ & MN & $\mathrm{AV} \mid$ & $M X M N \mid$ & $\mathrm{AV}$ & Mx & AV & & & & 50 & 55 & $050<$ & $<=$ Base \\
\hline & & & & & & & & & & & & & & \\
\hline$/ 98$ & 64 & 28 & 44 & 9234 & 43 & 6 & 1.8 & 277 & 0.00 & 0.10 & 7 & 5 & & \\
\hline $1 / 03 / 98$ & 65 & 35 & 49 & 9033 & 45 & 12 & 2.9 & 263 & 0.00 & 0.10 & 8 & 5 & 8 & \\
\hline $1 / 04 / 98$ & 58 & 36 & 44 & 9957 & 45 & 13 & 2.3 & 138 & 0.20 & 0.04 & 4 & 2 & 4 & \\
\hline $01 / 05 / 98$ & 55 & 34 & 44 & 10137 & 45 & 15 & 3.4 & 205 & 0.00 & 0.07 & 3 & 0 & 3 & \\
\hline
\end{tabular}

About Weather data is available for various locations in New Mexico in many different formats. There is also a tutorial demonstrating how to download some data sets

Precipitation and Atmospheric deposition is measured at six sites for New Mexico.

Hourly updated barometric readings and weather for various cities in New Mexico. Barometric readings are for sea level.

Corrections for elevation can be made using an on-line weather calculator. 
Name of data base CLIMOD (CLimate Information for Management and Operational Decisions)

Who assembled the data base Northeast Regional Climate Center

Who supports the data base Northeast Regional Climate Center

How to locate http://met-www.cit.cornell.edu/nrcc_home.html

Organization Northeast Regional Climate Center, Cornell University

Web Page Title Northeast Regional Climate Center

Why the data base exists To facilitate and enhance the collection, dissemination and use of climate data as well as to monitor and assess climatic conditions and impacts in the region.

Time period covered

Sample of data

About The Northeast Regional Climate Center serves Connecticut, Delaware, Massachusetts, Maryland, Maine, New Hampshire, New Jersey, New York, Pennsylvania, Rhode Island, Vermont, and West Virginia. The mission of the Northeast Regional Climate Center is to facilitate and enhance the collection, dissemination and use of climate data as well as to monitor and assess climatic conditions and impacts in the twelve-state, northeastern region of the United States. Its activities are intended to further the economic efficiency and general welfare of public and private institutions and individuals in the region.

The NRCC database includes a complete collection of historical climate data for the northeastern US as well as continually updated National Weather Service observations and forecasts. In addition, daily temperature and precipitation data are available from adjoining Canadian provinces as well as from a number of special state and local networks that measure additional climatic variables that are useful in studies of agricultural production, hydrology, and environmental impacts. NRCC also has special data sets of model-derived variables such as solar radiation and evaporation that are not widely observed. Other data sets have been developed in which any missing observation has been replaced with an estimated value to produce a serially complete record.

Data and information are disseminated to NRCC clients via telephone, facsimile, computer networks and the mail. In addition, direct access to the database is provided by an interactive computer software system developed by the NRCC known as CLIMOD (CLimate Information for Management and Operational Decisions). NRCC also distributes three monthly publications and one seasonal publication summarizing climatic conditions in the Northeast. 
Name of data base The Oklahoma Mesonet

Who assembled the data base Oklahoma Climatological Survey

Who supports the data base Oklahoma Climatological Survey

How to locate http://okmesonet.ocs.ou.edu

Organization Oklahoma Climatological Survey

Web Page Title The Oklahoma Mesonet

Why the data base exists To measure environmental conditions critical to decision makers in weather forecasting, agriculture, public safety, scientific research and education, transportation and other applications.

Time period covered 1991 - present

Sample of data

About Products include:

- Station model plots display as much information in as small of a space as possible. This particular station model plot includes the air temperature, dew point, rainfall, wind speed, wind gusts and wind direction.

- The interactive WxScope map can make hundreds of different kinds of interactive weather maps, such as a map showing wind speed and direction displayed as arrows, or vectors.

- Contour maps plot data in line contours, especially helpful in locating regions of sharp contrast, such as the change in the air temperature field across a frontal zone.

- The Meteogram is a set of graphs, plotted in a vertical series, that allows the viewer to compare how air temperature, dew point, soil temperature, wind speed, wind direction, rainfall, pressure and solar radiation change during the past 6 hours.

- Animated series of images of air temperature, wind, and dew point show how the environment changes over the past three hours.

- Monthly climatological summaries present the daily and monthly totals or averages for most parameters measured by the Oklahoma Mesonet. 
Name of data base Remote Sensing for Energy Conservation and Air Quality

Who assembled the data base Systems for World Surveillance, Inc.

Who supports the data base Systems for World Surveillance, Inc.

How to locate http://www.newc.com/rsat/apps/uhi_app/uhi_app.html

Organization R. S. A. T. Remote Sensing Advanced Technology

Web Page Title Thermal Mapping

Why the data base exists To demonstrate applications for remote sensing technology.

Time period covered

Sample of data There is a collection of very interesting thermal maps at this web site, including:

- Thermal maps of the Washington/Baltimore heat island and thermal maps of New York

City/Long Island, Sacramento, Atlanta, and Tallahassee and

- A brief document about the causes, costs, and corrective measures for heat islands.

A related page (http://www.newc.com/rsat/apps/georgia/sws_index.html) has land cover maps.

About While this site amounts to little more than a commercial for their remote sensing technology products, the thermal maps may prove to be very useful. For example, the web version of the publication "Painting the Town White--and Green" by Rosenfeld, et al, used a low-quality image of thermal map of Washington, D.C. A very high-quality image of the very same map appeared on this Thermal Mapping web page, so it was linked! 
Name of data base sci.geo.meteorology data sources FAQ

Who assembled the data base Ilana Stern, Data Support Section, Scientific Computing Division of the National Center for

Who supports the data base Ilana Stern, Data Support Section, Scientific Computing Division of the National Center for

How to locate http://www.scd.ucar.edu/dss/faq

Organization Data Support Section, Scientific Computing Division, National Center for Atmospheric Research

Web Page Title sci.geo.meteorology data sources FAQ

Why the data base exists To catalog sources of meteorology information

Time period covered $\mathrm{n} / \mathrm{a}$

Sample of data see Appendix B

About "sci.geo.meteorology FAQ"

This is the introduction to a series of FAQ postings for the Usenet newsgroup sci.geo.meteorology. "FAQ" stands for Frequently Asked Questions: these postings are intended to answer the general question, "Where can I get $\langle\mathrm{X}>$ ?" for just about any value of $\langle\mathrm{X}\rangle$ which has anything to do with meteorology.

There are listings of sources of weather and research data, CD-ROMs, Internet resources, and publications. 
Name of data base Selected Historical Climate Data

Who assembled the data base Southeast Regional Climate Center, South Carolina Department of Natural Resources

Who supports the data base Southeast Regional Climate Center, South Carolina Department of Natural Resources

How to locate http://water.dnr.state.sc.us/climate/sercc/historical_data.html

Organization Southeast Regional Climate Center, South Carolina Department of Natural Resources

Web Page Title SERCC - Data - Historical Climate Data

Why the data base exists The SERCC's mission is to provide timely, high quality, and pertinent climate data to the region.

Time period covered $1895-1996$

Sample of data Georgia Statewide Monthly Temperature Average 1895-1996

\begin{tabular}{lllllllllllllll} 
YEAR & JAN & FEB & MAR & APR & MAY & JUN & JUL & \multicolumn{2}{c}{ AUG } & SEP & OCT & NOV & DEC ANNUAL \\
1895 & 45.5 & 38.5 & 54.8 & 62.5 & 69.8 & 78.3 & 79.3 & 79.5 & 77.3 & 61.3 & 53.8 & 46.1 & 62.2 \\
1896 & 44.8 & 48.7 & 53.4 & 67.5 & 76.2 & 77.9 & 80.6 & 81.4 & 76.6 & 63.3 & 58.0 & 46.3 & 64.6 \\
1897 & 43.5 & 51.6 & 59.1 & 62.6 & 69.9 & 81.1 & 80.7 & 78.6 & 74.3 & 66.4 & 55.9 & 48.9 & 64.4 \\
1898 & 50.2 & 46.0 & 60.3 & 59.2 & 74.3 & 80.5 & 80.0 & 78.9 & 75.4 & 62.7 & 51.7 & 46.3 & 63.8 \\
1899 & 45.5 & 44.5 & 56.4 & 61.4 & 75.3 & 80.4 & 80.4 & 81.2 & 73.4 & 65.4 & 55.9 & 45.4 & 63.8
\end{tabular}

About The mission of the SERCC is to provide timely, high quality, and pertinent climate data and information to public and private users in Alabama, Florida, Georgia, North Carolina, South Carolina, and Virginia. Objectives used to achieve this mission include: (1) the provision of a timely, personal response to all inquiries for climate data and information, (2) the operation of dial-up and Internet-accessible computerized regional services and databases, (3) the development of expertise to work on key regional climate issues and problems, and interpret climate forecasts, (4) the issuance of various publications and papers appropriate to the needs of the user community in the Southeast, and (5) develop the capability to measure the value and use of services.

There exists monthly average temperature and precipitation databases. 


\section{Name of data base}

Who assembled the data base

Who supports the data base

How to locate http://www.nc-climate.ncsu.edu/sco/services.html

Organization The State Climate Office of North Carolina

Web Page Title Climatological Services

Why the data base exists

Time period covered

Sample of data

About The State Climate Office of North Carolina provides a wealth of information which is available to everyone (government agencies, industry, academic and private researchers, as well as the private individual) at no charge. Observations are taken at numerous meteorological stations located across the state. Data does not appear to be available on the web, but the web can be used to request information. 


\section{Name of data base General Climate Summaries}

Who assembled the data base State Climatologist, Georgia, University of Georgia

Who supports the data base State Climatologist, Georgia, University of Georgia

How to locate http://www.bae.uga.edu/climate/info.html

Organization State Climatologist, Georgia, University of Georgia

Web Page Title State Climatologist, Georgia - Information Services

Why the data base exists The Office of the State Climatologist strives to assist anyone interested in the climate of Georgia. The office also provides analytical services related to Georgia's climate.

Time period covered Daily data from 1930 for Atlanta, some hourly data as recent as 1997

Sample of data Information provided by the Southeast Regional Climate Center. Data obtained on January, 1997

Station: (090451) ATLANTA_WSO_AIRPORT,GA

From: $1930 / 1$ to: $1939 / 12$

\begin{tabular}{|c|c|c|c|c|c|c|c|c|}
\hline YYYY & $\mathrm{mm}$ & $d d$ & $\begin{array}{c}\text { prcp } \\
\text { (in) }\end{array}$ & $\begin{array}{l}t \max \\
\text { (F) }\end{array}$ & $\begin{array}{l}\text { tmin } \\
\text { (F) }\end{array}$ & $\begin{array}{l}\text { mean } \\
\text { (F) }\end{array}$ & $\mathrm{DD}$ & $\begin{array}{l}\text { snow } \\
\text { (in) }\end{array}$ \\
\hline 1930 & 01 & 01 & 0.00 & 64 & 45 & 55 & 10 & 0.0 \\
\hline 930 & 01 & 02 & 1.05 & 67 & 49 & 58 & 7 & 0.0 \\
\hline 330 & 01 & 03 & 0.00 & 54 & 31 & 43 & 22 & 0.0 \\
\hline 30 & 01 & 04 & 0.00 & 49 & 27 & 38 & 27 & 0.0 \\
\hline 930 & 01 & 05 & 0.00 & 49 & 33 & 41 & 24 & 0.0 \\
\hline
\end{tabular}

About Good climate data for various locations in Georgia. The sample data is hourly climate data, five years of which is available for Atlanta. Other cities merely have daily summaries with precipitation data, but no indication of cloudiness. 


\section{Name of data base Weather Data Online}

Who assembled the data base Kent R. Campbell, Utah Climate Center

Who supports the data base Utah Climate Center in cooperation with the National Climatic Data Center

How to locate http://climate.usu.edu/free/default2.htm

Organization Utah Climate Center, Utah State University

Web Page Title Utah Climate Center: Weather Data Online

Why the data base exists To providing access to daily data for locations throughout the United States and in several locations throughout the world. Without funding, donations are requested.

Time period covered Various beginning dates (1900, for example), up through March 1997

Sample of data 0404,04978102's history: July 1948 to December 1996

You requested from 1995 to 1995

Elements Definitions:

DTOTPCPN = Daily total precipitation, Inches

DTOTSNFL = Daily total snowfall, Inches

DSNWDPTH = Daily snow depth on the ground at time of observation, Inches

DMXARTMP = Daily maximum air temperature, Degrees F

DMNARTMP = Daily minimum air temperature, Degrees F

DOBARTMP = Daily air temperature at time of observation, Degrees $F$

DWTHRINF = Daily weather information, Unitless

$-99999, \mathrm{M}=$ Missing value

Flags( $F$ in header): $M=$ Missing, $E=$ Estimated, $T=$ Trace

LINES WITH ALL MISSING VALUES ARE NOT PRINTED!

CTRY,STATION\#,YEAR,MN,DY,DTOTPCPN,F,DTOTSNFL,F,DSNWDPTH,F,DMXART MP,F,DMNARTMP,F,DOBARTMP,F,DWTHRINF,F

$0404,04978102,1995,01,01,0,0,0,0,48,41,,-99999, M,-99999, M$

$0404,04978102,1995,01,02,0.06,0,0,0,48,39,,-99999, M,-99999, M$

$0404,04978102,1995,01,03,0.92,0,0,0,50,40,-99999, \mathrm{M},-99999, \mathrm{M}$

$0404,04978102,1995,01,04,0.52,0,0,051,, 45,, 48,-99999, \mathrm{M}$

$0404,04978102,1995,01,05,1.07,0,0,0,50,45,, 49,-99999, M$

About Daily historical data for many weather stations all over the world!

One can locate weather stations in more rural areas outside of urban areas to make heat island comparisons. There seems to be information about weather conditions, but not all stations have such data.

The data, however, is free and readily available. 